\title{
Persistence in surgical training
}

Citation for published version (APA):

Dominguez Torres, L. C. (2021). Persistence in surgical training: the role of job crafting and leadership.

[Doctoral Thesis, Maastricht University]. Ipskamp Printing BV. https://doi.org/10.26481/dis.20210223ld

Document status and date:

Published: 01/01/2021

DOI:

10.26481/dis.20210223ld

Document Version:

Publisher's PDF, also known as Version of record

\section{Please check the document version of this publication:}

- A submitted manuscript is the version of the article upon submission and before peer-review. There can be important differences between the submitted version and the official published version of record.

People interested in the research are advised to contact the author for the final version of the publication, or visit the DOI to the publisher's website.

- The final author version and the galley proof are versions of the publication after peer review.

- The final published version features the final layout of the paper including the volume, issue and page numbers.

Link to publication

\footnotetext{
General rights rights.

- You may freely distribute the URL identifying the publication in the public portal. please follow below link for the End User Agreement:

www.umlib.nl/taverne-license

Take down policy

If you believe that this document breaches copyright please contact us at:

repository@maastrichtuniversity.nl

providing details and we will investigate your claim.
}

Copyright and moral rights for the publications made accessible in the public portal are retained by the authors and/or other copyright owners and it is a condition of accessing publications that users recognise and abide by the legal requirements associated with these

- Users may download and print one copy of any publication from the public portal for the purpose of private study or research.

- You may not further distribute the material or use it for any profit-making activity or commercial gain

If the publication is distributed under the terms of Article $25 \mathrm{fa}$ of the Dutch Copyright Act, indicated by the "Taverne" license above, 
Persistence in surgical training:

The role of job crafting and leadership 


\section{"Problems are from Indian or arrow" \\ Colombian proverb \\ "Los problemas son de indio o de flecha" \\ Proverbio Colombiano}

The research reported here was carried out at

\section{Maastricht University in Leanning!}

in the School of Health Professions Education

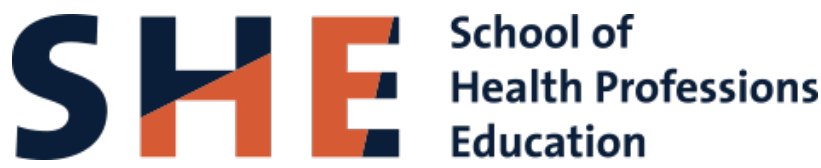

(C) copyright Luis Carlos Dominguez, 2021

ISBN 978-94-642I-246-4

Cover design by Ipskamp Printing Maastricht

Design and print by Ipskamp Printing Maastricht 


\section{Persistence in surgical training: the role of job crafting and leadership}

\section{DISSERTATION}

To obtain the degree of Doctor at the Maastricht University,

on the authority of the Rector Magnificus,

Prof. Dr. Rianne M. Letschert

in accordance with the decision of the Board of Deans,

to be defended in public Tuesday, February 23, 2021, at 16:00 hours

by

Luis Carlos Dominguez Torres 
Supervisors

Prof. dr. L.P.S. Stassen

Prof. dr. D.H.J.M. Dolmans

Co-supervisor

Dr. W.S. de Grave

\section{Assessment Committee}

Prof. dr. I.C. Heyligers (chair)

Prof. dr. A.D.C. Jaarsma, University Medical Centre Groningen

Dr. K.D. Könings

Prof. dr. F.W.J.M. Smeenk

Dr. B. Verhoeven, Radboudumc Nijmegen 


\section{Table of Contents}

\section{Chapter I}

General Introduction

Chapter 2

Taking control: Is job crafting related to the intention to leave surgical training?

Chapter 3

Job Crafting to Persist in Surgical Training: A Qualitative Study From

the Resident's Perspective

Chapter 4

Transformational leadership encourages residents' job crafting in surgical training:

A mixed-methods study of residents' perceptions

Chapter 5

How surgical leaders transform their residents to craft their jobs:

surgeons' perspective

Chapter 6

Discussion

Summary

Impact paragraph 
General Introduction

CHAPTER I

,

$x^{2}$

\section{and}
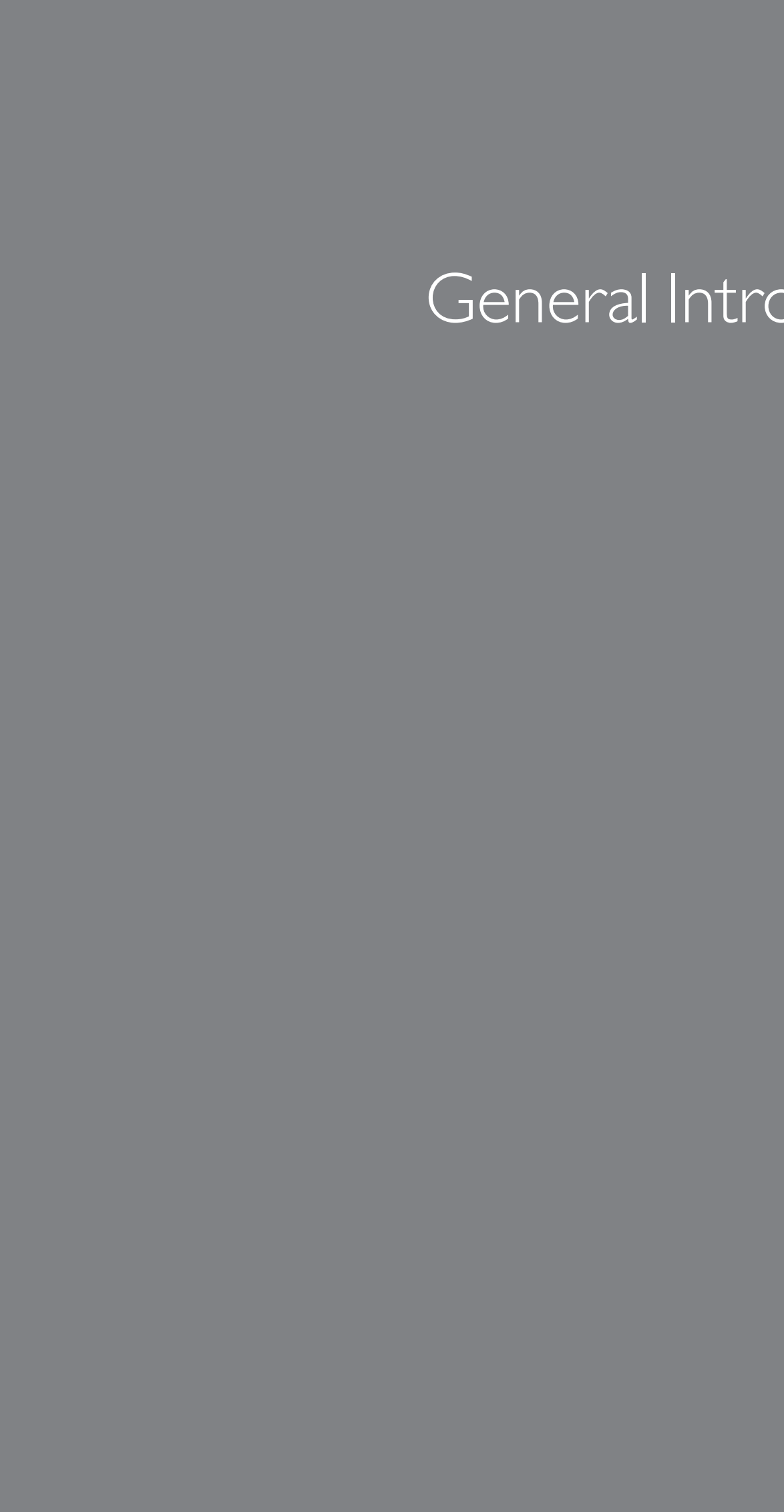
Surgery is an essential component of global health, welfare, and development (I). At least $30 \%$ of the global burden of disease is surgical (2). The sustainability of the provision of surgical care depends, to a large extent, on the surgical workforce (I). Educating and training future surgeons is therefore crucial in this endeavor. Unfortunately, there is a global shortage of surgeons that will threaten the safe provision of surgical care in the coming years, especially in low- and middleincome countries (LMICs) (3-5). The Global Health Observatory data repository (World Health Organization) estimated this global shortage to be 939,943 in 2017 (6). One of the most important causes of this shortage is that surgeons and residents leave the profession $(1,4)$, mostly because of retirement, death, brain drain, and perceived poor salary and quality of life (4). While influx of young surgeons should compensate for this shortage, also here the numbers are insufficient. Reasons are multifactorial and vary per country, if present, including a limited number of medical school graduates (4), little interest of medical students in pursuing a surgical career $(7,8)$, scarce infrastructure of and investment in residency training at the local level $(I)$, and attrition of active residents from training programs $(9,10)$.

Especially the latter, residents' attrition, has become a global concern during the last years. Referring to the proportion of residents that does not complete postgraduate surgical training (II), attrition varies geographically. While it appears to be high in Pakistan (38.6\%) (I2), followed by the United States, Canada, and the United Kingdom (18\% - 20.4\%), lower numbers have been reported in Australia and New Zealand (15\%) (13), the Netherlands (8.4\%) (14), and West China (8\%) (I5). Several studies that explored the problem of attrition before and after its appearance focused on active residents with serious intentions to leave training, which concerns some 12.6 to $58 \%$ of surgical residents (16-20). The consequences of attrition are large; not only does it have an impact on the provision of surgical care as previously mentioned, it also dramatically affects the individual and programmatic level. More specifically, residents who leave surgery often feel demoralized because of wasted time and resources (2l-23). Most of them go on to pursue non-surgical residencies (56-62\%), particularly anesthesiology, radiology, or family medicine (24-26). Programs, on the other hand, experience more selection and training costs $(23,27)$, as well as difficulties to replace the residents who left (28-30).

In the first half of the present chapter, we will categorize the available research on residents' attrition from surgical training into three general perspectives: an individual, a programmatic, and a sociocultural perspective (Table I). After having described each perspective and its gaps, we will shift the focus away from attrition and onto persistence. Then, in the second part of this chapter, we will present the research questions and elaborate on how theory can help us to answer these. At the end of the chapter, we will present the context of the studies and a general overview of the four empirical studies included in this dissertation. 
Table I. Current perspectives in the study of residents' attrition in surgical training

\begin{tabular}{lll}
\hline Perspective & Definition & Example \\
\hline $\begin{array}{l}\text { Individual } \\
\text { perspective }\end{array}$ & $\begin{array}{l}\text { Residents' personal attributes contribute } \\
\text { to attrition. }\end{array}$ & $\begin{array}{l}\text { Sex, pregnancy, age, ethnicity, marital status, } \\
\text { personal traits, previous performance, } \\
\text { personal financial concerns. }\end{array}$ \\
$\begin{array}{l}\text { Programmatic } \\
\text { perspective }\end{array}$ & $\begin{array}{l}\text { Factors in the surgical residency program } \\
\text { lead to attrition. }\end{array}$ & $\begin{array}{l}\text { Location and type of programs, year of } \\
\text { training, duty hour regulations, and selection } \\
\text { procedures. }\end{array}$ \\
$\begin{array}{l}\text { Sociocultural } \\
\text { perspective }\end{array}$ & $\begin{array}{l}\text { The social and cultural factors embedded } \\
\text { in the dynamics of surgical training in the }\end{array}$ & $\begin{array}{l}\text { Negative behaviors toward residents } \\
\text { (bullying, harassment), workload, work } \\
\text { workplace influence attrition. }\end{array}$ \\
\hline
\end{tabular}

\section{Residents' attrition from an individual perspective}

From an individual perspective, previous research has pointed to various demographic factors as causes of attrition, including sex, age, ethnicity, marital status, and pregnancy. Despite the vast amount of studies, it is still difficult to determine their definitive role. For instance, the available evidence has offered contradictory findings regarding the role of sex $(9,10)$, age $(16,31,32)$, marital status $(32,33)$, and ethnicity $(33,34)$. Other studies, moreover, have refuted the idea that certain specific factors would predict attrition, as was the case of pregnancy in a recent systematic review (35).

In the same vein, another group of studies explored the role of residents' traits in mediating attrition, such as behavioral styles, psychological profiles, and grit $(23,36,37)$. However, these studies had limitations. The traits were not generalizable to different training contexts and had not been subject to longitudinal assessment throughout the surgical program, which prevented them from being fully accepted as predictors of attrition. Finally, yet other studies focused on previous academic performance $(38,39)$, residents' personal interests (e.g., arts, sports) $(3 I, 38,40)$, and financial concerns during training $(4 I-43)$. The role of these factors in mediating attrition, however, remains inconclusive up to this day.

\section{Residents' attrition from a programmatic perspective}

Similar to the previous perspective, research from a programmatic perspective has focused extensively on the programmatic factors that contribute to attrition. Different systematic reviews have demonstrated that attrition and thoughts of leaving occur in the early years of training, especially in the first and second years, but continue throughout the program, albeit at a lower rate $(9,10)$. What is more, the proportion of surgical residents that progresses to the next year of training is lower than in 
non-surgical specialties (44).Although not conclusive, attrition seems to be higher in military programs than in civilian programs $(32,34)$ and also higher in programs with great reputation $(45)$ and with a long-standing tradition of attrition (16,34).The number of residents being trained simultaneously (size of the program) remains a controversial factor in attrition (46).At the same time, the available studies on the role of working hour regulations in attrition, too, are inconclusive. Interestingly, some studies have reported that attrition rates have actually gone up after these regulations were introduced $(9,24,25)$, while others have not confirmed that association $(47,48)$. Finally, the role of selection of students has gained increasing attention due to its purported potential to diminish attrition from training programs (27); its real effectiveness, however, remains limited.

\section{Residents' attrition from a sociocultural perspective}

A third perspective on attrition we find in the literature is concerned with the influence of sociocultural factors in the surgical training workplace. Central to that viewpoint is the idea that modern surgical training, at least in Western educational contexts, is still characterized by rigor, hierarchy, high demands and competitiveness for residents (49-5I). These features have been suggested to be instrumental in residents' development: they would prepare residents for a rigorous career, ensure their learning and acquisition of "a healthy aversion to mistakes while also building resilience" (52). Moreover, it has been argued that residents must be able to deal with such stressors and fatigue because surgical practice requires that capacity (50). Nonetheless, these same features of training might also explain why the surgical workplace is a place where negative behaviors, such as bullying, discrimination, and harassment, more easily take hold $(13,53)$. A recent systematic review indeed reported high rates of bullying $(37.7 \%-40.3 \%)$, discrimination (22.4\%), and harassment in surgical training (3I.2\%) (54), with few variations in their prevalence across North American, European and Australasian countries and Japan $(20,55-$ 59). Additionally, the said features of training contribute to a high level of demands placed on residents, such as workload, pressure for efficiency and standards, and strict compliance with work schedules. These demands reduce the quality of residents' education if they are prioritized over their teaching, feedback, and operative autonomy $(60,61)$. The negative behaviors, high demands, and stress contribute to residents' attrition in two ways: They are key components of the poor educational culture of training programs $(13,20)$, and they contribute to residents' burnout $(62,63)$, an immediate precursor of attrition $(20,64)$. Sadly, in the case of surgical residents, the burnout rate reaches as high as $58.39 \%(45.72 \%-70.04 \%)(65)$.

Fortunately, however, initiatives have been undertaken worldwide to eliminate excessive working hours (48) and negative behaviors in the workplace $(13,66)$, and to improve the learning environment (67). Although these initiatives were developed in the past 20 years, they may not have been implemented equally in different countries and training programs yet. Additionally, their intended outcomes are inconsistent and are influenced by local cultural factors and the social dynamics of programs (20). 


\section{The positive side of the coin: How do surgical residents persist in training? A missing link in the puzzle of attrition}

Most of the aforementioned studies looked at the problem from the perspective of residents who tend to leave training. Only a limited number of studies, however, have looked at it from a positive side (68-70), an approach that calls for an elucidation of what the vast majority of residents actually do to persist in training. Persistence is defined as "the voluntary continuation of a goaldirected action in spite of obstacles, difficulties, or discouragement"(7I).

A key concept in such a positive exploration of the problem of attrition is residents' "work engagement," which is the opposite of burnout. While on the one hand work engagement depends on residents' intrinsic motivation to craft their working conditions, on the other it requires specific actions on the part of institutions and surgical departments to ensure such conditions are favorable (e.g., working schedules, supervision). The former actions by residents are coined “job crafting” (72). The assumption that residents' job crafting and work engagement are linked to persistence in surgical training has not yet been studied in depth.

Another aspect that deserves attention is the role of supervisors and leaders. To date, not many studies have looked at the role of leaders or surgeons and how they help transform their residents to craft their jobs, while enhancing their work engagement. Introducing a leadership perspective might reveal how surgeons understand and reflect on their role as educators, reject unacceptable behaviors, promote residents' well-being, share values, and deliver high-quality education.

The research mentioned above is dominated by a quantitative positivist epistemology and only weakly supported by qualitative evidence. Qualitative research will add information from a different angle and may assist in understanding the important issues of attrition and persistence and in promoting the latter.

\section{Research questions}

This $\mathrm{PhD}$ dissertation aims to further our understanding of residents' work engagement and persistence in surgical training. To this end, it addresses the following two research questions:

I. To what extent do surgical residents feel that they possess job-crafting abilities and which job-crafting mechanisms do they use to enhance their work engagement to persist in training? (Studies I and 2).

2. How do supervisors' leadership styles relate to residents' job-crafting abilities from the perspective of both residents and supervisors? (Studies 3 and 4). 


\section{Theoretical framework}

\section{THE JOB DEMANDS-RESOURCES THEORY}

Early in the present century, scholars and organizations started to take an interest in burnout. In 200I, Maslach, Schaufeli, and Leiter, a group of American and Dutch researchers, defined burnout as a syndrome of high emotional exhaustion accompanied by high depersonalization (cynical and negative attitude toward work) and/or low personal performance. Burnout has become a serious issue in different occupations, including the health professions, because of its relevance to negative outcomes at work. The scope of research on burnout grew in two directions. The first strand focused on the identification of common burnout symptoms. The Maslach Burnout Inventory (MBI), for instance, was developed and rapidly accepted for that purpose (73). The second strand sought to explain why burnout occurs. One of the most accepted explanations was offered by Demerouti and colleagues in the Netherlands who introduced the Job Demands-Resources (JD-R) Model (74). In this model, burnout was the result of high job demands, which were defined as "the physical, psychological, social, or organizational aspects of the job that require sustained physical and/or psychological effort and are therefore associated with certain physiological and/or psychological costs" (74). Workload, work pressure, and conflicts are examples of such demands. Interestingly, these researchers found that people, even in the face of high job demands, might not suffer a burnout if they have certain specific working conditions, known as job resources. These were defined as "the physical, psychological, social, or organizational aspects of the job that are functional in achieving work goals, reducing job demands and the associated physiological and psychological costs, or stimulating personal growth, learning, and development" (74). Autonomy, feedback, and collaboration at work are but a few examples of such resources.

The earlier findings on the predictors of burnout encouraged researchers to test the relationship between job demands and resources. In particular, Bakker and Demerouti found that a specific type of "positive" demands that require effort but that potentially promote personal growth and achievement (such as responsibility and new projects), may, in the presence of adequate resources, initiate a "motivational process" (75). They coined such positive demands "challenging demands." In this research, the authors drew attention to the concept of "work engagement." In earlier studies, Maslach and Leiter had already conceptualized "engagement" in terms of its respective scores on the $\mathrm{MBI}$, which were the exact opposite of burnout: low scores for exhaustion and cynicism, and high scores for accomplishment. The JD-R model elaborated on that conceptualization, as well as on its measurement. Work engagement refers to a "mental state where employees feel full with physical energy (vigor), are enthusiastic about the content of their work and the things they do (dedication), and are so immersed in their work activities that time seems to fly (absorption)" (76). To assess that construct, Schaufeli and colleagues developed and validated the "Utrecht Work Engagement Scale" in 2002 (77). Subsequently, an extensive body of research was conducted in different occupations, corroborating the mechanisms of "health 
impairment" (i.e., burnout) and "motivation" (i.e., work engagement). This allowed the JD-R model to become a flexible and dynamic theoretical framework to explain these processes (78).

Central to the JD-R theory is the notion that people who are motivated are likely to display job crafting behavior, that is, "the proactive changes that employees make in their job demands and resources" (72). More specifically, job crafting aims to increase job resources and challenging demands and to diminish certain "negative" demands known as "hindering job demands." Cavanaugh et al. (cited by Bakker and Demerouti) defined such hindering demands as the "work circumstances that involve excessive or undesirable constraints that interfere with or inhibit an individual's ability to achieve valued goals" (76). By doing so, job crafters are able to optimize and take control of their working conditions (job demands and resources), enhancing their work engagement in the process. As such, job crafting can be considered a proactive, bottom-up approach to work engagement (79).

Another development in the JD-R theory is the strategic or top-down approach to enhance work engagement (79). In other words, the theory holds that Human Resources Management and daily leaders have a responsibility to offer people in their organization adequate resources and challenges. Through effective leadership, such leaders can positively affect the attitudes, performance, and psychological health of their followers in the organization, thereby promoting work engagement (79). An example of such leadership is transformational leadership, which will be further explained in the next part.

Despite the growing interest in approaches to work engagement, the JD-R theory still fails to explain the mechanisms linking job-crafting to work engagement, the role of leaders in those mechanisms and, finally, the variations between these mechanisms across different contexts $(75,80,8 \mathrm{I})$. Since most research has been conducted from a quantitative perspective, qualitative studies might offer an in-depth understanding of these theoretical gaps (8I).

\section{DAILY LEADERSHIP TO PROMOTE WORK ENGAGEMENT: A FOCUS ON THE TRANSFORMATIONAL LEADERSHIP THEORY}

Closely related to the notion that daily leadership can promote work engagement, as proposed in the JD-R theory, is the idea that leaders can transform their followers in positive ways. Such "transformation" has been the subject of extensive research during the last years and it has been used to explain the influence of leaders on organizational outcomes (82).

The transformational leadership theory began with the seminal work of James Burns (1978), an American historian and political scientist. In his book "Transforming leadership" he explained how great leaders interacted with society and were able to change the course of history (83). Later, 
Bass and Avolio, two American scholars in the field of leadership studies, introduced the word "transformational" as a substitute for "transforming," initiated the conceptualization of that leadership type, and refined the instruments for its measurement (84-86). In the end, it were Antonakis et al. who defined transformational leaders as those who are "proactive, raise follower awareness for transcendent collective interests, and help followers achieve extraordinary goals" (87). It became the most accepted definition the main characteristics of which are:

"(a) Idealized influence (attributed) refers to the socialized charisma of the leader, whether the leader is perceived as being confident and powerful, and whether the leader is viewed as focusing on higher-order ideals and ethics; (b) idealized influence (behavior) refers to charismatic actions of the leader that are centered on values, beliefs, and a sense of mission; (c) inspirational motivation refers to the ways leaders energize their followers by viewing the future with optimism, stressing ambitious goals, projecting an idealized vision, and communicating to followers that the vision is achievable; (d) intellectual stimulation refers to leader actions that appeal to followers' sense of logic and analysis by challenging followers to think creatively and find solutions to difficult problems; and (e) individualized consideration refers to leader behavior that contributes to follower satisfaction by advising, supporting, and paying attention to the individual needs of followers, and thus allowing them to develop and self-actualize" (87).

During the last decades, several empirical studies have provided evidence for the positive outcomes of transformational leaders at the individual, group, and organizational level (88). However, little is known on how transformation actually occurs. We therefore need more research into the process whereby leaders transform their followers (82). However, the methodological limitation to capture followers' transformation complicates efforts to fill this gap. Qualitative and mixed-methods research might assist in such exploration (89).

\section{Research context}

This study was conducted in Colombia that has a population of approximately 48.2 million (2018). The total number of surgeons in the country is 2,475 (2018), which corresponds to five surgeons in 100,000 inhabitants $(90)$, a number that is quite distant from the global workforce densities that were estimated at 20-40 specialist surgeons in 100,000 individuals by the Lancet Commission for Global Surgery (I). Surgeons in Colombia therefore appear to be working at or beyond capacity, performing 2,690-3,090 procedures in 100,000 people per year (90).

We conducted the study from December, 2015, to June, 2020. Participants were under the national model for residency training that was in force between 1992 and July, 2020. In that model, the institutions of higher education were responsible for training. Universities coordinated residents' training at health institutions using a model of progressive delegation and supervision. Control of 
that model was divided among the Ministries of Health and Education. In that model, residents were considered as "postgraduate students," meaning they did not have a contract or receive a salary or any other social security benefits from the health institutions. Moreover, they had to pay a tuition fee for their training (close to 12,000 USD annually). In their daily practice, however, residents had to comply with clinical duties. Being licensed for medical practice, they also had a legal responsibility in patient care. Some new regulations were introduced into the model at different stages. The national government gave some scholarships to finance residents' education and installed a national regulation stipulating that residents should not work more than 66 hours per week.

In Colombia, the process of residency training is operationalized as follows. Medical careers last six years, including an internship of one year. Upon completion, doctors apply directly to private or public universities for a residency position; there is no national system of admission. General surgery residency spans approximately 80 positions per year spread over 20 active programs (2020). In June of 2020, a total of 380 surgical residents were active in these programs. Three surgical programs are accredited as high-quality in accordance with national standards; Two more are in the process of attaining that accreditation. Considering the number of affiliated institutions, each program employs more than 30 surgical supervisors. As soon as residents have completed four years of full-time training, they can apply for a sub-specialty program. Program directors reported the rate of residents' attrition in general surgery to be close to $15 \%$.

\section{Dissertation overview}

This dissertation presents four empirical studies that aim to enhance our understanding of residents' persistence in surgical training (Table 2). The dissertation is built on the fundamentals of the JD-R and transformational leadership theories. Central to the research is the idea that persistence strongly depends on residents' work engagement, which, in turn, is conditioned by at least two important requirements. First, to optimize their job demands and resources in the workplace, residents must have well-developed job crafting abilities. Second, surgeons' leadership plays a central role in the positive transformation of residents to craft their jobs. In Chapter 2, we investigated the relationship between residents' job crafting and the intention to leave training, including the influence of work engagement. In Chapter 3, we took a closer look at the specific mechanisms underlying residents' job crafting that would enhance work engagement and persistence, using a Constructivist Grounded Theory (CGT) Design based on the perspective of residents. In Chapter 4, we used survey questionnaires and in-depth interviews with residents to investigate the relationship between surgeons' leadership and residents' job crafting. In Chapter 5, we conducted a CGT study from the perspective of surgeons to explore how surgeons transform their residents to craft their jobs. In Chapter 6, we discussed our findings and their implications for the study of residents' attrition, the strengths and limitations of our research, and the theoretical and practical implications flowing from our work. Finally, in Chapter 7, we explored the social relevance of this research.The dissertation ends with summaries in both English and Dutch. 
Table 2. Overview of PhD studies

\begin{tabular}{|c|c|c|c|c|}
\hline Chapter & 2 & 3 & 4 & 5 \\
\hline \multirow[t]{3}{*}{$\begin{array}{l}\text { Research } \\
\text { questions }\end{array}$} & $\begin{array}{l}\text { I. To what extent do } \\
\text { surgical residents possess } \\
\text { job-crafting skills and does } \\
\text { this differ across the years } \\
\text { of surgical training? }\end{array}$ & $\begin{array}{l}\text { I. Which job-crafting } \\
\text { mechanisms are used by } \\
\text { surgical residents to } \\
\text { enhance their work } \\
\text { engagement and } \\
\text { persistence in the program } \\
\text { from the residents' } \\
\text { perspective? }\end{array}$ & $\begin{array}{l}\text { I. To what extent are } \\
\text { supervisors' } \\
\text { leadership styles } \\
\text { associated with } \\
\text { residents' job crafting } \\
\text { in surgical training and } \\
\text { why, from residents' } \\
\text { perspective? }\end{array}$ & $\begin{array}{l}\text { I. What actions } \\
\text { do surgeons with } \\
\text { a transformational } \\
\text { leadership style } \\
\text { undertake to } \\
\text { strengthen their } \\
\text { residents' job } \\
\text { crafting in training, } \\
\text { from surgeons' } \\
\text { perspective? }\end{array}$ \\
\hline & $\begin{array}{l}\text { 2. What are the } \\
\text { relationships between job- } \\
\text { crafting skills, well-being at } \\
\text { work (as measured by work } \\
\text { engagement and burnout } \\
\text { rates) and the intention to } \\
\text { leave the program in } \\
\text { surgical residents? }\end{array}$ & $\begin{array}{l}\text { 2. Which mechanisms are } \\
\text { used by supervisors to } \\
\text { stimulate surgical } \\
\text { resident's job-crafting to } \\
\text { enhance their work } \\
\text { engagement and persis- } \\
\text { tence in the program from } \\
\text { the residents' perspective? }\end{array}$ & & $\begin{array}{l}\text { 2. What } \\
\text { consequences do } \\
\text { these actions have } \\
\text { for the resident, } \\
\text { from surgeons' } \\
\text { perspective? }\end{array}$ \\
\hline & $\begin{array}{l}\text { 3. What are the differences } \\
\text { in job-crafting skills and } \\
\text { well-being (as measured by } \\
\text { work engagement and } \\
\text { burnout rates) between } \\
\text { surgical residents with } \\
\text { serious intentions to leave } \\
\text { the program and those } \\
\text { without such intentions? }\end{array}$ & & & \\
\hline $\begin{array}{l}\text { Theoretical } \\
\text { lenses }\end{array}$ & $\begin{array}{l}\text { Job demands-resources } \\
\text { theory }\end{array}$ & $\begin{array}{l}\text { Job demands-resources } \\
\text { theory }\end{array}$ & $\begin{array}{l}\text { Job demands- } \\
\text { resources theory / } \\
\text { Full Range Model of } \\
\text { Leadership }\end{array}$ & $\begin{array}{l}\text { Job demands- } \\
\text { resources theory / } \\
\text { Full Range Model } \\
\text { of Leadership }\end{array}$ \\
\hline $\begin{array}{l}\text { Methodology / } \\
\text { design }\end{array}$ & $\begin{array}{l}\text { Quantitative cross- } \\
\text { sectional study }\end{array}$ & $\begin{array}{l}\text { Qualitative constructivist- } \\
\text { grounded theory design }\end{array}$ & $\begin{array}{l}\text { Sequential } \\
\text { explanatory mixed- } \\
\text { methods research }\end{array}$ & $\begin{array}{l}\text { Qualitative } \\
\text { constructivist- } \\
\text { grounded theory } \\
\text { design }\end{array}$ \\
\hline $\begin{array}{l}\text { Context / } \\
\text { participants }\end{array}$ & $\begin{array}{l}202 \text { general surgery } \\
\text { residents from } 15 \text { residency } \\
\text { programs in Colombia }\end{array}$ & $\begin{array}{l}25 \text { general surgery } \\
\text { residents from five } \\
\text { residency programs in } \\
\text { Colombia }\end{array}$ & $\begin{array}{l}\text { Quantitative phase: } \\
\text { II6 general surgery } \\
\text { residents from seven } \\
\text { residency programs in } \\
\text { Colombia } \\
\text { Qualitative phase: } 14 \\
\text { general surgery } \\
\text { residents from seven } \\
\text { residency programs in } \\
\text { Colombia }\end{array}$ & $\begin{array}{l}\text { I6 general } \\
\text { surgeons } \\
\text { (supervisors) from } \\
\text { four residency } \\
\text { programs in } \\
\text { Colombia }\end{array}$ \\
\hline Data sources & Survey questionnaires & $\begin{array}{l}\text { In-depth individual semi- } \\
\text { structured interviews }\end{array}$ & $\begin{array}{l}\text { Survey questionnaires } \\
\text { / In-depth individual } \\
\text { semi-structured } \\
\text { interviews }\end{array}$ & $\begin{array}{l}\text { In-depth individual } \\
\text { semi-structured } \\
\text { interviews }\end{array}$ \\
\hline
\end{tabular}




\section{References}

I. Meara JG, Leather AJM, Hagander L,Alkire BC,Alonso N,Ameh EA, et al. Global Surgery 2030:

Evidence and solutions for achieving health, welfare, and economic development.Vol. 386, The Lancet. Lancet Publishing Group;2015. p. 569-624.

2. Shrime MG, Bickler SW,Alkire BC, Mock C. Global burden of surgical disease:An estimation from the provider perspective.Vol. 3,The Lancet Global Health. Elsevier Ltd;20I5. p. S8-9.

3. Hoyler M, Finlayson SRG, McClain CD, Meara JG, Hagander L. Shortage of doctors, shortage of data:A review of the global surgery, obstetrics, and anesthesia workforce literature [Internet].Vol.38,World Journal of Surgery.World J Surg; 2014 [cited 2020 Jun 24]. p. 269-80.Available from: https://pubmed.ncbi. nlm.nih.gov/24218153/

4. Bergström S, McPake B, Pereira C, Dovlo D.Workforce Innovations to Expand the Capacity for Surgical Services. In: Disease Control Priorities, Third Edition (Volume I): Essential Surgery [Internet]. TheWorld Bank; 2015 [cited 2020 Jun 24].p. 307-I6.Available from:https://www.ncbi.nlm.nih.gov/books/ NBK333504/

5. Are C.Workforce Needs and Demands in Surgery. Surg Clin North Am [Internet]. 2016 Feb I [cited 2018 Nov 23];96(I):95-II 3.Available from:https://linkinghub.elsevier.com/retrieve/pii/S00396I09I500I632

6. GHO |By category | Surgical workforce - Reported data by country [Internet]. [cited 2020 Aug 25]. Available from: https://apps.who.int/gho/data/node.main.HWF9?lang=en

7. Scally CP, Minter RM. Medical School Training for the Surgeon. Surg Clin North Am [Internet]. 2016 Feb [cited 2018 Nov 2 ]];96(I):I-13.Available from:http://www.ncbi.nlm.nih.gov/pubmed/266I20I5

8. Schmidt LE, Cooper CA, GuoWA. Factors influencing US medical students' decision to pursue surgery.J Surg Res [Internet]. 2016 Jun I [cited 2018 Nov 2 I];203(I):64-74.Available from: http://www.ncbi.nlm.nih. gov/pubmed/27338536

9. Shweikeh F, Schwed AC, Hsu CH, Nfonsam VN. Status of Resident Attrition From Surgical Residency in the Past, Present, and Future Outlook.J Surg Educ [Internet]. 2018 Mar [cited 2018 May 25];75(2):254-62. Available from: http://linkinghub.elsevier.com/retrieve/pii/S1931720417300983

10. Khoushhal Z, Hussain MA, Greco E, Mamdani M,Verma S, Rotstein O, et al. Prevalence and causes of attrition among surgical residents a systematic review and meta-analysis. In:JAMA Surgery [Internet]. 2017 [cited 2018 May 25].p. 265-72.Available from: http://archsurg.jamanetwork.com/article. aspx?doi=10.100I/jamasurg.2016.4086

II. Van Zanten M, Boulet JR, McKinley D,Whelan GP.Attrition Rates of Residents in Postgraduate Training Programs.Teach Learn Med [Internet]. 2002 Jul [cited 2020 Jul 26]; 14(3): 175-7.Available from: http://www. tandfonline.com/doi/abs/I0.1207/SI53280I5TLMI403_7

12. Nadeem M, Effendi MS, Hammad Ather M.Attrition in surgical residency programmes: Causes and effects. Arab J Urol [Internet]. 2014 [cited 2020 Jul I8];12(I):25-9.Available from:/pmc/articles/ PMC4434499/?report=abstract

13. Forel D,Vandepeer M, Duncan J,Tivey DR, Tobin SA. Leaving surgical training: some of the reasons are in surgery.ANZ J Surg [Internet].20I8 May I [cited 2020 Mar 21];88(5):402-7.Available from:http://www. ncbi.nlm.nih.gov/pubmed/294II 485

14. Bustraan J, Dijkhuizen K,Velthuis S,Van Der Post R, Driessen E,Van Lith JMM, et al.Why do trainees leave hospital-based specialty training? A nationwide survey study investigating factors involved in attrition and subsequent career choices in the Netherlands.Vol.9, BMJ Open. BMJ Publishing Group; 2019.

15. Wang $X Y$, Rodríguez AC, Shu MR. Challenges to implementation of medical residency programs in china:A five-year study of attrition from west China Hospital.Acad Med [Internet]. 2010 Jul [cited 2020 Jul 18];85(7): I 203-8.Available from:http://journals.Iww.com/0000 I888-201007000-00024 
16. Gifford E, Galante J, Kaji AH, Nguyen V, Nelson MT, Sidwell RA, et al. Factors associated with general surgery residents' desire to leave residency programs: A multi-institutional study. JAMA Surg [Internet]. 2014 Sep I [cited 2018 May 25];149(9):948-53. Available from: http://archsurg. jamanetwork.com/article.aspx?doi=10.1001/jamasurg.2014.935

17. Ellis RJ, Holmstrom AL, Hewitt DB, Engelhardt KE, Yang AD, Merkow RP, et al. A comprehensive national survey on thoughts of leaving residency, alternative career paths, and reasons for staying in general surgery training. Am J Surg. 2020 Feb I;219(2):227-32.

18. Ginther DN, Dattani S, Miller S, Hayes P. Thoughts of Quitting General Surgery Residency: Factors in Canada. J Surg Educ [Internet]. 2016 May [cited 2018 May 25];73(3):513-7. Available from: http:// linkinghub.elsevier.com/retrieve/pii/SI93I720415002895

19. Adams S, Ginther DN, Neuls E, Hayes P. Attitudes and factors contributing to attrition in Canadian surgical specialty residency programs. Can J Surg [Internet]. 2017 Aug I [cited 2020 Jul 14];60(4):247-52. Available from: https://pubmed.ncbi.nlm.nih.gov/28562235/

20. Ellis RJ, Hewitt DB, Hu YY, Johnson JK, Merkow RP, Yang AD, et al. An Empirical National Assessment of the Learning Environment and Factors Associated With Program Culture. Ann Surg. 2019 Oct I;270(4):585-92.

21. Sullivan MC, Yeo H, Roman SA, Ciarleglio MM, Cong X, Bell RH, et al. Surgical residency and attrition: Defining the individual and programmatic factors predictive of trainee losses. J Am Coll Surg [Internet]. 2013 Mar [cited 2020 Jul 14];216(3):46I-7I. Available from: https://pubmed.ncbi.nlm. nih.gov/23266420/

22. Bongiovanni T, Yeo H, Sosa JA, Yoo PS, Long T, Rosenthal M, et al. Attrition from surgical residency training: Perspectives from those who left. Am J Surg [Internet]. 2015 Oct [cited 2018 May 25];2I0(4):648-54. Available from: http://linkinghub.elsevier.com/retrieve/pii/S000296I0I5003657

23. Foster KN, Neidert GPM, Brubaker-Rimmer R, Artalejo D, Caruso DM. A psychological profile of surgeons and surgical residents. In: Journal of Surgical Education. J Surg Educ; 2010. p. 359-70.

24. Yeo H, Bucholz E, Ann Sosa J, Curry L, Lewis FR, Jones AT, et al. A national study of attrition in general surgery training: Which residents leave and where do they go? Ann Surg [Internet]. 2010 Sep [cited 2018 May 25];252(3):529-34. Available from: https://insights.ovid.com/crossref ?an $=00153307-201001280-00014$

25. Everett CB, Helmer SD, Osland JS, Smith RS. General surgery resident attrition and the 80 -hour workweek. Am J Surg. 2007 Dec;194(6):75I-7.

26. Longo WE, Seashore J, Duffy A, Udelsman R. Attrition of categoric general surgery residents: results of a 20 -year audit. Am J Surg [Internet]. 2009 Jun [cited 2020 Jul 14];197(6):774-8. Available from: https://pubmed.ncbi.nlm.nih.gov/l9178898/

27. Gardner AK, Grantcharov T, Dunkin BJ. The Science of Selection: Using Best Practices From Industry to Improve Success in Surgery Training. J Surg Educ [Internet]. 2018 Mar I [cited 2020 Jul 14];75(2):278-85. Available from: https://pubmed.ncbi.nlm.nih.gov/2875II86/

28. Stover W, Gill S, Schenarts K, Chahine AA. Defining the Applicant Pool for Postgraduate Year-2 Categorical General Surgery Positions. J Surg Educ [Internet]. 2018 Jul I [cited 2020 Jul 14];75(4):870-6. Available from: https://pubmed.ncbi.nlm.nih.gov/29242045/

29. Leibrandt TJ, Mehall JR, Rhodes RS, Morris JB. How do general surgery replacement residents match up with those recruited through the National Resident Matching Program? Am J Surg [Internet]. 2004 Jun [cited 2020 Jul 14];I87(6):702-4. Available from: https://pubmed.ncbi.nlm.nih. gov/I519186I/

30. Aufses AH, Slater $\mathrm{GI}$, Hollier LH. The nature and fate of categorical surgical residents who "drop out.” Am J Surg [Internet]. 1998 Mar [cited 2020 Jul I4];175(3):236-9. Available from: https:// pubmed.ncbi.nlm.nih.gov/9560128/ 
3I. Naylor RA, Reisch JS, Valentine RJ. Factors related to attrition in surgery residency based on application data. Arch Surg. 2008 Jul;143(7):647-5I.

32. Rolland G, Ahnfeldt EP, Chestnut CH, Cromer RM, Faler BJ, Galusha AD, et al. Attrition Rate in Military General Surgery GME and Effect on Quality of Military Programs. J Surg Educ [Internet]. 2019 Nov I [cited 2020 Jul 14];76(6):e49-55. Available from: https://pubmed.ncbi.nlm.nih. gov/31492639/

33. Yeo HL, Abelson JS, Mao J, Lewis F, Michelassi F, Bell R, et al. Who Makes It to the End?: A Novel Predictive Model for Identifying Surgical Residents at Risk for Attrition. Ann Surg [Internet]. 2017 Sep [cited 2018 May 25];266(3):499-507. Available from: http://insights.ovid.com/crossref ?an $=00000658-201709000-00013$

34. Yeo HL, Abelson JS, Symer MM, Mao J, Michelassi F, Bell R, et al. Association of Time to Attrition in Surgical Residency With Individual Resident and Programmatic Factors. JAMA Surg [Internet]. 2018 Feb 2 I [cited 20I8 May 25]; Available from: http://archsurg.jamanetwork.com/article. aspx?doi=10.1001/jamasurg.2017.6202

35. Todd AR, Cawthorn TR, Temple-Oberle C. Pregnancy and Parenthood Remain Challenging During Surgical Residency. Acad Med. 2020 Mar;I.

36. Bell RM, Fann SA, Morrison JE, Lisk JR. Determining personal talents and behavioral styles of applicants to surgical training: A new look at an old problem, part i. J Surg Educ. 2011 Nov;68(6):534-4I.

37. Salles A, Lin D, Liebert C, Esquivel M, Lau JN, Greco RS, et al. Grit as a predictor of risk of attrition in surgical residency. Am J Surg [Internet]. 2017 Feb I [cited 2020 Apr 5];213(2):288-91. Available from: http://www.ncbi.nlm.nih.gov/pubmed/27932088

38. Symer MM, Abelson JS, Gade L, Mao J, Sosa JA, Yeo HL. Association between American Board of Surgery in-training examination score and attrition from general surgery residency. Surg (United States) [Internet]. 2018 Aug I [cited 2020 Jul 14];164(2):206-II. Available from: https://pubmed.ncbi. nlm.nih.gov/2980356I/

39. Kelz RR, Mullen JL, Kaiser LR, Pray LA, Shea GP, Drebin JA, et al. Prevention of surgical resident attrition by a novel selection strategy. Ann Surg [Internet]. 2010 Sep [cited 2018 May 25];252(3): 537-4I. Available from: https://insights.ovid.com/crossref?an=00153307-201001280-00015

40. Alterman DM, Jones TM, Heidel RE, Daley BJ, Goldman MH. The predictive value of general surgery application data for future resident performance. In: Journal of Surgical Education [Internet].J Surg Educ; 201 I [cited 2020 Jul 14]. p. 5I3-8. Available from: https://pubmed.ncbi.nlm.nih.gov/22000538/

41. Dolan PT, Symer MM, Mao JI, Sosa JA, Yeo HL. National prospective cohort study describing how financial stresses are associated with attrition from surgical residency. Am J Surg. 2020;

42. Yoo PS, Tackett JJ, Maxfield MW, Fisher R, Huot SJ, Longo WE. Personal and Professional WellBeing of Surgical Residents in New England. J Am Coll Surg [Internet]. 2017 Jun [cited 2018 May 25];224(6):I0I5-9. Available from: http://linkinghub.elsevier.com/retrieve/pii/SI07275I5I63I7288

43. O'Callaghan J, Mohan $\mathrm{H}$, Harries R. The non-monetary costs of surgical training. Bull R Coll Surg Engl [Internet]. 2018 Nov 29 [cited 2020 Jul I8];100(8):339-44. Available from: https://publishing. rcseng.ac.uk/doi/l0.1308/rcsbull.2018.339

44. Siotos C, Payne RM, Mirdad A, Siotou K, Lifchez SD, Cooney DS, et al. Failure-to-Progress Through Surgical Residency: A 9-Year Analysis. J Surg Educ. 2020 Jan I;77(I): 178-88.

45. Abelson JS, Sosa JA, Symer MM, Mao J, Michelassi F, Bell R, et al. Association of expectations of training with attrition in general surgery residents. JAMA Surg [Internet]. 2018 Aug I [cited 2020 Jul 14];/53(8):7I2-7. Available from: https://pubmed.ncbi.nlm.nih.gov/297I0278/

46. Neumayer LA, Cochran A, Melby S, Foy HM, Wallack MK. The state of general surgery residency in the United States: Program director perspectives, 200I. Arch Surg [Internet]. 2002 Nov I [cited 2020 Jul 20];137(II):I262-5. Available from: https://pubmed.ncbi.nlm.nih.gov//2413314/ 
47. Leibrandt TJ, Pezzi CM, Fassler SA, Reilly EF, Morris JB. Has the 80-hour work week had an impact on voluntary attrition in general surgery residency programs? J Am Coll Surg [Internet]. 2006 Feb [cited 2020 Jul 14];202(2):340-4. Available from: https://pubmed.ncbi.nlm.nih.gov/l6427562/

48. Bilimoria KY, Chung JW, Hedges L V., Dahlke AR, Love R, Cohen ME, et al. National clusterrandomized trial of duty-hour flexibility in surgical training. N Engl J Med [Internet]. 2016 Feb 25 [cited 2020 Jul 14];374(8):7/3-27. Available from: https://pubmed.ncbi.nlm.nih.gov/26836220/

49. Jackson T, Zhou C, Khorgami Z, Jackson D, Agrawal V, Taubman K, et al. Traumatized Residents —It's Not Surgery. It's Medicine. J Surg Educ [Internet]. 2019 Nov I [cited 2020 Jul 20];76(6):e3040. Available from: https://pubmed.ncbi.nlm.nih.gov/31477549/

50. Coverdill JE, Bittner JG, Park MA, Pipkin WL, Mellinger JD. Fatigue as impairment or educational necessity? Insights into surgical culture. Acad Med [Internet]. 201 I [cited 2020 Jul 20];86(I0 Suppl). Available from: https://pubmed.ncbi.nlm.nih.gov/21955773/

5I. Mcilhenny C, Kurashima Y, Chan C, Hirano S, Domínguez-Rosado I, Stefanidis D. General Surgery Education Across Three Continents. Am J Surg. 2017;

52. Liang R, Anthony A, Leditschke IA. Five myths about unacceptable behaviour in surgical education. ANZ Journal of Surgery. Blackwell Publishing; 2020.

53. Halim UA, Riding DM. Systematic review of the prevalence, impact and mitigating strategies for bullying, undermining behaviour and harassment in the surgical workplace. $\mathrm{Br}$ J Surg [Internet]. 2018 Oct I [cited 2020 Jun 9]; 105(II):I390-7. Available from: http://doi.wiley.com/10.1002/bjs.10926

54. Huang Y, Chua TC, Saw RPM, Young CJ. Discrimination, Bullying and Harassment in Surgery: A Systematic Review and Meta-analysis. Vol. 42, World Journal of Surgery. Springer New York LLC; 2018. p. 3867-73.

55. Fitzgerald CA, Smith RN, Luo-Owen X, Turay D, Ferrada P, Han J, et al. Screening for harassment, abuse, and discrimination among surgery residents: An EAST multicenter trial. In: American Surgeon. Southeastern Surgical Congress; 2019. p. 456-6I.

56. Zhang LM, Ellis RJ, Ma M, Cheung EO, Hoyt DB, Bilimoria KY, et al. Prevalence, Types, and Sources of Bullying Reported by US General Surgery Residents in 2019. Vol. 323, JAMA - Journal of the American Medical Association. American Medical Association; 2020. p. 2093-5.

57. Nally DM, Elsey E, Humm G, Mohan HM. Perceptions of the Annual Review of Competence Progression (ARCP) in surgical training in the UK and Ireland: A prospective cross sectional questionnaire study. Int J Surg. 2019 Jul I;67:117-22.

58. Crebbin W, Campbell G, Hillis DA, Watters DA. Prevalence of bullying, discrimination and sexual harassment in surgery in Australasia. ANZJ Surg [Internet]. 2015 Dec I [cited 2020 Jul 19];85(I2):905-9. Available from: https://pubmed.ncbi.nlm.nih.gov/26510837/

59. Nagata-Kobayashi S, Maeno T, Yoshizu M, Shimbo T. Universal problems during residency: Abuse and harassment. Med Educ [Internet]. 2009 Jul [cited 2020 Jul 20];43(7):628-36. Available from: https://pubmed.ncbi.nlm.nih.gov/19573/85/

60. Teman NR, Gauger PG, Mullan PB, Tarpley JL, Minter RM. Entrustment of general surgery residents in the operating room: Factors contributing to provision of resident autonomy. J Am Coll Surg [Internet]. 2014 Oct I [cited 2020 Jul 19];219(4):778-87. Available from: https://pubmed.ncbi.nlm.nih. gov/251589II/

6I. McKendy KM, Watanabe Y, Lee L, Bilgic E, Enani G, Feldman LS, et al. Perioperative feedback in surgical training: A systematic review [Internet]. Vol. 214, American Journal of Surgery. Elsevier Inc.; 2017 [cited 2020 Jul 20]. p. II7-26. Available from: https://pubmed.ncbi.nlm.nih.gov/28082010/

62. Hu YY, Ellis RJ, Hewitt DB, Yang AD, Cheung EO, Moskowitz JT, et al. Discrimination, abuse, harassment, and burnout in surgical residency training. In: New England Journal of Medicine. Massachussetts Medical Society; 2019. p. 174I-52.

63. Gleason F, Malone E, Wood L, Baker SJ, Hollis RH, Richman JS, et al. The Job Demands-Resources 
Model as a Framework to Identify Factors Associated With Burnout in Surgical Residents. J Surg Res [Internet]. 2020 Mar I [cited 2020 Jul 20];247:I2I-7. Available from: https://pubmed.ncbi.nlm.nih. gov/31785888/

64. Elmore LC, Jeffe DB, Jin L, Awad MM, Turnbull IR. National Survey of Burnout among US General Surgery Residents. In: Journal of the American College of Surgeons [Internet]. Elsevier Inc.; 2016 [cited 2020 Jul 20]. p. 440-5I. Available from: https://pubmed.ncbi.nlm.nih.gov/27238875/

65. Low ZX, Yeo KA, Sharma VK, Leung GK, Mclntyre RS, Guerrero A, et al. Prevalence of Burnout in Medical and Surgical Residents: A Meta-Analysis. Int J Environ Res Public Health [Internet]. 2019 Apr 26 [cited 2019 Sep 30];16(9):1479. Available from: http://www.ncbi.nlm.nih.gov/pubmed/31027333

66. Wild JRL, Ferguson HJM, McDermott FD, Hornby ST, Gokani VJ. Undermining and bullying in surgical training: A review and recommendations by the Association of Surgeons in Training [Internet]. Vol. 23, International Journal of Surgery. Elsevier Ltd; 2015 [cited 2020 Sep 9]. p. S5-9. Available from: https://pubmed.ncbi.nlm.nih.gov/26369864/

67. Lee N, Appelbaum N, Amendola M, Dodson K, Kaplan B. Improving resident well-being and clinical learning environment through academic initiatives. J Surg Res [Internet]. 2017 Jul I [cited 2020 Jul 20];2I5:6-II. Available from: https://pubmed.ncbi.nlm.nih.gov/28688662/

68. Hughes BD, Perone JA, Cummins CB, Sommerhalder C, Tyler DS, Bowen-Jallow KA, et al. Personality testing may identify applicants who will become successful in general surgery residency. J Surg Res. 2019 Jan I;233:240-8.

69. Quillin RC, Pritts TA, Hanseman DJ, Edwards MJ, Davis BR. How Residents Learn Predicts Success in Surgical Residency. J Surg Educ [Internet]. 20I3 Nov [cited 2018 May 25];70(6):725-30. Available from: http://linkinghub.elsevier.com/retrieve/pii/S19317204I3002365

70. Salles A, Wright RC, Milam L, Panni RZ, Liebert CA, Lau JN, et al. Social Belonging as a Predictor of Surgical Resident Well-being and Attrition. J Surg Educ. 2019 Mar I;76(2):370-7.

7I. Character Strengths and Virtues: A Handbook and Classification [Internet]. [cited 2020 Jul 20]. Available from: https://www.apa.org/pubs/books/43I7046

72. Tims M, Bakker A, Derks D. Development and validation of the job crafting scale. J Vocat Behav [Internet]. 2012 Feb I [cited 20I8 Sep 6];80(I):I73-86. Available from: https://www.sciencedirect. $\mathrm{com} /$ science/article/abs/pii/S0001879111000789

73. Maslach C, Schaufeli WB, Leiter MP. Job Burnout. Annu Rev Psychol [Internet]. 200I Feb 28 [cited 2019 Sep 4];52(I):397-422. Available from: http://www.annualreviews.org/doi/I0.1I46/annurev. psych.52.1.397

74. Demerouti E, Nachreiner F, Bakker AB, Schaufeli WB. The job demands-resources model of burnout. J Appl Psychol [Internet]. 200I [cited 2020 Jul 22];86(3):499-5I2. Available from: / record/2001-06715-012

75. Bakker AB, Hakanen JJ, Demerouti E, Xanthopoulou D. Job resources boost work engagement, particularly when job demands are high. J Educ Psychol [Internet]. 2007 May [cited 2020 Jul 22];99(2):274-84. Available from: /record/2007-06672-004?casa_token=06bXf8AqfmUAAAAA:hh zrcVatgWKqHHbzplnvRQ0iSqhAAU0KFIOYDX2NBJLAckTzV5exvqzcVy4emx6kESdnYVOEqb_88I5d5tn3nlaW

76. Bakker AB, Demerouti E. Job demands-resources theory: Taking stock and looking forward. J Occup Health Psychol [Internet]. 2017 [cited 2018 May 26];22(3):273-85. Available from: https:// www.isonderhouden.nl/doc/pdf/arnoldbakker/articles/articles_arnold_bakker_444.pdf

77. Schaufeli W, Salanova M, González-romá V, Bakker A. The Measurement of Engagement and Burnout: A Two Sample Confirmatory Factor Analytic Approach. J Happiness Stud [Internet]. 2002 [cited 2020 Jul 23];3(I):7I-92. Available from: https://link.springer.com/ article/I0.1023/A:I015630930326 
78. Bakker AB, Demerouti E, Sanz-Vergel Al. Burnout and Work Engagement: The JD-R Approach. Annu Rev Organ Psychol Organ Behav [Internet]. 2014 [cited 2018 May 25];I(I):389-4II. Available from: https://www.isonderhouden.nl/doc/pdf/arnoldbakker/articles/articles_arnold_bakker_348.pdf

79. Bakker AB. Strategic and proactive approaches to work engagement. Vol. 46, Organizational Dynamics. 2017.

80. Wang H, Demerouti E, Bakker AB. A review of job crafting research: The role of leader behaviors in cultivating successful job crafters. In: Sharon K. Parker UKB, editor. Proactivity at Work: Making Things Happen in Organizations. Ist editio. New York: Routledge.; 2016. p. 77-104.

81. Lazazzara A, Tims M, de Gennaro D. The process of reinventing a job: A meta-synthesis of qualitative job crafting research.J Vocat Behav [Internet]. 2019 Jan 6 [cited 2019 Aug 13]; Available from: https:// www.sciencedirect.com/science/article/pii/S0001879119300016

82. Siangchokyoo N, Klinger RL, Campion ED. Follower transformation as the linchpin of transformational leadership theory: A systematic review and future research agenda. Leadersh Q. 2020 Feb I;3I(I).

83. MacGregor Burns J. Transforming Leadership. New Yoork: Grove Press; 1978. 240 p.

84. Bass B. Leadership and performance beyond expectations. New York: Free Press; 1985.

85. Antonakis J, Avolio BJ, Sivasubramaniam N. Context and leadership: an examination of the nine-factor full-range leadership theory using the Multifactor Leadership Questionnaire. Leadersh Q [Internet]. 2003 Jun I [cited 2018 Dec 2I];I4(3):26I-95. Available from: https://www.sciencedirect.com/science/ article/pii/S1048984303000304

86. Avolio BJ. Full Range Leadership Development. Second Edi. United States of America: SAGE Publications; 2013. 280 p.

87. Antonakis J, Avolio BJ, Sivasubramaniam N. Context and leadership: an examination of the nine-factor full-range leadership theory using the Multifactor Leadership Questionnaire \$. [cited 2018 Sep 6]; Available from: https://pdfs.semanticscholar.org/ab7d/6b49ca750c6444c67f8befbdc6b8d24b4615.pdf

88. Avolio B. Full Range Leadership. In: Full Range Leadership Development. SAGE Publications, Inc.; 2014. p. 49-74.

89. Stentz JE, Plano Clark VL, Matkin GS. Applying mixed methods to leadership research: A review of current practices. Leadersh Q [Internet]. 20I2;23(6):II73-83. Available from: http://dx.doi. org/10.1016/j.leaqua.2012.10.00I

90. Hanna JS, Herrera-Almario GE, Pinilla-Roncancio M, Tulloch D, Valencia SA, Sabatino ME, et al. Use of the six core surgical indicators from the Lancet Commission on Global Surgery in Colombia: a situational analysis. Lancet Glob Heal [Internet]. 2020 May I [cited 2020 Jun 24];8(5):e699-7I0. Available from: https://pubmed.ncbi.nlm.nih.gov/32353317/ 


\section{CHAPTER 2}

\section{Taking control: Is job crafting related to the intention to leave surgical training?}

Dominguez LC, Stassen L, de Grave W, Sanabria A, Alfonso E, Dolmans D. PLoS One. 2018 Jun I;I3(6):e0I97276. doi: 10.137I/journal.pone. 0197276. eCollection 2018. 


\section{Abstract}

\section{OBJECTIVE}

The intention to leave surgical training, hereinafter referred as proxy of "attrition," is associated with poor well-being in the workplace.Attrition is suggested to diminish when residents possess jobcrafting skills, that is, the ability to redefine their job in meaningful ways and maximize well-being at work by increasing structural and social resources and challenges and decreasing hindering demands. However, the evidence supporting this relationship is scant. This study sought to: I) investigate to what extent residents possess job-crafting skills and compare residents' levels of job-crafting skills across years of residency training;2) investigate the relationship between job crafting, well-being as measured by burnout and work-engagement rates, and the intention to leave; and 3) compare the levels of jobcrafting skills and well-being between residents with and without serious intentions to leave.

\section{METHODS}

This cross-sectional study was conducted in fifteen residency programs in Colombia. Surgical residents completed different questionnaires including the Dutch Job Crafting Scale (DJCS), MBI-Human Services Survey (MBI-HSS), Utrecht Work Engagement Scale (UWES- I7) and an adapted version of the Nurse Turnover Intention Scale (NTIS). The objectives were addressed by independent analyses of variance (ANOVA), structural equation modeling techniques (SEM) and independent t-tests, respectively.

\section{RESULTS}

A total of 202 residents participated. Residents generally scored high on their job-crafting skills to increase structural and social resources as well as challenging demands, but were less positive about their skills to reduce hindering demands. No differences across years of training were found. Job crafting correlated positively with work-engagement, which was inversely related to the intention to leave. Conversely, job crafting correlated negatively with burnout, which bore a positive relationship to the intention to leave. Residents with serious intentions to leave exhibited lower levels of most jobcrafting skills and work-engagement, compared to those without such intentions.

\section{CONCLUSIONS}

This study adds evidence that attrition is a process mediated by residents' well-being at work, which can be molded by their job-crafting endeavors. Future research is needed to evaluate the effectiveness of interventions aimed at cultivating resident's job-crafting abilities in order to reduce attrition. 


\section{Introduction}

Attrition in surgery is a serious issue, with $20 \%$ of residents dropping out, and an even greater proportion, some $32 \%$ to $58 \%$, having serious intentions to leave the program $[1,2,3]$. Attrition has negative consequences not only for individuals, but also for education and healthcare systems, representing significant losses of resources and time for training [4,5]. Additionally it is associated with difficulties to replace residents and workforce shortages of future surgeons $[2,6,7]$. Recent evidence indicates that attrition is more closely associated with a poor state of well-being at work than with demographic and individual factors, which seems plausible as learning takes place almost exclusively in a workplace-based environment $[2,3,5,6]$.

Excessive training demands and related lifestyle issues, nurture this poor state of well-being $[2,8,9,10,1 \mathrm{I}]$, which may lead to burnout, a state characterized by emotional exhaustion, depersonalization and lack of personal accomplishment, ultimately associated with serious thoughts of leaving training $[12,13,14,15]$. A recent U.S. publication revealed for instance that, of the surgical residents who considered leaving the residency (44\%), a majority met the criterion for burnout [16]. The work environment, however, can also have a moderating effect on attrition, which is the case when levels of work engagement are high. Work engagement is a state opposite to burnout characterized by vigor, dedication, and absorption [12], which foster satisfaction, quality of life and resident's retention in surgical training $[17,18,19]$.

Although residents fulfill a dual role as trainees and workers in clinical environments, the process of attrition may be considered similar to that of leaving a job, in which the strongest predictor is the intention to leave, defined as the conscious and deliberate willingness to leave the job [20,2I]. Such intentions are mediated, inter alia, by the individual's well-being at work, attitude, and expectations about the organizational turnover, and by subjective norms and social pressure [22,23]. In surgical training, two approaches have been proposed to improve working conditions and reduce such intentions among residents: I) to restrict the number of weekly working hours, the impact of which on attrition has been minimal $[4,24,25,26]$; and 2) to promote residents' abilities to transform working conditions by themselves [2,27,28]. The latter approach relates to the idea of "job crafting," that is, employees' ability to strategically balance demands and resources at work on the one hand with their personal abilities and needs on the other [29]. Job crafting is a type of proactive personenvironment (PE) fit behavior, oriented to achieve a better fit between one's own attributes and that of the internal work- environment [30].Wrzesniewski and Dutton introduced the concept to explain the physical and cognitive changes that individuals make in the task or relational boundaries at work [3I].The aims of job crafting are to take control, to create a positive self-image and to connect to others. These aims are attained by task, relational and cognitive crafting [ $3 \mathrm{I}]$. In doing so, employees take control to increase personal satisfaction, improve their relationships with others, extend their knowledge about work avoiding negative consequences, and participate actively in job design [3।,32]. However, there is little evidence that this approach will actually reduce attrition in surgery. 
The current concept of job crafting is embedded in the Job Demands-Resources (JD-R) theory, a dynamic model used to understand, explain, and predict well-being in terms of burnout and work engagement rates, their causes, and performance outcomes, irrespective of the occupational setting [12,33]. Within JD-R theory, job crafting encapsulates a set of four skills, specifically the ability to: (I) increase structural resources (those that promote responsibility, autonomy, and/or knowledge about work), (2) increase social resources (those that promote socialization, such as feedback and coaching, and satisfactory interactions with others, such as social support and collaboration), (3) increase challenging demands (those that promote personal growth and personal achievement), and (4) decrease hindering demands (those circum- stances that involve excessive or undesirable constraints that interfere with or inhibit the achievement of valued goals, such as role conflict and workload) [12,32].

In general, employees who engage in job crafting have been demonstrated to perform better, as they are more engaged and less prone to burnout [34,35]. Whether this also holds true for trainees who learn by working in educational contexts such as medical residencies, however, has not yet been sufficiently investigated. Similarly, the impact of trainees' job-crafting endeavors on training outcomes has received scant attention. Most studies have hitherto concentrated on trainee attributes, such as grit (defined as passion and perseverance for long term outcomes), resilience and conscientiousness, which have been found to strongly predict academic success [36,37,38,39]. What these studies failed to address, however, is how such attributes help trainees to change their own well-being at work, increasing and reducing the levels of work engagement and burnout, respectively, and influencing performance outcomes (e.g., staying in or leaving the program). A focus on job-crafting skills in trainees may help fill this gap. Unfortunately, it still remains inconclusive whether job crafting is a skill that surgical residents automatically develop over time, as a mechanism to control the continuous changes in demands and resources in the workplace. We expect job-crafting skills to be instrumental in such workplace-based learning environments, for training outcomes depend not only on efforts of faculty members to create a good training climate [40], but also on residents, who in daily practice must cope with tensions between service delivery and education. In fact, the decision to leave a program may largely depend on residents' ability to control and effectively change the work environment and, consequently, to find purpose and meaning in the residency training. In sum, the surgical realm needs in-depth knowledge about the role of job-crafting skills and its related practical implications for continuing professional development and support of residents. This may also enhance our understanding of the processes involved in residents' retention because job crafting is a mediator between both, situational and personal predictors, and work engagement at the individual and organizational levels $[41,42]$. In practice, this perspective could be input for the call for research about attrition in surgical training from a positive side [43].

The purpose of this study is therefore to investigate the relationship between job crafting in surgical training and the intention to leave the program. To this end, we will address the following research questions $(R Q)$ and hypotheses $(H)$ : 
RQ I: To what extent do surgical residents possess job-crafting skills and does this differ across the years of surgical training?

The main hypothesis underpinning this question is:

HI: Job-crafting skills differ significantly across years of training

RQ 2: What are the relationships between job-crafting skills, well-being at work (as measured by work engagement and burnout), and the intention to leave the program in surgical residents?

In order to investigate these relationships, we incorporated them into the theoretical model presented in Fig I. The hypotheses underpinning these relationships are:

$\mathrm{H}$ 2: Job-crafting skills are inversely related to the intention to leave the program.

H3a: Job crafting is negatively related to burnout.

$\mathrm{H} 3 \mathrm{~b}$ : Burnout is positively related to the intention to leave the program.

$\mathrm{H} 4 \mathrm{a}$ : Job crafting is positively related to work engagement

H4b: Work engagement is negatively related to the intention to leave the program.

RQ 3: What are the differences in job-crafting skills and well-being (as measured by work engagement and burnout rates) between surgical residents with serious intentions to leave the program and those without serious intentions?

The main hypothesis underpinning this question is:

H5: Levels of job-crafting skills and work engagement are lower and the incidence of burnout higher among residents with serious intentions to leave the program compared to those without these intentions. 


\section{Materials and methods}

\section{SETTING}

Medical training in Colombia consists of a six-year undergraduate program that includes one internship year. Upon completion, doctors apply to private or public universities for a residency position. The surgical residency spans approximately 400 positions, which are distributed between 21 programs (2015). Residents complete four years of full-time training, and then apply for a sub-specialty program of two more years. They pay a tuition fee to the university but usually do not receive a salary from hospitals. Few residents receive a semi-annual governmental scholarship. The national policy on duty hours is 66 hours/week.

\section{PARTICIPANTS}

Twenty-one programs of General Surgery were asked to participate. We sent invitations to program directors or deans of medical schools. Five programs never responded. One program rejected the invitation. Finally we invited 284 residents from 15 programs located in seven cities across the country. Based on the power analysis, the present study required a sample of 197 participants ( $\alpha$ error $=.05 ; \beta$ error $=.20 ; 95 \% \mathrm{Cl}$ ).

\section{RESEARCH DESIGN}

This is a quantitative cross-sectional study following a correlational approach. We obtained ethical approval for the present study from the Commission of Medical Education, Faculty of Medicine, Universidad de la Sabana, Colombia (Reference number: 14/2015)

\section{MEASURES AND INSTRUMENTS}

We measured job-crafting skills using a Spanish version of the Dutch job-crafting scale (DJCS) [34,44], which consists of 21 items ranging from I (never) to 5 (very often). The scale's $\alpha$ coefficient of reliability ranged from $0.70-0.80$ [34,44]. The instrument contains four subscales that each one measures one job-crafting skill:

- Skill I: the ability to increase structural resources (5 items). One such item read, for instance: "I make sure that I use my capacities to the fullest."

- Skill 2: the ability to increase social resources (5 items). For instance: "I ask others for feedback on my job performance."

- Skill 3: the ability to increase challenging demands (5 items). For example: "When an interesting project comes along, I offer myself proactively as project co-worker." 
- Skill 4: the ability to decrease hindering demands (6 items). For example: "I manage my work so that I try to minimize contact with people whose problems affect me emotionally." We measured the intention to leave using an adapted version of the Nurse Turnover Intention Scale (NTIS) [45]. Because the scale was not available in Spanish language, we translated it from English into Spanish, adhering to the procedure set out in the IQOLA recommendations [46]. The scale consists of three items ranging from I (never) to 5 (very often/likely). It has a proven $\alpha$ coefficient of 0.85 [45]. One of these items read: "How often did you generate the idea to leave the surgery residency in the past six months?"

To gauge work engagement we used a Spanish version of the UtrechtWork Engagement Scale (UWES17) [47], which comprises 17 items ranging from 0 (never) to 6 (always-every day). It reportedly has a Cronbach's alpha of 0.88-0.95.An example of such an item is:"I find the work that I do full of meaning and purpose." Finally, we used a Spanish version of the MBI-Human Services Survey (MBI-HSS) to quantify burnout [48]. The scale consists of 22 items ranging from 0 (never) to 6 (always-every day) distributed in three domains (emotional exhaustion, depersonalization and personal accomplishment). One of these items read, for example:"I feel frustrated by my job”. Burnout results from a combination of high levels of emotional exhaustion with high levels of depersonalization or low levels of personal accomplishment [49].The scale's $\alpha$ coefficients of reliability ranged from $0.7 \mathrm{I}-0.90$ [48].

\section{Procedure}

We prepared a paper-based questionnaire for data collection. After we had pilot tested and subsequently adjusted the instruments, we contacted the program directors and/or deans of the medical schools in order to explain the purpose of the study. When they voluntarily agreed to participate, we organized different visits to surgical meetings in ten programs, which all residents regularly attended (usually once a week). There we informed residents of the study's purpose, anonymity, confidentiality, and further management of information. In the remaining five programs, the program directors arranged the collection of information. We deliberately did not distribute the instrument during clinical activity, nor did we give participants any financial compensation or any other type of incentive. We collected data in the period spanning October to December, 20I5. Once completed, the main researcher coordinated the transcription and organization of data in order to guarantee the quality and integrity of information.

\section{Statistical analysis}

Resident questionnaires that exceeded $50 \%$ missing data were excluded from further analyses. On the contrary, questionnaires with less than $50 \%$ missing data were imputed by the expectationmaximization technique. Frequencies and descriptive statistics were measured to gain insight in 
relevant study sample characteristics. We calculated the mean, standard deviation and ranges of each domain of burnout. The cut-offs for high, moderate and low levels of each domain were calculated according to the standard recommendations [49]. The rate of burnout was reported as percentage.

To test $\mathrm{HI}$, we computed the mean scores and standard deviations (SD) for each skill on the DJCS, as criterion variables.We defined that scores of 4.0 or higher were considered as good, between 3.0 and 4.0 as sufficient, and below 3.0 as low (scale I-5). We then performed univariate analyses of variance (ANOVA) for each skill, considering the year of residency as predictor variable. In each ANOVA we calculated the sum of squares (SS) as a crude measure of variability, the mean square (MS) as variance estimate, and the mean square error (MSE) as measure of error variance. The differences for each ANOVA were considered significant when $P<.05$. The proportion of variance in each skill accounted for by the year of residency was calculated by the omega squared $(\omega 2)$ as index of effect size. Following the available recommendations, a $\omega 2=.01$ represents a small effect, $\omega 2=.06$ a medium effect, and $\omega 2$ $=.14$ a large effect [50].

We tested the hypothetical relationships expressed in $\mathrm{H} 2$ through $\mathrm{H} 4 \mathrm{~b}$ and represented as a model in Fig I using structural equation modeling (SEM). We applied SEM analyses because these are highly flexible statistical procedures that allow researchers to test theoretical models by analyzing correlational data [5I]. SEM is useful because it provides information with regards to hypothesized relationships in a sample of participants. SEM informs about how the theoretical model fits against the empirical data, with the aims to inform logical and consistent relationships between independent, mediator and dependent variables. However, SEM does not provide cause and effect, like the evidence provided by an experiment [5I].

Fig I. Theoretical model. Skill I: the ability to increase structural resources. Skill 2: the ability to increase social resources. Skill 3: the ability to increase challenging demands. Skill 4: the ability to decrease hindering demands“.

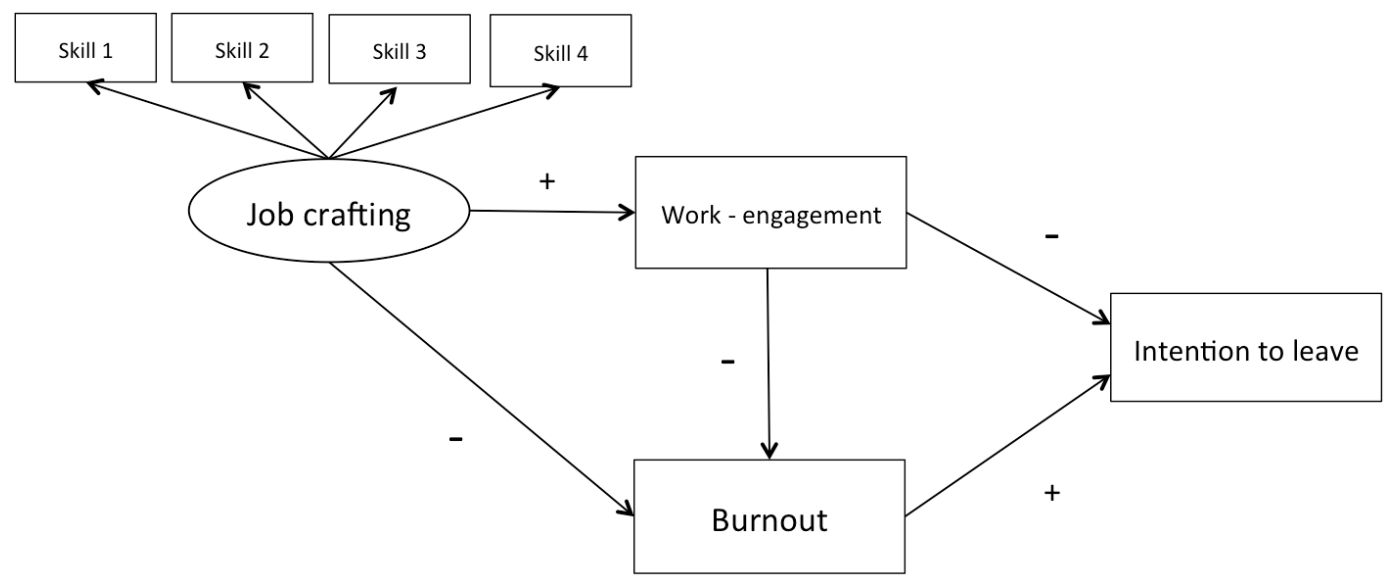


For SEM analyses, we initially established convergent validity of the model based on inter- scale correlations (satisfactory if $<.70$; significant when $P<.05$ ). Also, we calculate the coefficients of reliability for each scale. The internal consistency of scales was considered appropriate if the $\alpha$ coefficient of reliability was $>.70$. Next, we followed a model-fit procedure to test the whole hypothesized model against the empirical data by using the method of maximum likelihood of estimation. We selected this method given the fixed number of observations in the sample and its normal distributions. The free parameters (those estimated from the data) were nonstandardized. We assessed model fit based on the standardized root mean square residual (SMRS), root mean square error of approximation (RMSA), comparative fit index (CFI), and Tucker-Lewis index (TLI). The cut-offs for good fit were: SMRS $p<.08$ for good fit and $<.12$ for acceptable fit, RMSA <.06 for good fit and <. 10 for acceptable fit, and CFI and TLI >.95 for good fit and $>.90$ for acceptable fit [5I].

Additionally, we conducted mediation analyses to measure the indirect and direct effects of job crafting, work engagement and burnout on the intention to leave surgical training in the theoretical model. The indirect effect of one variable on a second variable is defined as the part of the total effect that is transmitted by one o more mediating variables in the model [5I]. In the present study we measured two indirect effects. First, we estimated the indirect effect of job crafting on the intention to leave mediated by burnout and work engagement. Second, we estimated the indirect effect of work engagement on the intention to leave mediated by burnout. On the other hand, the direct effect is defined as the part of the total effect that is not mediated by another variable [5I]. In the present study we measured two direct effects. First, we estimated the direct effect of work engagement on the intention to leave not mediated by burnout. Then, we estimated the direct effect of burnout on the intention to leave not mediated by work engagement and job crafting. The effects were considered significant when $\mathrm{p}<.05$. Finally, we informed the unstandardized path coefficients (b coefficients) for any path between the independent and the dependent variables included in the model $(p<.05)$.

To test $\mathrm{H} 5$, we grouped our study population into residents with (Group I) and residents without (Group 2) serious intentions to leave the program.We defined such intentions based on participants' scores for the three items on the NTIS: those with high scores (4: often/likely; and 5:very often/likely) were assigned to Group I; the remainder to Group 2. For each group we calculated the mean scores and SD per skill.We conducted independent t-tests to deter- mine whether the mean scores per skill of Group I were significantly different from those of Group $2(P<.05)$. We computed Cohen's d statistic to indicate the size of the difference between means for each variable in both groups $(95 \% \mathrm{Cl})$. The reference criteria for interpreting the $d$ statistic were: small size $d= \pm .20$, medium size $d= \pm .50$, and large size $d= \pm .80$ [52]. Finally, we calculated the differences in the incidence of burnout between both groups using the chi-squared test $\left(\chi^{2}\right)(p<.05)$. We performed the statistical analysis using Stata- 13 software. 


\section{Results}

A total of 202 surgical residents (men: 63.9\%) agreed to participate, denoting a response rate of 7I.1\%. Residents were aged between 23 and 41 years old, with a mean age of 28.63 (SD: 2.96). One hundred and thirty-one of these residents (64.9\%) were from private programs. The number of participants per program ranged from 6 to 23 residents. The main characteristics of participants are described in Table I.

Table I. Characteristics of the study population 0

\begin{tabular}{|c|c|}
\hline Characteristics & Study sample \\
\hline Number of residents & 202 \\
\hline Male residents, $\mathrm{n}$ & 129 \\
\hline Female residents, $\mathrm{n}$ & 73 \\
\hline Number of training programs evaluated, $n$ & 15 \\
\hline Number of public programs, $n$ & 6 \\
\hline Number of private programs, $n$ & 9 \\
\hline Number of residents per public programs, $n$ & 71 \\
\hline Number of residents per private programs, $n$ & 131 \\
\hline \multicolumn{2}{|l|}{ Number of residents per years of residency training, $n$} \\
\hline I & 67 \\
\hline 2 & 43 \\
\hline 3 & 45 \\
\hline 4 & 47 \\
\hline
\end{tabular}

\section{DESCRIPTIVE FINDINGS}

The mean score and SD $(95 \% \mathrm{Cl})$ for intention to leave was I.39 (.59) (I.30-I.47). The scores for job crafting skills were: ability to increase structural resources (skill I) $=4.50$ (.34) $(4.45-$ 4.55); ability to increase social resources (skill 2) = $3.86(.68)(3.76-3.95)$; ability to increase challenging demands (skill 3) = 3.39 (.7I) (3.29-3.49); ability to decrease hindering demands $($ skill 4$)=2.7 \mathrm{I}(.14)(2.6 \mathrm{I}-2.82)$. Hence, residents generally scored high on their job-crafting skills to increase structural and social resources as well as challenging demands, but were less positive about their skills to reduce hindering demands. The score for work engagement was 5.38 (.47) (5.3I-5.45). The global percentage of burnout was 33.2 (67 residents). Half of the residents scored high on emotional exhaustion, $30 \%$ high on depersonalization and $41,6 \%$ low on personal accomplishment. The mean scores and the distribution of residents in each domain of burnout are presented in Table 2 . 
Table 2. Burnout among surgery residents $(n=202)$. Mean scores (SD and ranges) per domain and percentage of residents in each domain

\begin{tabular}{lllll}
\hline Domain & Mean score, SD, range & Low (\%) & Moderate (\%) & High (\%) \\
\hline Emotional Exhaustion & $28.11(10.23)(5-52)$ & 14 & 29.7 & 55.4 \\
Depersonalization & $10.35(6.36)(0-28)$ & 44.1 & 25.7 & 30.2 \\
Personal accomplishment & $35(4.81)(17-42)$ & 41.6 & 40.1 & 18.3 \\
\hline
\end{tabular}

SD: standard deviations

\section{RESULTS FROM SEM ANALYSES}

The descriptive statistics, inter-scale correlations, and reliability estimates are displayed in Table 3 . Correlations ranged from -0.004 to 0.40 , satisfying the recommended criterion $(<0.70)$. Moreover, the model showed adequate fit to the empirical data: $\mathrm{SMRS}=.05 ; \mathrm{RMSA}=.065 ; \mathrm{CFI}=.93$ and TLI $=.87$.

Table 3. Correlations, descriptive statistics, and coefficients of reliability (on the diagonal) for the included variables

\begin{tabular}{|c|c|c|c|c|c|c|c|c|c|}
\hline Variable (Scale) & $M$ & SD & I & 2 & 3 & 4 & 5 & 6 & 7 \\
\hline $\begin{array}{l}\text { Skill I: ability to } \\
\text { increase structural } \\
\text { resources (DJCS) (a) (I) }\end{array}$ & 4.50 & .34 & $(0.74)$ & & & & & & \\
\hline $\begin{array}{l}\text { Skill 2: ability to } \\
\text { increase social } \\
\text { resources (DJCS) (a) (2) }\end{array}$ & 3.86 & .68 & $.19 * *$ & $(0.76)$ & & & & & \\
\hline $\begin{array}{l}\text { Skill 3: ability to } \\
\text { increase challenging } \\
\text { demands (DJCS) (a) (3) }\end{array}$ & 3.39 & .71 & $.27 * *$ & $.39 * *$ & $(0.82)$ & & & & \\
\hline $\begin{array}{l}\text { Skill 4: ability to } \\
\text { reduce hindering } \\
\text { demands (DJCS) (a) (4) }\end{array}$ & 2.71 & .74 & .10 & $.15^{*}$ & $.28 * *$ & $(0.8 \mathrm{I})$ & & & \\
\hline $\begin{array}{l}\text { Intention to leave } \\
\text { (NTIS) (b) (5) }\end{array}$ & 1.39 & .59 & $-.19 * *$ & -.13 & -.13 & $.14 *$ & $(0.65)$ & & \\
\hline $\begin{array}{l}\text { Work engagement } \\
\text { (UWES-17) (c) (6) }\end{array}$ & 5.38 & .47 & $.28 * *$ & $.21^{* *}$ & $.35 * *$ & .12 & $-.40 * *$ & $(0.80)$ & \\
\hline $\begin{array}{l}\text { Burnout (MBI-HSS) (c) (7) } \\
(0.85)\end{array}$ & - & - & -.07 & $-.16^{*}$ & $-.20 * *$ & -.0004 & $.36 * *$ & $-.31 * *$ & \\
\hline
\end{tabular}

$\mathrm{N}=202 * \mathrm{P}<.05: * * \mathrm{P}<.01$. Dutch Job-Crafting Scale (DJCS); Nurse Turnover Intention Scale (NTIS), Utrecht Work Engagement Scale (UWES); Maslach Burnout Inventory - Human Services Survey (MBIHSS); $\mathrm{M}=$ Mean; SD = Standard Deviation. a) Scale of I-5, I = Never, 5 = Very often. b) Scale of I-5, I = Never, $5=$ Very often/likely. c) Scale of 0-6, 0 = Never, 6 = Always/Every d 
Considering the proposed model, the results of mediation analyses indicated that $100 \%$ of total effects of job crafting on the intention to leave surgical training were indirect effects $(p<.05)$. In other words, the total effects of job crafting were mediated by burnout and work engagement. The indirect effect of job crafting via burnout was $-.19(48,7 \%)(p<.05)$. In turn, the indirect effect of job crafting via work engagement was $-.20(51,7 \%)(p<.05)$. These results confirmed that both mediating variables (burnout and work-engagement) transmitted the total effect of the first variable (job crafting) on the second variable (intention to leave). On the other hand, $18.4 \%$ of the total effects of work engagement on the intention to leave were indirect effects. The indirect effect of work engagement via burnout was $-.047(p<.05)$. Conversely the direct effect of work engagement on the intention to leave was $-.20(p<.05)$, corresponding to $81.6 \%$ of the total effects. Finally, $100 \%$ of the total effects of burnout on the intention to leave were direct effects $(.39)(p<.05)$. Fig 2 represents the model for the intention to leave surgical training with unstandardized path coefficients.

Fig 2. Theoretical model (including path coefficients and p values). Skill I: the ability to increase structural resources. Skill 2: the ability to increase social resources. Skill 3: the ability to increase challenging demands. Skill 4: the ability to decrease hindering demands

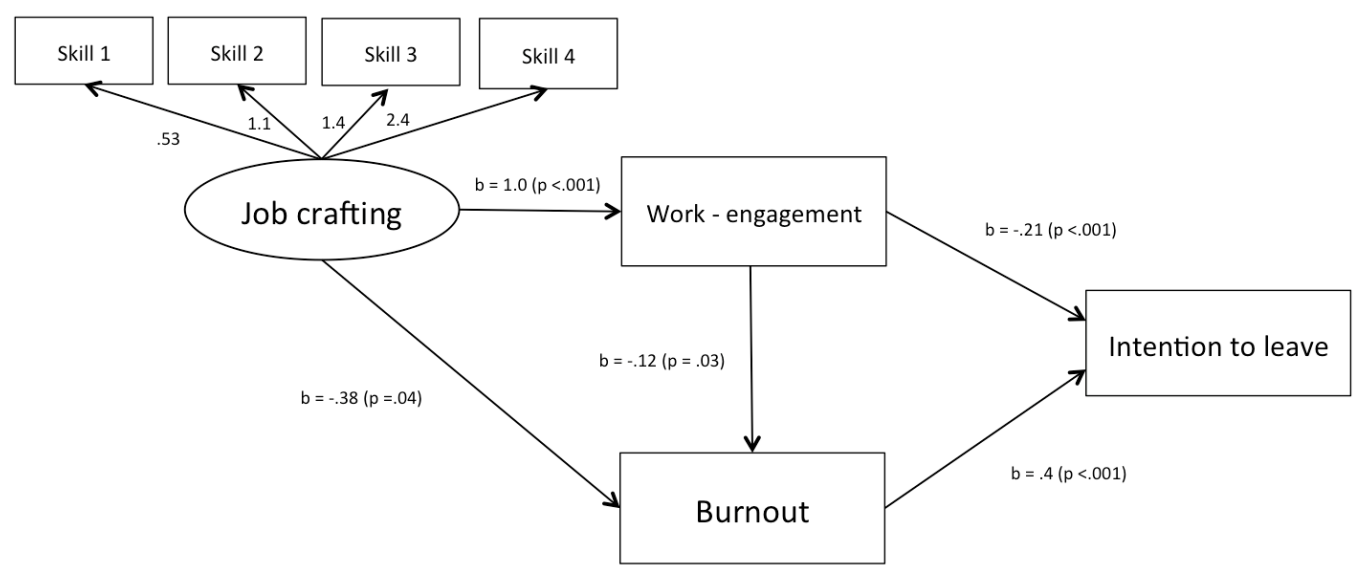

\section{TEST OF HYPOTHESES}

HI: Job-crafting skills differ significantly across years of training

The levels of skills I to 3 were moderately high for all years of training, but those of skill 4 remained consistently low. Based on ANOVAs, we found non-significant differences in level of skills between the years of training $(p<.05)$. The proportion of variance $(\omega 2)$ presented small effect sizes for all skills accounted for by the year of residency. These results are presented in Table 4. We therefore reject $\mathrm{HI}$. 


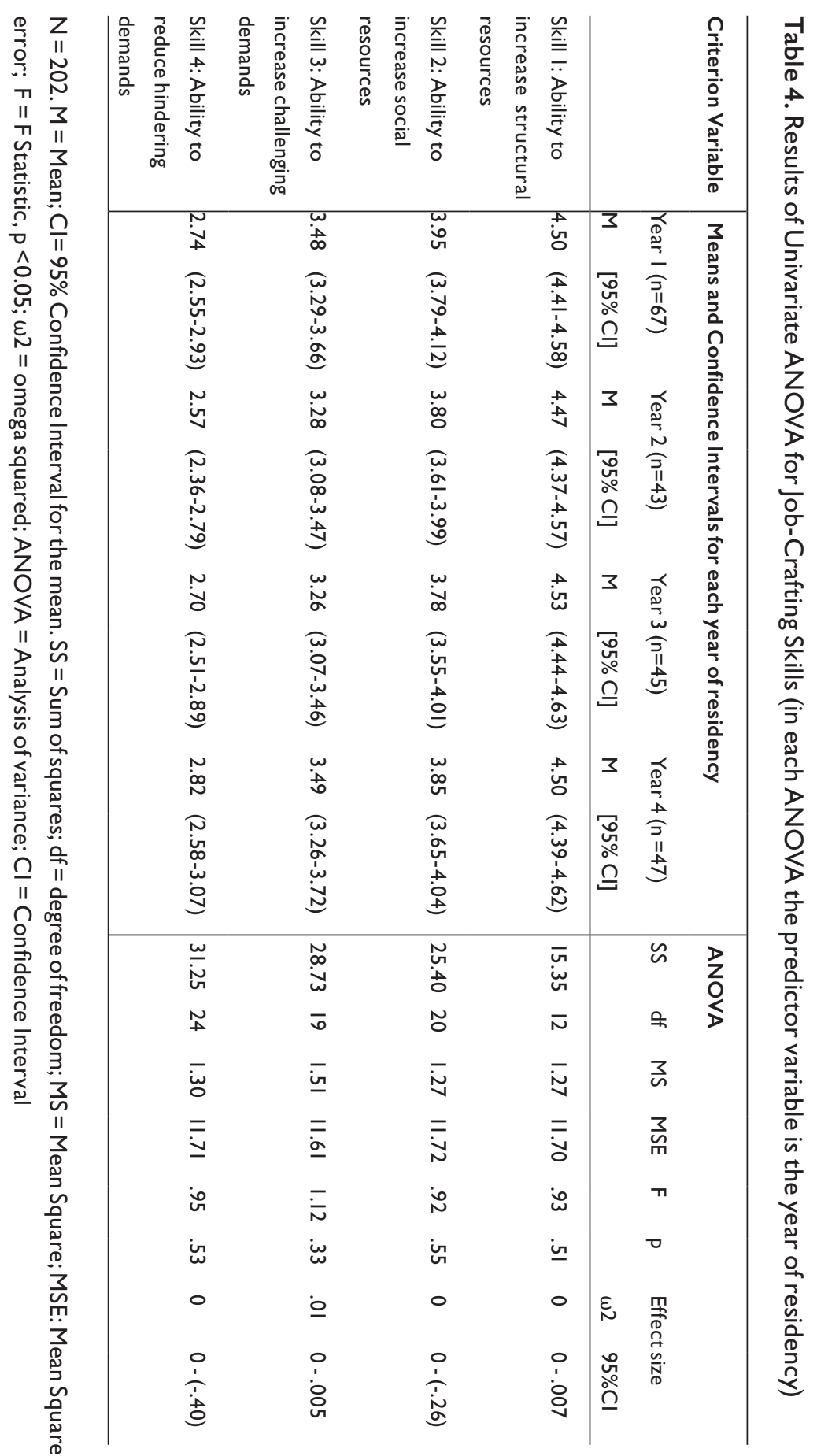


$\mathrm{H}$ 2: Job-crafting skills are inversely related to the intention to leave the program.

We found that skill I (increase structural resources) correlated negatively (-.19) with the intention to leave and skill 4 (reducing hindering demands) correlated positively (.14) with the intention to leave. The other two job crafting skills showed no significant correlations with the intention to leave (Table 3). Consequently, we partially accept $\mathrm{H} 2$, considering that only two out of four job crafting skills were related with the intention to leave.

$\mathrm{H} 3 \mathrm{a}$ : Job crafting is negatively related to burnout; $\mathrm{H} 3 \mathrm{~b}$ : Burnout is positively related to the intention to leave the program.

The results of SEM analyses indicated that job crafting was negatively related to burnout $(b=-.38$, $\mathrm{P}=.04$ ) (Fig 2). Similarly, we found negative significant correlations between two job-crafting skills and burnout (skill 2 and skill 4 , which correlate respectively -.16 and -.20) (Table 3). We therefore accept $\mathrm{H} 3 \mathrm{a}$. In $\mathrm{H} 3 \mathrm{~b}$ burnout was positively related to the intention to leave $(\mathrm{b}=.4, \mathrm{p}<$ $.00 \mathrm{l}$ ) (Fig 2). Additionally, we found that burnout was negatively related to work engagement ( $b$ $=-.12, \mathrm{p}=.03)$. We therefore accept $\mathrm{H} 3 \mathrm{~b}$.

$\mathrm{H} 4 \mathrm{a}$ : Job crafting is positively related to work-engagement; $\mathrm{H} 4 \mathrm{~b}$ : Work engagement is negatively related to the intention to leave the program.

The results of SEM analyses indicated that job crafting was positively related to work engagement $(b=1.0, p<.001)$ (Fig 2). In turn, we found positive significant correlations between three out of four job-crafting skills and work engagement (skill I: $\mathrm{p}<.0$ I; skill 2: $<<.0$ I; skill 3:p <.0I) (Table 3).We therefore accept $\mathrm{H} 3 \mathrm{a}$. In $\mathrm{H} 4 \mathrm{~b}$ work engagement was negatively related to the intention to leave $(b=-.2 \mathrm{I}, \mathrm{p}<.00 \mathrm{I})$ (Fig 2). Thus, we accept H4b.

H5: Levels of job-crafting skills and work engagement are lower and the incidence of burnout higher among residents with serious intentions to leave the program compared to those without these intentions.

Twenty-three participants (II.9\%) had serious intentions to leave the program (Group I). This group presented lower levels of skill I $(p<.05)$ and skill $3(p<.05)$ compared to residents without such intentions (Group 2). Hence, we partially this part of H5. We also found lower scores for work engagement $(p<.05)$ and higher burnout rates $(p<.05)$ in this group. Thus, we accepted this part of $\mathrm{H} 5$. The differences between the two groups in means of all job-crafting skills were small. These results are presented in Table 5. 


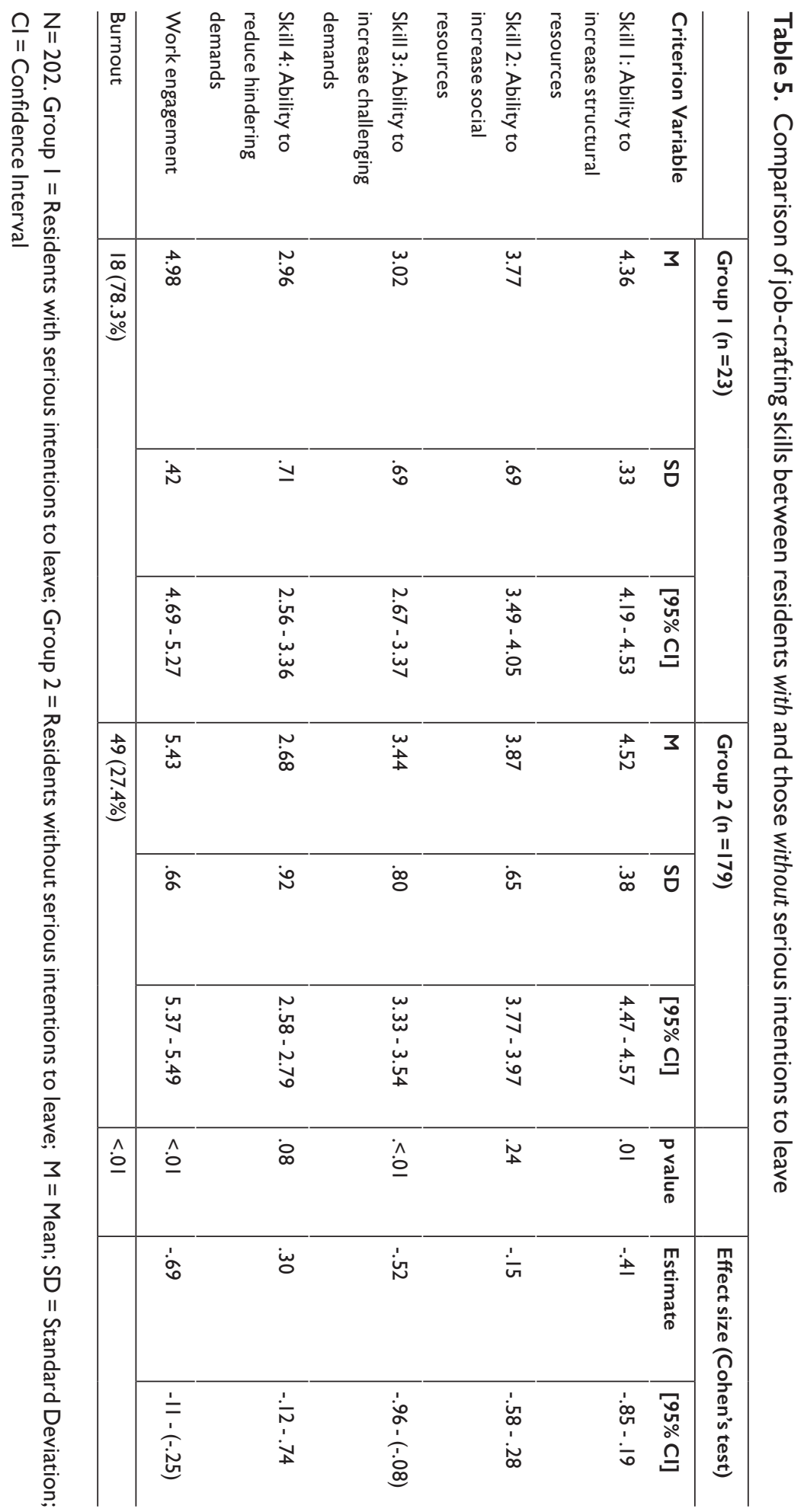




\section{Discussion}

This study sought to explore the job-crafting skills in surgical residents in relation to their well-being at work (as measured by work engagement and burnout rates) and the intention to leave the training program.A first observation was that, irrespective of the year of training, the job-crafting scores for the ability to increase structural resources were good (above 4, scale I-5), those for the ability to increase social resources and challenging demands sufficient (between 3.0 and 4.0), and those for the ability to reduce hindering demands low (below 3.0, scale I-5). No differences between years of training were found. A second observation was that job crafting was positively related to work engagement and negatively related to burnout, while burnout was positively and work engagement negatively related to the intention to leave. Our final observation was that residents with serious intentions to leave exhibited lower levels of most job-crafting skills and work engagement, compared to those without such intentions.

The first observation suggests that surgical residents, regardless of training year, are able to deal with the complexity of the workplace-based learning environment by crafting their ability to increase structural and social resources throughout the program. This finding indicates that job crafting is a type of person environment (PE) fit behavior well developed in surgery residents from early stages, instead of only a personal trait. The current evidence on job crafting literature supports this observation [3I,4I]. In this regard, residents are not only skillfully to increase structural resources, such as responsibility and autonomy, and social resources, which promote socialization and fulfilling interactions, they are also able to positively increase challenging demands although too a lesser extent, for instance starting new interesting projects, which can foster personal growth. Similar findings have been found in other realms of medical education focused in the proactive seeking behaviors that enable residents to find educational resources and diminish demands in the workplace $[53,54,55]$. Our findings indicated that the ability to reduce hindering demands (skill 4), however, appeared to be less present in residents from all years. This finding would suggest that the resident's skills to reduce hindering demands are less well developed. At the present, we do not have a satisfactory explanation for this finding. Future research may seek to explain the lack of this latter ability (e.g. through the lens of resilience and spirituality frameworks) and may focus on how to increase resident's empowerment in order to deal with hindrances at the workplace.

Our second and third observations place in context the relevance of resident's proactivity at work to understand the intention to leave, mediated by well-being. Preliminary research in the field of medical education has a limited scope to explain the influences of proactivity on well- being and performance. For instance, autonomy and challenge seeking behaviors inform the proactive changes that trainees initiate to gain entrustment of professional activities, autonomy, responsibility and opportunities [53,54]. Similarly, feedback-seeking behavior describes the proactive changes oriented to increase supervision, coaching, feedback and social support [55]. Nonetheless, how 
these proactive seeking behaviors foster burnout and work engagement remains inconclusive. The present study adds evidence in this realm. We explored the relationships between resident's proactivity, throughout job crafting, and performance out- comes (intention to leave), mediated by burnout and work engagement. We believe that this framework is relevant due to different reasons. Currently, surgical training requires residents not only to gradually acquire clinical and operative skills, but also to become skillful performers of modern healthcare in general. As these competences are nowadays subject to heightened control and regulations, residents become more alert to their responsibility for service delivery. Consequently, they may become more preoccupied with increasing efficiency at work, dealing with clinical load and work-pressure, than with academic and lifestyle aspects, making them more vulnerable to burnout and intentions to leave the program. Previous studies have suggested that, in order to deal with these challenges and reduce attrition, surgical programs must recruit residents who have the ability to handle such environments $[2,27,28,56]$. In particular, an important body of literature has explored the relationships between individual traits and attrition in surgical training. For instance, significant attention has been offered to grit, a personal trait referred to perseverance and passion [36,57,58]. Preliminary studies suggested that grit might identify those residents who are at risk for poor psychological well-being, but these studies did not reach statistical significance between grit and attrition [36,57]. Despite these findings, a more recent publication reported that grit was correlated with resident's psychological well-being and attrition in surgical training (measured by the intentions to leave) (58). By using regression analysis, grit was a positive predictor of psychological well-being $(B=0.77$, $P<0.01)$, a negative predictor of resident's depression $(B=-0.28, P<0.0 I)$ and negative predictor of attrition $(B=-0.99, p<.05)$. However, grit was not a significant predictor of burnout [58]. Studies with a larger number of participants, including different statistical analyses (e.g. path analysis) are required to investigate the associations between grit, burnout and work engagement and attrition. Conversely, in our study we explored a different perspective to understand the resident's abilities to fit with the environment, instead of personal traits. We demonstrated that job crafting was a strong predictor of work engagement, which, in turn, was inversely related to the intention to leave surgical training. We assume that those residents who have well-developed skills to fit with the environment, are able to engage at work and stay in the program. The findings have been supported by preliminary research indicating the positive relationships of job crafting with performance, at individual and organizational levels [40,4I]. The contribution of this study, in sum, is that the intention to leave is a process mediated by residents' well-being at work, which can be molded by their job-crafting abilities. Hence, according to our findings we hypothesize that job crafting appears as an ability to reduce intention to leave. These insights help us better understand the process involved in residents' retention, thereby approaching the phenomenon from a positive stance.

One of the strengths of this study is its adequate sample size $(n=202)$ based on the power, bias and a thumb rule indicating at least 100 or 200 observations to conduct SEM analyses [59]. Moreover, the surgical residents in our study population came from different universities, 
including public and private institutions, and from a wide range of years of training. The response rate of $71 \%$ proved sufficient as well. Additionally, we applied instruments that were valid and reliable and translated into Spanish language in accordance with international recommendations. Lastly, we identified a set of plausible hypotheses, which were tested using a robust statistical analysis. A limitation of this study is that we did not measure the structure of the work environment, such as the degree of autonomy residents enjoyed and their involvement in jobrelated decision-making [60]. Furthermore, the generalizability of our results may be limited as Colombia's national policies differ from those of other countries. Residents in Colombia must pay a fee to the universities and they work fewer hours in comparison to other countries (e.g. United States). Additionally, it is not easy to obtain a position for surgical training in the country, with the many applicants by far exceeding the number of available positions. The approximate ratio of applicants/position is almost: 20:I in most programs. We therefore expect that residents are less likely to leave the program, even when working conditions may demand it, because they do not want to waste this unique opportunity in their professional careers, nor the financial resources invested. Hence, the decision to leave the program in this case was potentially influenced by factors external to the working environment. These findings can be generalizable to contexts where the number of surgical positions and funding from government are limited. We therefore invite replication of this research in different contexts.

This study has implications for practice and future research. As for practice, the knowledge that job crafting can improve well-being in highly complex environments where residents combine learning and work may make us want to revisit our coaching strategies. Being aware of this specific job-crafting ability by which job demands (e.g., expectations, making difficult decisions) and job resources (e.g., autonomy, supervision and feedback) can be adapted to the individual's needs creates opportunities for trainers and trainees alike; for instance, we can incorporate this new insight into interventions aimed at continuous improvement and career development and use it as input for job redesign. In such venture, bearing in mind that most job-crafting skills do not change across the program, the skills to reduce hindering demands (e.g. unrealistic expectations, and mental and emotional intensity at work), deserve particular attention, as they seem to be less well developed. These interventions can add information to the current literature on job crating. In particular more information is required on the effectiveness of job-crafting interventions designed to promote self-directed employee behaviour and to strengthen personal resources [4I].

First and foremost, however, we must explore the workplace structure, focusing in particular on the positive and negative value of different demands and resources at the surgical environment. In particular, from our results is essential to explore the value of hindering demands and resources of training (positive and negative) and how they are related to job crafting and, ultimately, to attrition. This exploration could lead to design-specific interventions aimed to boost performance outcomes by improving the relationships between residents and the hindering constituents of the 
surgical work environment. The effectiveness of such interventions and residents' receptivity to them requires future research, as do the relationships between the workplace infrastructure and job-crafting behaviors. Similarly, varying degrees of autonomy and supervision, for instance, regulate the extent to which residents are in control of their work, potentially affecting their jobcrafting opportunities to reduce hindrances. The role of empowering leadership and job crafting can offer an interesting perspective to explore these relationships in surgical training. Similarly the role of job crafting assessment for selection purposes deserves special attention. Further studies are required on this topic. To conclude, the present study has explored and confirmed the relationship between job crafting, well-being at work, and attrition in surgery. Its findings expose a new view on job crafting as a fundamental ability for dealing with the complex learning and work environment in surgery, creating opportunities for future research.

\section{References}

I. Bell RH Jr, Banker MB, Rhodes RS, Biester TW, Lewis FR. Graduate medical education in surgery in the United States. Surg Clin North Am. 2007; 87(4):8II-23 https://doi.org/I0.1016/j. suc.2007.06.005 PMID: 1788878।

2. Ginther DN, Dattani S, Miller S, Hayes P. Thoughts of Quitting General Surgery Residency: Factors in Canada. J Surg Educ. 2016; 73(3):513-7. https://doi.org//0.1016/j.jsurg.2015.II.008 PMID: 26708490

3. Gifford E, Galante J, Kaji AH, Nguyen V, Nelson MT, Sidwell RA, et al. Factors Associated With General Surgery Residents' Desire to Leave Residency Programs: A Multi-institutional Study. JAMA Surg. 2014; 149(9):948-53 https://doi.org//0.100I/jamasurg.2014.935 PMID: 25075473

4. Yeo H, Bucholz E, Ann Sosa J, Curry L, Lewis FR Jr, Jones AT, et al. A national study of attrition in general surgery training: which residents leave and where do they go? Ann Surg. 2010; 252(3):529-3 https://doi.org/I0.1097/SLA.0b0I3e3I8If2789c PMID: 20739854

5. Sullivan MC, Yeo H, Roman SA, Ciarleglio MM, Cong X, Bell RHJ, et al. Surgical residency and attrition: defining the individual and programmatic factors predictive of trainee losses. J Am Coll Surg. 20I3; 2I6(3):46I-7I. https://doi.org/I0.1016/j.jamcollsurg.20I2.II.005 PMID: 23266420

6. Longo WE, Seashore J, Duffy A, Udelsman R. Attrition of categoric general surgery residents: results of a 20-year audit. Am J Surg. 2009: 197(6):774-8 https://doi.org//0.1016/j. amjsurg.2008.06.038 PMID: 19178898

7. Leibrandt TJ, Fassler SA, Morris JB. Attrition and replacement of general surgery residents. Surg Clin North Am. 2004; 84(6):I525-35 https://doi.org/I0.1016/j.suc.2004.06.0II PMID: I550I273

8. Maher Z, Milner R, Cripe J, Gaughan J, Fish J, Goldberg AJ. Stress training for the surgical resident. Am J Surg. 20I3; 205(2):169-74. https://doi.org/I0.10I6/j.amjsurg.20I2.10.007 PMID: 23331982

9. Hochberg MS, Berman RS, Kalet AL, Zabar SR, Gillespie C, Pachter H. The stress of residency: recognizing the signs of depression and suicide in you and your fellow residents. Am J Surg. 2013; 205 (2):14I-6. https://doi.org/I0.1016/j.amjsurg.2012.08.003 PMID: 23246287

10. Rieger A, Fenger S, Neubert S, Weippert M, Kreuzfeld S, Stoll R. Psychophysical workload in the operating room: primary surgeon versus assistant. Surg Endosc. 2015; 29(7):1990-8. https://doi. org/l0. 1007/s00464-014-3899-6 PMID: 25303917

II. Jennings ML, Slavin SJ. Resident Wellness Matters: Optimizing Resident Education and Wellness 
through the Learning Environment. Acad Med. 2015; 90(9):1246-50. https://doi.org//0.1097/ACM. 0000000000000842 PMID: 26177527

12. Bakker AB, Demerouti E, Sanz-Vergel AI. Burnout and Work Engagement: The JD-R Approach Annu. Rev. Organ. Psychol. Organ. Behav. 20I4;(I):389-4II

13. Dyrbye LN, Thomas MR, Power DV, Durning S, Moutier C, Massie FS Jr, et al. Burnout and serious thoughts of dropping out of medical school: a multi-institutional study. Acad Med. 2010; 85(I):94102. https://doi.org/I0.1097/ACM.0b0I3e3I8Ic46aad PMID: 20042833

14. Dyrbye L, Shanafelt T. A narrative review on burnout experienced by medical students and residents. Med Educ. 2016; 50(I):I32-49. https://doi.org/I0.IIII/medu.I2927 PMID: 26695473

15. Pulcrano M, Evans SR, Sosin M. Quality of Life and Burnout Rates across Surgical Specialties: A Systematic Review. JAMA Surg. 2016 Jul 13. [Epub ahead of print]

16. Elmore LC, Jeffe DB, Jin L, Awad MM, Turnbull IR. National Survey of Burnout among US General Surgery Residents. J Am Coll Surg. 2016 May 26. pii: SI072-75I5(16)30I85-5.

17. Mache S, Vitzthum K, Klapp BF, Danzer G. Surgeons' work engagement: influencing factors and relations to job and life satisfaction. Surgeon. 2014; 12(4):I8I-90. https://doi.org//0.1016/j. surge.2013.II. 015 PMID: 24325934

18. Lases SS, Arah OA, Pierik EG, Heineman E, Lombarts MJ. Residents' engagement and empathy associated with their perception of faculty's teaching performance. World J Surg. 2014; 38(II):275360. https://doi.org//0.1007/s00268-0I4-2687-8 PMID: 25008244

19. Moalem J, Schwartz SI. Three-phase model for surgical training: a proposal for improved resident training, assessment, and satisfaction. J Surg Educ. 2012 Jan-Feb; 69(I):70-6. https://doi. org/I0.1016/j. jsurg.20II.07.003 PMID: 22208836

20. Hom PW, Mitchell TR, Lee TW, Griffeth RW. Reviewing Employee Turnover: Focusing on Proximal Withdrawal States and an Expanded Criterion Psychological Bulletin 2012; 138(5)

21. Boswell W, Ren LR, Hinrichs AT. Voluntary Employee Turnover: Determinants, Processes and Future Directions. In: Barling J, Cooper C. (Ed) The SAGE Handbook of Organizational Behavior Volume One: Micro Approaches, SAGE Publications, London, 2008.

22. Ajzen I. The theory of planned behavior. Organizational Behavior and Human Decision Processes, 1991; 50(2):179-2

23. van Dam K. Time frames for leaving. Career Development International, 2008; 13(6):560-57I.

24. Everett CB, Helmer SD, Osland JS, Smith RS. General surgery resident attrition and the 80-hour work- week. Am J Surg. 2007; 194(6):75I-6 https://doi.org/I0.1016/j.amjsurg.2007.08.033 PMID: 18005766

25. Kohanzadeh S, Hayase Y, Lefor MK, Nagata Y, Lefor A T . Factors affecting attrition in graduate surgical education. Am Surg. 2007; 73(I0):963-6 PMID: 17983057

26. Leibrandt TJ, Pezzi CM, Fassler SA, Reilly EF, Morris JB. Has the 80-hour work week had an impact on voluntary attrition in general surgery residency programs? J Am Coll Surg 2006; 202(2):340-4. https:// doi.org//0.1016/j.jamcollsurg.2005.09.018 PMID: 16427562

27. Coverdill JE, Carbonell AM, Fryer J, Fuhrman GM, Harold KL, Hiatt JR, et al. A new professionalism? Surgical residents, duty hours restrictions, and shift transitions. Acad Med 20I0; 85(I0 Suppl):S72-S5.

28. Kelz RR, Mullen JL, Kaiser LR, Pray LA, Shea GP, Drebin JA, et al. Prevention of surgical resident attrition by a novel selection strategy. Ann Surg. 2010; 252(3):537-I https://doi.org//0.1097/SLA. 0b0I3e3I8If27a50 PMID: 20739855

29. Tims M, Bakker AB. Job crafting: Towards a new model of individual job redesign. South African Journal of Industrial Psychology, 2010;(36):I-9.

30. Parker SK, Bindl UK. Proactivity atWork:A Big Picture Perspective on a Construct that Matters. In Parker 
SK, Bindl UK (Eds). Proactivity atWork: MakingThings Happen in Organizations. Routledge, UK. 2017

31. Wrzesniewski A, Dutton JE. Crafting a job: Revisioning employees as active crafters of their work. Academy of Management Review, 200I;(26):179-20I.

32. Bakker AB. Top-Down and Bottom-Up Interventions to Increase work engagement. APA Handbook of Career Intervention: Vol. 2. Applications, Hartung P. J., Savickas M. L., and Walsh W. B. (Editors-in- Chief) American Psychological Association, USA, 2015.

33. Albrecht SL, Bakker AB, Gruman JA, Macey W, Saks A. Employee engagement, human resource management practices and competitive advantage. Journal of Organizational Effectiveness: People and Performance, 2015; 2(I):7-35

34. Tims M, Bakker A, Derks D. Development and validation of the job crafting scale. Journal of Vocational Behavior 2012;(80):173-186

35. Tims M, Bakker A, Derks D, van Rhenen W. Job Crafting at the Team and Individual Level: Implications for Work Engagement and Performance. Group \& Organization Management 2013; 38(4) 427-454

36. Burkhart RA, Tholey RM, Guinto D, Yeo CJ, Chojnacki KS. Grit: a marker of residents at risk for attrition? Surgery. 2014; I55(6):1014-22. https://doi.org/I0.1016/j.surg.2014.01.015 PMID: 24856I2I

37. Howe A, Smajdor A, Stö ckl A. Towards an understanding of resilience and its relevance to medical training. Med Educ. 20I2; 46(4):349-56. https://doi.org/I0.IIII/j.I365-2923.20II.04I88.x PMID: 22429170

38. Doherty EM, Nugent E. Personality factors and medical training: a review of the literature. Med Educ. 20II; 45(2):I32-40. https://doi.org/I0.IIII/j.I365-2923.20I0.03760.x PMID: 2I208259

39. Walker A, Hines J, Brecknell J. Survival of the Grittiest? Consultant Surgeons Are Significantly Grittier Than Their Junior Trainees. J Surg Educ, Vol. 73, Issue 4, p730-734 https://doi.org//0.1016/j. jsurg. 2016.01.012 PMID: 27025568

40. Lombarts KM, Heineman MJ, Scherpbier AJ, Arah OA. Effect of the Learning Climate of Residency Pro- grams on Faculty's Teaching Performance as Evaluated by Residents. PloS one. 2014; 9(I):e865I2 https://doi.org//0.137I/journal.pone.00865I2 PMID: 24489734

4I. Plomp J., Tims M., Akkermans J., Khapova S.N., Jansen P.G.W, \& Bakker A.B. Career competencies and job crafting: How proactive employees influence their well-being. Career Development International, 2016: 21, 587-602.

42. Le Blanc P.M., Demerouti E., \& Bakker A.B. How can I shape my job to suit me better? Job crafting for sustainable employees and organizations. In Chmiel N., Fraccaroli F. \& Sverke M. (Eds), An introduction to work and organizational psychology: An international perspective (3rd edition; pp. 48-63). New York: Wiley, 2017.

43. Wasserman MA. A Strategy to Reduce General Surgery Resident Attrition: A Resident's Perspective. JAMA Surg. 2016 Mar; I5I(3):215-6. https://doi.org//0.100I/jamasurg.2015.4607 PMID: 26650772

44. Ficapal-Cusı P, Torrent-Sellens J, Boada-Grau J, Hontangas-Beltran P. “Job change without changing job? Exploring job crafting in Spain" [online working paper]. (Working Paper Series; WPI4005). IN3 Working Paper Series. IN3 (UOC) 2014. [Accessed: 10/05/2017].<http://journals.uoc.edu/ ojs/index. php/in3-working-paper-series/article/view/nl4-ficapalcusi-torrent-sellens-boada-grauhontangasbeltran/nl4-ficapal-cusi-torrent-sellensboada-grau-hontangas-beltran>

45. Yang Y, Liu YH, Liu JY, Zhang HF. The impact of work support and organizational career growth on nurse turnover intention in China. International Journal of Nursing Sciences, 2015; 2(2): 134-139

46. Bullinger M, Alonso J, Apolone G, Leplège A, Sullivan M, Wood-Dauphinee S, et al. Translating health status questionnaires and evaluating their quality: the IQOLA Project approach. International Quality of Life Assessment. J Clin Epidemiol. 1998; 5I(II):913-23. PMID: 98I7I08 
47. Shaufeli WB, Bakker A. Work engagement Scale. Preliminary Manual. Occupational Health Psychology Unit Utrecht University, 2003. Available in: http://www.beanmanaged.com/doc/pdf/ arnoldbakker/articles/articles_arnold_bakker_87.pdf

48. Maslach C, Schaufeli WB, Leiter MP. Job burnout. Annu Rev Psychol 2001; 52:397-422. https://doi. org/I0.II46/annurev.psych.52.I.397 PMID: III483II

49. Maslach C, Jackson SE, Leiter MP. Maslach Burnout Inventory. Manual ( 3rd ed.). Palo Alto, CA: Consulting Psychologists Press, 1996.

50. Kirk RE. Practical significance: A concept whose time has come. Educational and psychological measurement, 1996;(56):746-759

5I. Hatcher L. Advanced statistics in research. Shadow Finch Media, USA, 2013

52. Cohen J. Statistical power analysis for the behavioural sciences ( 2nd Ed). Hillsdale, NJ: Lawrence Erlbaum Associates, 1998.

53. Hauer KE, Ten Cate O, Boscardin C, Irby DM, Lobst W, O'Sullivan PS. Understanding trust as an essential element of trainee supervision and learning in the workplace. Adv Health Sci Educ Theory Pract. 20I4 Aug; 19(3):435-56. https://doi.org/I0.1007/sI0459-0I3-9474-4 PMID: 23892689

54. Ten Cate O Hart D, Ankel F, Busari J, Englander R, Glasgow N, et al. Entrustment Decision Making in Clinical Training. Acad Med. 2016 Feb; 91(2):191-8. https://doi.org//0.1097/ ACM.000000000000I044 PMID: 26630606

55. Crommelinck M, Anseel F. Understanding and encouraging feedback-seeking behaviour: a literature review. Med Educ. 20I3 Mar; 47(3):232-4I https://doi.org/I0.IIII/medu. I2075 PMID: 23398009

56. Louridas M, Szasz P, Montbrun S, Harris KA, Grantcharov TP. Optimizing the Selection of General Surgery Residents: A National Consensus. J Surg Educ. 2016 Jul 28. pii: SI93I-7204(I6)3009I-5.

57. Salles A, Cohen GL, Mueller CM. The relationship between grit and resident well-being. Am J Surg. 20I4 Feb; 207(2):25I-4 https://doi.org/I0.10I6/j.amjsurg.2013.09.006 PMID: 24238604

58. Salles A, Lin D, Liebert C, Esquivel M, Lau JN, Greco RS, Mueller C. Grit as a predictor of risk of attrition in surgical residency. Am J Surg. 2017 Feb; 213(2):288-29l. https://doi.org/l0.1016/j. amjsurg.2016. 10.012 PMID: 27932088

59. Wolf EJ, Harrington KM, Clark SL, Miller MW. Sample Size Requirements for Structural Equation Models: An Evaluation of Power, Bias, and Solution Propriety. Educational and psychological measurement. 2013; 76(6):9/3-934. https://doi.org//0.II77/00I3I644I3495237 PMID: 25705052

60. O'Driscoll MP, Pierce JL, Coghlan AM. The Psychology of Ownership: Work environment structure, organizational commitment and citizenship behaviours. Group \& Organization Management, 2006; 3I (3): 388-4I 


\section{CHAPTER 3}

\section{Job Crafting to Persist in Surgical Training: A Qualitative Study From the Resident's Perspective.}




\begin{abstract}
Background: Attrition in surgical training, a result of poor well-being at work, continues to rise. Work-engagement and persistence, the other side of the coin, depend on the proactivity of residents to optimize the demands and resources in the workplace to achieve a better fit with the environment. This type of proactivity refers to job-crafting. In this study, we sought to explore the specific mechanisms underlying residents' job-crafting to enhance work-engagement and persistence, as well as the role of supervisors in this endeavour.

Materials and Methods: We used a constructivist grounded theory design. We conducted semistructured interviews of active residents. During the analysis of verbatim protocols, we developed codes and categories and identified the main themes (job-crafting mechanisms) related to workengagement and persistence. We anticipated procedures to engage in reflexivity.

Results: The residents showed six job-crafting mechanisms (build trust with supervisors, manage proactively, seek help, see errors and frustrations as learning opportunities, find a suitable worklife balance and seek challenges actively). The supervisors contributed to residents' job-crafting with four mechanisms (earning the trust of the residents, providing guidance and support, allowing residents to fulfil tasks befitting a surgeon in training and offering increasingly challenging tasks to residents).

Conclusions: Work engagement and persistence in training are active processes that depend on the ability of residents to take advantage of resources and challenges and to diminish hindering demands at the workplace. Future research should focus on the perspectives of the supervisor, as well as on the effectiveness of job-crafting interventions, to enhance work-engagement.
\end{abstract}




\section{Introduction}

Attrition is a concept used to define departure from a program without successful completion $(I, 2)$. Up to $18 \%$ of surgical residents leave their programs (3). The cost of attrition is significant for the health care services and it worsens the already existing crisis of the global surgery workforce (3-5). Additionally, it entails significant losses in educational resources and leads to demoralization and failures in the cohesion of the remaining residents $(6,7)$.

Extensive literature has focused on programmatic and individual factors to understand the causes of attrition and its possible solutions. Although most cases occur in the first year of training $(8,9)$, the prevalence of attrition varies with the size, type and tradition of programs $(9-\mathrm{II})$. In the programmatic perspective, the rates of attrition remain high despite reduced working hour schemes $(12,13)$ and interventions aimed to improve resident support (14), such as mentoring $(\mathrm{II}, \mathrm{I5})$ and remediation $(7,16,17)$. Individual factors also have received attention. Some studies reveal a higher prevalence of attrition in women $(3,9,18)$, while other studies do not confirm this association $(12,19,20)$. Similarly, the lack of individual traits, such as grit $(21)$, motivational behaviours (22), action-based learning style (23) and realistic expectations of training (24) have been found more prevalent among leavers, but they have not been entirely accepted as the main causes of attrition. From this individual perspective, the solutions have focused on the selection of appropriate residents (18,25-27). The impact of selection on attrition, however, appears minimal (28).

The conflicting information from the programmatic and individual factors and the dual role of residents as workers and trainees have promoted a different perspective focused on resident wellbeing at the workplace (29-33). From this angle, poor well-being at work is considered one of the top triggers for attrition $(6,11,34,35)$. In general, poor well-being has been explained by the excessive demands of training, such as workload and work pressure $(3,7,36)$, inferior quality of teaching and mentoring $(3,6,7,36,37)$, and mistreatment of residents, such as undermining and bullying (3,38-40). Interestingly, based on this perspective of focus on resident wellbeing, the academic conversation on work engagement and persistence, the opposite of resident attrition, has become more prominent. Theoretically, work engagement describes a positive and fulfilling state of mind of vigour, dedication, and absorption at work (4I). In particular, work engagement depends on the proactivity of workers to optimize and handle their demands (such as workload and physical, emotional and organizational demands) and resources (such as support, autonomy and feedback) to achieve a better fit with the work environment $(4 I, 42)$. This type of proactivity refers to job-crafting. By using job-crafting, workers can achieve a feeling of ownership, gain control and knowledge at work, and aim to invest time and effort in their jobs (42). 
In surgical training, a previous study confirmed the positive relationships of residents' jobcrafting with their work engagement and persistence (29). Unfortunately, the specific mechanisms underlying residents' job-crafting are not yet fully known (29). Research to deepen this knowledge is important because it can contribute to the call to investigate and elucidate the processes involved in residents' persistence in surgical education $(6,9,29)$ and, from a theoretical stance, to understand the mechanisms related with work engagement in specific job-contexts $(42,43)$. In particular, this type of research can add explanations to the mechanisms linking proactivity with specific outcomes at the workplace, focusing on the dynamic role of workers to craft their jobs (e.g., residents) and the influence of their leaders in this venture (e.g., supervisors) (42). Given the paucity of evidence in this matter, the aims of the present study are to explore the mechanisms involved in residents' job-crafting to enhance their work engagement and persistence in the surgical program and identify the contributions of their supervisors to these endeavours from the residents' perspective. We sought to address the following research questions (RQ):

RQI: Which job-crafting mechanisms are used by surgical residents to enhance their work engagement and persistence in the program from the residents' perspective?

RQ2: Which mechanisms are used by supervisors to stimulate surgical resident's job-crafting to enhance their work engagement and persistence in the program from the residents' perspective?

\section{Methods}

\section{RESEARCH DESIGN}

We chose a constructivist grounded theory design to answer the research questions. This design acknowledges the subjectivity of participants and researchers to understand the social reality (44). The constructivist paradigm rebounds in the type of the present research because knowledge is actively co-constructed from human interactions, shared experiences and relationships (45). The background of the researchers and the theoretical framework had implications in this matter. LCD, AS and LPS are active surgeons and clinical supervisors. Moreover, all three hold positions as directors of residency programs. DD and WdG, on the other hand, are educationalists and researchers with extensive experience in the field of medical education. They have theoretical perspectives on postgraduate training and workplace-based learning. Additionally, the current literature on the Job-Demands Resources Theory (JD-R theory), which explains work engagement and job-crafting, guided our data collection and analysis (4I). The JD- $R$ is a dynamic model to understand, and predict well-being at work, in terms of burnout and work engagement, their precursors (demands and resources) and performance (4I). In the core of this framework is the idea that work engagement is crucial 
for job-related outcomes. Considering our background as researchers and the theoretical underpinnings, we anticipated our influences at different stages of this study. These issues engaged us in reflexivity with ourselves, with the research and the audience. Reflexivity refers to the process through researchers reflect on their approach to knowledge generation (46). Considering that the present research underlies on a constructivist perspective, this reflection is important due to our interactions with the participants in the surgical environment, our experiences, beliefs and theoretical assumptions as researchers. To achieve reflexivity, we completed the procedures for sampling, data collection, analysis and presentation of findings according to preliminary recommendations $(46,47)$

\section{GENERAL CONTEXT}

The research took place in Colombia. Surgical training in Colombia consists of a 4-year university-based program, after which qualified surgeons can apply to train in second specialties, which lasts an additional two or three years. At the date of this study, twenty active programs offer four hundred positions per year. Aspiring residents must apply directly at each university since there is no national admission system. Most programs still hold a long-standing Halstedian tradition of hierarchical teaching. Residents pay an annual fee to universities. In turn, the affiliated hospitals receive a reimbursement from universities for the tuition of the residents, but residents do not receive a salary. Residents work 66 hours per week according to the national regulations.

\section{PARTICIPANTS}

With formal consent of the program directors, we invited 25 residents of five programs in the two largest cities to participate. We aimed to recruit the maximum diversity of residents per program, gender, and postgraduate year of training by stratified sampling methods. These methods aimed to facilitate comparisons, enrichment and transferability of findings (48). Considering that LCD and AS are directors of two participant programs, they avoided participating in the recruitment, data collection and member checking in their own programs. After recruitment, LCD and AS contacted the participants personally to explain the aims and scope of the study.

\section{DATA COLLECTION AND ANALYSIS}

The present study focused on the residents' perceptions and experiences in the workplace. We anticipated sensitive information on detailed and personal issues from participants. To face these issues, we preferred individual in-depth, semi-structured interviews, and we prepared, 
piloted and fine-tuned an interview guide. At this stage (prior to data collection), we conducted a first process of translation of the main concepts (e.g. work-engagement) from English into Spanish language. We followed preliminary recommendations $(49,50)$, in order to develop a clear interview guide, free of technicalities and confusions for the participants. The interview guide was embedded in the STARR model (situation, task, activity, result and reflection), a funnel method to stimulate a regular conversation with the participants, based on their preliminary experiences at the workplace (please see Appendix A). From September to November 2017, we conducted and audiotaped the interviews in Spanish language. During data collection we assured a second process of active translation from English into Spanish language, in order to preserve the meaning of the main concepts $(49,50)$. After each interview, LCD and AS exchanged a summary of the main findings and impressions. Simultaneously, research assistants initiated the manual transcription of the audio records in Spanish language. During this process, we used previous interview data to emphasize specific topics with the next participants, in order to get a depth knowledge of issues, while we preserved the main structure of our interview guide.

For data analysis, we followed a standardized stepwise procedure (44). Preliminarily, we stored and organized the verbatim transcript using the Atlas.ti software in Spanish language. For member checking, we sent the verbatim transcript to the participants and asked on the accuracy of the interview, which did not result in comments. For the analysis, LCD and AS read the overall content of the verbatim transcripts independently. Both researchers developed inductive codes of the main range of ideas by in vivo coding, repetition and exploration of underlying concepts in Spanish language. Simultaneously, they used deductive codes devised from the interview guide, the JD-R theory and their professional experience as clinical supervisors (Step I). Then, iteratively, LCD and AS compared the single codes (deductive and inductive) across the interviews in the dataset, and by different subgroups of participants, to identify patterns and notice associations (Step 2). We reviewed all interviews, but we gained theoretical saturation and thematic sufficiency after fifteen interviews. The third stage of the cycle refers to categorization and conceptualization of data (Step 3). Both researchers grouped codes with similar attributes into broad categories of concepts, and they translated these codes and categories into English language. At this point, all authors reviewed and performed an iterative process of forward and backward translations to fine tune and identify potential mistranslations of codes and categories according to preliminary recommendations $(49,50)$. Then, the analysis was moved towards a more abstract level until all authors reached a consensus of the main concepts and themes (mechanisms) in English language. Finally, all components of the analysis were placed together to develop our theoretical understanding of resident's work-engagement and persistence in surgical training (Step 4). At this stage, all authors approved the final framework after an iterative verification and refinement of the theory. We validated our findings by comparison with the available literature. Finally, the objects for the dissemination of findings (main concepts, themes and quotations) were submitted to further processes of forward and backward translations 
$(49,50)$, until all authors agreed with the final version and meaning of the text. The analytic cycle is presented in Figure I.

Figure I. The analytic cycle (based on the standardized stepwise procedure described by Hennink MM, Hutter I and Bailey A) (44).

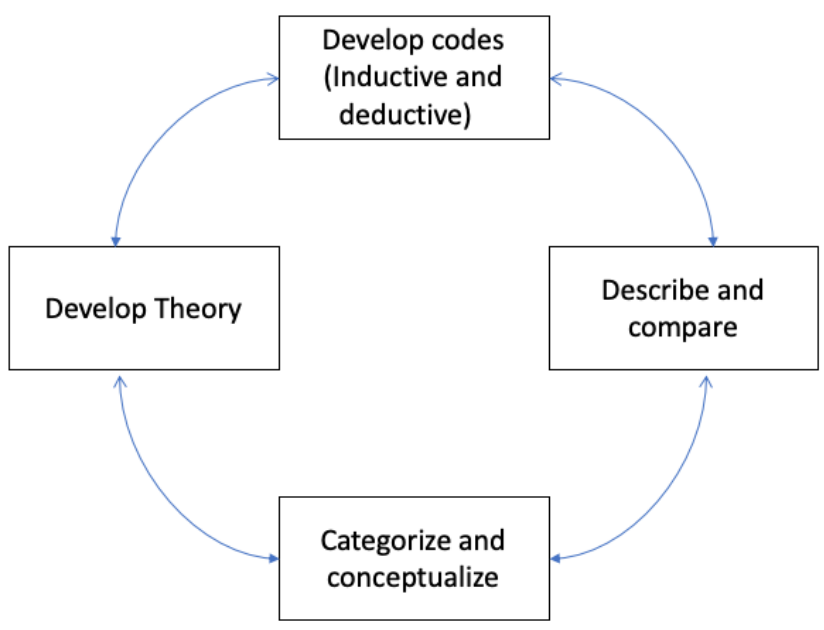

\section{RESEARCH ETHICS}

The Universidad de la Sabana (Colombia) granted the ethical approval (\# 14/2015). All residents voluntarily participated and did not receive any incentives. The residents signed an informed consent form describing the purpose of recruitment and conditions of participation. We withheld detailed information of the participants to ensure confidentiality and anonymity.

\section{Results}

The interviews lasted from 31 to 71 minutes. Female residents represented $44 \%$ of participants. The distribution of participants by the postgraduate year of training corresponded to Year-I ( $=6)$, Year-2 $(n=7)$, Year-3 $(n=6)$ and Year-4 $(n=6)$.

Ten overarching mechanisms to enhance the resident's work engagement and persistence in the program, in line with the concept of job-crafting, were identified. Mechanisms I-6 were related to RQI, and mechanisms 7-10 were related to RQ2. We present a description of these mechanisms and representative quotations of the participants. We also present a diagram of the main findings (Figure 2). 
Figure 2. An explanation of job-crafting mechanisms and the contributions of supervisors to enhance residents' work engagement and persistence in surgical training from the residents' perspective. This figure shows the job-crafting mechanisms (right) and the mechanisms used by supervisors to foster the residents' job-crafting (left). The intersection of circles represents the contributions of both residents and supervisors to residents' work engagement and persistence in training.

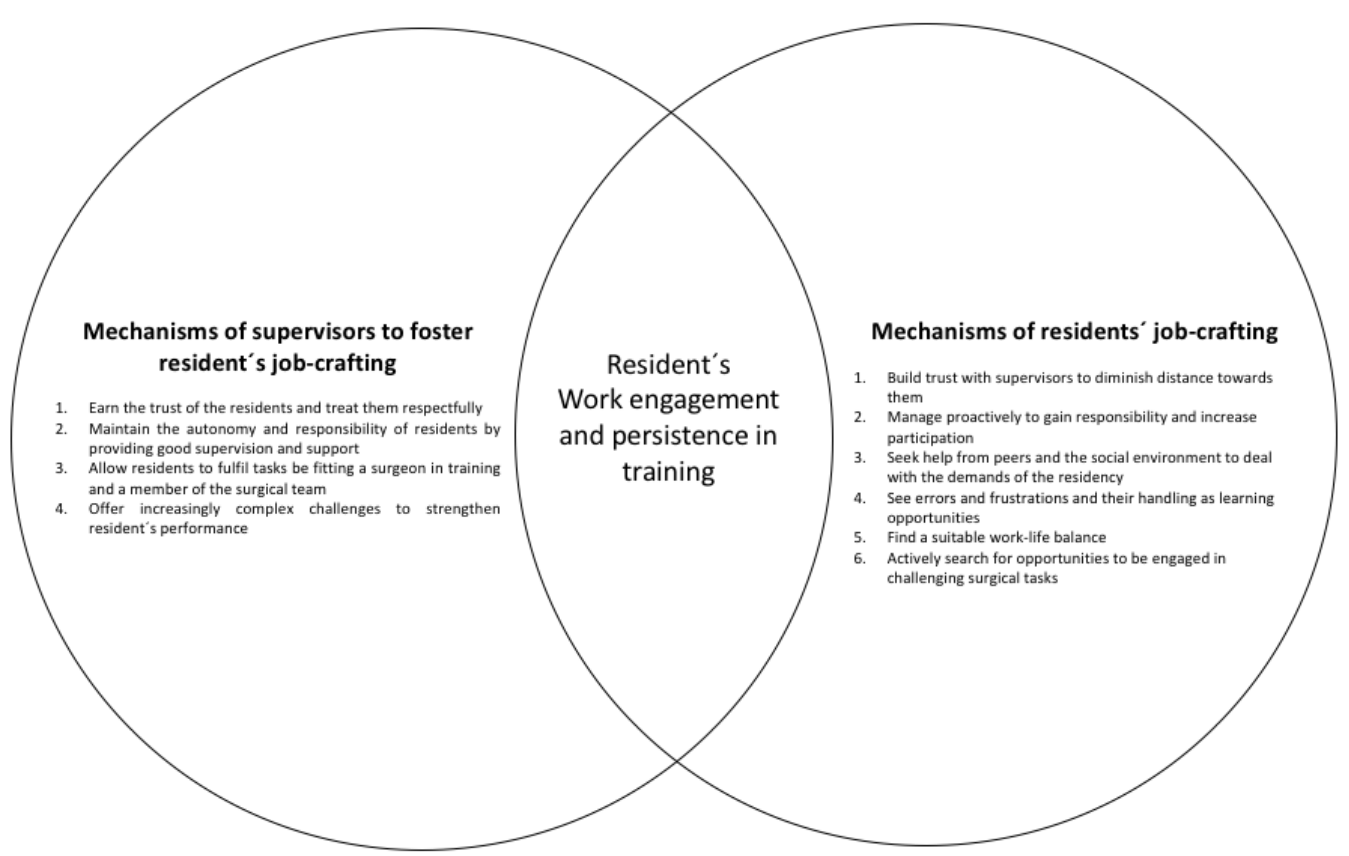

One year after completing the interviews (November 2018) none of the residents had left the training. All participants of Year-4 of training finished the program successfully. The remaining continue as active residents in their respective programs.

\section{MECHANISMS OF RESIDENTS' JOB-CRAFTING TO ENHANCE THEIR WORK ENGAGEMENT AND PERSISTENCE IN TRAINING}

Mechanism I: Build trust with supervisors to diminish distance towards them

Showing responsibility for the safety of patients, being honest and showing awareness of ones' limitations were essential to developing trust with supervisors. These aspects aimed to guarantee the legal obligations of the supervisors during patient care. 
"In surgery, you have to establish a relationship of trust with supervisors because they are lending their name and title to treat patients. They believe that one should strive to not make any errors and that one will not harm the patients" ( $2^{\text {nd }}$ year resident).

Responsibility was perceived by residents as gathering knowledge and commitment to following up with patients, as well as in their efforts to prevent complications and keep supervisors informed. Honesty, in particular, was observed as "not telling lies" and in the trustworthy delegation of tasks to other team members. A resident of third year of training, for instance, describes the scope of honesty on trust with supervisors.

"Supervisors are very emphatic that if you do not know something, you should say so ... They do not judge because you do not know; they judge because you tell lies" (3rd year resident).

When residents felt they could rely on their supervisors, they felt motivated and important, which diminished feelings of fear and distance towards them. As a result, they gained power and meaning at work and thus persisted in training.

"I have an important role, and they trust me a lot (supervisors). To the extent to which you interact and show who you are, they have confidence in you and give you power; otherwise, there is no way to endure this (residency training)" (I st year resident).

Mechanism 2: Manage proactively to gain responsibility and increase participation

Residents perceived the importance of being proactive in the decision-making process, demonstrating initiative and negotiating capabilities with their supervisors. Active participation was related to their ability to argue coherently based on medical knowledge and selection and organization of relevant clinical information.

"If one shows interest and proves to be prepared, more doors will be opened, and more possibilities will be presented [...], one must always be ahead of what one believes [...] as one develops throughout the residency, one knows which information is relevant and which is not" $\left(3^{\text {rd }}\right.$ year resident).

Initiative was perceived in the ability to coordinate patient care or to start actions in critical situations without immediate supervision. These abilities, together with those of assertive communication, were essential for negotiation. When residents were proactive, they perceived more trust from their supervisors. They also gained autonomy and responsibility and challenges at the workplace, which contributed to strengthening their motivation, meaning at work and will to persist. 
"Being proactive, I feel good, and they (supervisors) do not tell me what to do ... I also see that they have more confidence in what I say ... it is the empowerment that I give to myself. I've learned a lot from this. It makes me feel committed to patients and never leave a patient whom one is treating. It makes me feel that this is really what I want... It makes me more convinced of what I am doing"'(Ist year resident).

Mechanism 3: Seek help from peers and the social environment to deal with the demands of the residency

Residents recognized that surgical training may be strenuous and demanding and is difficult at times to face alone. Being aware of their place into the hierarchy and knowing their own limits were important issues for asking for help. Residents developed relationships with others within (e.g., peers, supervisors) or outside the workplace (e.g., family and friends) who had the potential to assist them when clinical load, complexity or pressure and stress surpassed their resilience.

"If you need help, you have to ask for it. Fortunately, among us, we are partners, and if there is any doubt, we try to take time to help each other. It is important to rely on other doctors such as emergency doctors and nurses because they are a good help.... that relieves the workload" ( $3^{\text {rd }}$ year resident)

Similarly, support of others allowed them to obtain feedback, develop a sense of meaning at work, get advice in facing difficult situations, reach career goals and persist.

"I have strong ties of friendship with my peers of the same level of training. We help each other, we collaborate, and we rescue each other. Sometimes residency is like a football game. There are heated moments and moments of friction because of the work stress, so having a good team is fundamental to survival" $\left(2^{\text {nd }}\right.$ year resident).

"I'm not just a doctor... I am a daughter, wife, sister, friend and I have to fulfil all those roles...my life is not just surgery. They help me continue this (residency program)" ( $4^{\text {th }}$ year resident).

Mechanism 4: See errors and frustrations and their handling as learning opportunities

Errors in patient care, within a strict culture of surgical training, were perceived as a foremost cause of loss of confidence from supervisors and source of frustration. Facing errors with honesty and emotional intelligence were felt to be important tools by residents to manage committed errors and to rebuild trust with their supervisors. A senior resident, for instance, described how emotional intelligence helped to overcome errors and difficulties in training. 
"When I make a mistake, the first thing I have to do is to ask to myself what was wrong, why I failed, and how I am going to improve. The second thing is to convince myself that everything that I do is not wrong. From ten things that I do, nine are good and one can go wrong. I have to assume that error. My strategy is to think about good things and self-assess bad situations. Later on, when I am in a similar situation, I will know how to act and prevent it from happening again. My supervisors realize that. This strategy allows me to have clarity about what I want (to be a surgeon)" (3rd year resident).

Support of others (also observed in mechanism 3) was critical for dealing with errors and frustrations and to recover motivation. It allowed one to overcome difficulties, to develop tenacity and persist in becoming surgeons.

"During my first year of residency, I had a supervisor who bullied me a lot due to my performance [...] He could not terrify me, and I decided to seek him out more [...] He noticed that I took greater charge of patient care and follow-up [...] and then he gave me the opportunity to do everything [...] I used many tools, one of which was to request the help of my senior resident and seek his advice in dealing with that situation [...] I reached the conclusion that my goal is to be a surgeon, and if they mistreat me, it does not matter; I am going to be a surgeon! That is my instrument, to become transcendental and to find the strength in reaching my objective [...] I often thought of leaving the program, many times, but when you strengthen yourself with these tools, you see the road clearly" ( $2^{\text {nd }}$ year resident).

\section{Mechanism 5: Find a suitable work-life balance}

Residents valued the adequate balance between work, personal and family life to be engaged and to persist in training. Healthy detachment from the workplace to take advantage of other facets of life and prevent "alienation" was important for recovering, "enduring" and enjoying training. This mechanism allowed the residents to reflect on difficult situations and improve their relationships with others. Similarly, meaning was found at work when the residents balanced training with other dimensions of their life.

"I am doing the residency to have better opportunities to develop myself as a person. For that reason, I wanted to be a surgeon. But that does not mean that I have to kill myself.There are other things in life that are also important. Now l'm on the countdown to finish my training" $\left(4^{\text {th }}\right.$ year resident). 
Mechanism 6:Actively search for opportunities to be engaged in challenging surgical tasks

Residents mentioned that searching for complex cases and challenging tasks was crucial to strengthen themselves as surgeons in training. Their proactivity and trust from their supervisors were crucial in these endeavours. Successfully accomplished and challenging tasks improved their motivation and performance, contributing to reaffirming their career goals. A resident in the third year of training, for instance, described the relationship between his proactivity, challenges and motivation during an emergency situation.

"A patient arrived with a precordial wound with cardiac tamponade [...] then he entered into cardiac arrest [...] in that situation, losing any second is detrimental to the patient's life. So, while the surgeon was scrubbing in, I said, "Doctor, I'm going to open". I did the sternotomy and the pericardiotomy, and I took out the blood clots and gave him direct cardiac massage.Then, the supervisor arrived, and he realized the gravity of the situation and what I did. For the first time, he congratulated me on my initiative [...] That day, all my efforts were rewarded, all that I did during night shifts, all the late nights, everything l've done.The patient is alive; he left ICU and was transferred to the surgical ward [...] A surgeon has to have that initiative... I open him, or he dies ... I'm more motivated than ever! "( $3^{\text {rd }}$ year resident).

\section{MECHANISMS OF SUPERVISORS TO FOSTER RESIDENT'S JOB-CRAFTING TO ENHANCE WORK ENGAGEMENT AND PERSISTENCE}

\section{Mechanism 7: Earn the trust of the residents and treat them respectfully}

For residents, trustworthy supervisors are essential for motivation. They were deemed as such if they were responsible educators who demonstrated respect for the resident, adopted the role of a guide and showed openness and transparency in the residents' assessment. When supervisors took on this role, the residents experienced "real teaching", an increased feeling of autonomy and eagerness to seek opportunities to further build trust with the supervisors and themselves.

"Doctor $X$ has encouraged me a lot to complete surgical procedures for my level (...). He always helps me, and he is my "surgical assistant”. So, he guides me and tells me that I am doing a good job (...) That helps a lot and feels good because that shows that they (supervisors) trust me and that they are expecting good things from me (...) I feel happy and stimulated" (3rd year resident).

Residents perceived respect when supervisors avoided derogatory judgements, mistreatment and discrimination. A junior resident, for instance, described the relationship between disrespect and the loss of trust in his supervisor. 
"When I had an encounter with the instructor and we talked, or I felt mistreated, then one loses the initiative and confidence. Many times, surgeons confuse exigency with respect. So, when they (supervisors) cross that line, one wants to be away from that person. One does not take the initiative, but one does unfortunately have the minimum requirement to comply" $\left(2^{\text {nd }}\right.$ year resident).

Finally, transparency and objectivity during assessments and avoiding retaliatory and punitive practices were perceived as trustworthy behaviours of supervisors. Residents, for instance, mentioned how retaliation was related to the lack of trust and, ultimately, with the intention to leave training.

"If I fail as a resident, I wish the supervisor would tell me, "Hey, you're failing in this aspect and I'm going to assess you in this way", but instead he puts more pressure on me, taking me to the maximum limit of stress. This situation, instead of helping me in my shortcomings as a future surgeon, brings me to a state of stress in which the only way out is deciding to leave training" ( $2^{\text {nd }}$ year resident).

Reliability of supervisors was important for residents' proactive desire for new challenges and seeking help. Ultimately, reliability creates an environment for motivation.

"If you are in an environment where you feel good, you find yourself enjoying the residency, but on the contrary, if the environment makes you feel uncomfortable and the supervisors do not trust you, then you will lose interest in doing things and end up doing them just because it is your obligation" ( $3^{\text {rd }}$ year resident).

\section{MECHANISM 8: MAINTAIN THE AUTONOMY AND RESPONSIBILITY OF THE RESIDENTS BY PROVIDING GOOD SUPERVISION AND SUPPORT}

Residents appreciated that the supervisors were available and receptive to support their needs at work (e.g., in cases of substantial clinical burden or complexity). Good supervisors are believed to avoid restrictions or excesses in residents' autonomy and, in this way, enhance responsibility during their participation in patient care and decision-making.

"One must be responsible... but should be supervised (...) Responsibility is a double-edged sword. If one has clear conceptual tools, that is extraordinary ... you become the owner of your patient, and that is very satisfactory: you cure his/her wounds, you see him/her every day, you are noting his/ her clinical evolution ... and you are taking the whole approach with the patient ... If you are responsible for a patient with a highly complex case and you do not have the conceptual tools, that becomes a scenario of anguish. Improper responsibility generates distress in a resident. That is one of the biggest problems... an anguish regime" ( $2^{\text {nd }}$ year resident). 
Furthermore, residents felt adequately supervised when they received permanent, respectful and constructive feedback, not only in cases of low performance but also when they did a good job.

"The best way to teach is to make positive reinforcements both about what is good and what is negative. The supervisor must avoid only negative or even contemptuous judgments because it causes the resident to lose confidence in him/herself" ( $2^{\text {nd }}$ year resident).

Autonomy and supervision helped to improve residents' motivation and performance. They especially found it important to seek new challenges and proactivity. They also foster trust in supervisors and better management of frustrations, contributing to strengthening their meaning at work and persistence.

"Having autonomy and letting go more in the surgical procedures makes one enjoy the work more and start to be calmer, less dependent on external things, more involved in the residency (...) It motivates me to keep doing things well, to improve more and to overcome difficulties (...) Finally, it is what one is going to do in the future, and if they (supervisors) are delegating and trusting, that motivates me ... one wants to receive more delegation and more trust.Then, it is a process of selfdemand to overcome all difficulties. At the end one wants to surpass oneself" (4 $4^{\text {th }}$ year resident).

\section{MECHANISM 9: ALLOW RESIDENTS TO FULFIL TASKS BE FITTING A SURGEON IN TRAINING AND A MEMBER OF THE SURGICAL TEAM}

For residents, the value that supervisors add to their role as surgeons in training was essential from the beginning of the program. Nonetheless, frequently during the first years of training, they perceived that supervisors valued their work more in terms of "secretaries" (e.g., dealing with paperwork) rather than residents. Feeling valued as a resident was perceived when their opinions were listened appreciatively, when they could participate actively in-patient care and introduce themselves to patients, families and other clinical departments as members of the surgical team.

"One begins to see that they (supervisors) are no longer treating me as the student but that they are also giving me the position of surgeon, even when I have not graduated ... one begins to take patient care personally. Instead of thinking “'m going to ask my supervisor”, one begins to make decisions and take charge of everything that is happening [...] one is gaining more confidence" $\left(2^{\text {nd }}\right.$ year resident).

Thus, when residents perceived themselves in the role of surgeons, they experienced meaning at work and motivation. Those outcomes further strengthen trust with supervisors, which, in turn, enhances engagement and the drive to persist. 
"Feeling important is when your opinion is taken into account [...] that you have value or significance for others [...] if you feel important, it makes staying in the residency much more comfortable in persisting and achieving what you want" ( $3^{\text {rd }}$ year resident).

"Doctor $X$ lets us focus on patients, do everything, schedule patients for surgery. He trusts us and lets us operate. One says, what a sensation! He is letting us "be surgeons" with the supervision of others. So, it's very rewarding ... it makes one feel that one is not just a "secretary" who came here to do the work for them (supervisors), but that he/she is my patient, I scheduled, operated, followed and discharged him/her.Then, it is a complete process. When they allow us to operate, it is a magical sensation! (...) When they let us be one... they let us reach the Promised Land" ( $2^{\text {nd }}$ year resident).

\section{MECHANISM I0: OFFER INCREASINGLY COMPLEX CHALLENGES TO STRENGTHEN THE RESIDENT'S PERFORMANCE}

Residents mentioned that challenges in the work environment (e.g., participating in complex surgeries and leading other residents) offered by their supervisors nourished the feeling of wanting additional challenges. Such challenging opportunities were important to help them overcome their fears and weaknesses, strengthen them and improve performance. A resident in the second year of training, for example, described her perceptions when she successfully completed her first total gastrectomy.

"He (supervisor) helped me lose my fear because in one way or another, one is always afraid ... during surgery, he told me "believe it!" It is a very nice satisfaction ... I feel that I will be ready for this [...] is something very rewarding for me and for him" ( $2^{\text {nd }}$ year resident).

These challenges were related to the trust and autonomy received from their supervisors as well as with their motivation. In their perception, supervisors offered more challenges when they perceived more proactivity and desire of the resident to seek challenges. Through these opportunities, residents also gained power in the environment, value and autonomy, contributing to strengthening their meaning at work, performance and intention to persist.

"What motivates me the most is that they (supervisors) allow me to increase my participation in complex surgeries because they recognize my potential and believe in my capabilities to perform more and more complex surgeries. During the last months, they have motivated me a lot (supervisors). I have to stay a lot of time in the hospital. If I have at arrive to the hospital at 3 am, it does not matter; all that I want is to operate" ( $3^{\text {rd }}$ year resident).

"I believe that one feels power ... That one has the ability, that if one is doing what one likes ... one feels a lot of power, and I feel able to finish (residency training)" ( $2^{\text {nd }}$ year resident). 


\section{Discussion}

Our study aimed to provide insights in the mechanisms that surgical residents use and value to optimize their demands and resources at the workplace to maintain their engagement and persist in training. These mechanisms illustrate residents' behaviours (building trust with supervisors, managing work proactively, seeking help from peers, seeing errors and frustrations as learning opportunities, finding a suitable work-life balance and seeking challenges) and the supervisors' contributions to the ability of residents to handle demands and resources (earning the trust of residents, providing guidance and support, allowing residents to perform the tasks befitting a surgeon in training and offering increasingly challenging tasks to residents).

Our type of research reveals other information in comparison with previous studies that have focused more on static programmatic and individual factors that promote attrition, but they reveal limitations in understanding persistence. The present findings show that persistence is an active process developed in the workplace, which depends on the proactive initiatives of residents. The findings are in line with previous studies, which demonstrate that proactivity is essential for the autonomy, responsibility and participation of trainees in complex tasks (5I-53) as well as to increase their supervision, adaptation and socialization (54). In these earlier studies, however, the concept of proactivity is conceptualized as individual attitudes and habits of mind related to reflexive self-assessments and feedback seeking behaviours in the trainees $(51,54)$. Our study, however, offers a different perspective of proactivity beyond personal or individual habits and is focused on the ability of residents to manage the demands and resources at the workplace to achieve a sense of ownership and control and fits with the training and the environment.

The first six mechanisms illustrate this type of proactive person-environment fit behaviour, in line with the concept of job-crafting. In particular, we observed permanent endeavours of residents to take advantage of structural and social resources in their daily work (e.g., by taking the initiative and autonomy, interacting with their supervisors and peers and nurturing trust with supervisors) to increase their participation and responsibility in patient care (mechanisms I-3) and to handle errors and frustrations (mechanism 4). Similarly, we observed proactive initiatives to increase challenging demands when engaging in complex tasks (mechanism 6) and to diminish hindrances, such as workload, pressure and conflict (mechanisms 3-4) to achieve a suitable work-life balance (mechanisms 5). These endeavours, however, would not be fruitful without the contribution of supervisors. Our study highlighted that supervisors should treat residents respectfully and offer good support to strengthen their competence and confidence for independent practice (mechanisms 7-8), offer opportunities for meaningful participation (mechanism 9), and exposure to complex cases and challenges (mechanism 10). These mechanisms exemplify the resources that supervisors can offer at the workplace to encourage the residents to craft their jobs. Preliminary evidence supports the leadership of supervisors in this realm when they maintain patient safety $(37,55)$, enable learning $(5 I, 56)$ and cultivate trust with trainees $(5 I, 57)$. In this line 
of reasoning, we believe that job crafting is crucial for the entrustment of professional activities at the workplace. From a theoretical stance, job-crafting can add new explanations to preliminary models describing how trust enables clinical participation and independent participation of residents in the patient care (5I). In particular, the factors influencing a supervisor's trust in a trainee are related to the supervisor, trainee, the supervisor-trainee relationship, task, and context. Our results contributed to understand the role of job-crafting on these factors in a complex environment for training. For instance, resident's behaviours towards proactivity by increasing structural resources (e.g. seeking for autonomy and responsibility), social resources (e.g. seeking for supervision, feedback and collaboration at the workplace), challenging demands (e.g. seeking for complex challenges) and diminishing hindrances at work, explain the contributions of trainees to the entrustment of professional activities. Similarly, supervisors' behaviours play a major role to strive the progressive entrustment of a wide range of complex tasks in surgical training, which ultimately also increases resident's job-crafting.

Additionally, in our perspective, residents' job-crafting contributed to work engagement and persistence for several reasons. First, job-crafting can contribute to strengthening residents' motivation in the context of training. This observation is in line with the idea that work engagement is cultivated by interactions in the social context through the individual abilities to anticipate, change and take control (58). Second, job-crafting could strengthen the perception of residents about their own work as something meaningful. In our findings, for instance, we observed that residents' job-crafting was crucial to feeling valuable, responsible, and active on the surgical team. Previous research supports these findings $(43,59)$, as well as the role of supervisors to encourage employees to move towards higher purposes and meaning (60). Finally, resident's job-crafting is perceived to contribute to improving residents' performance and competence, especially when residents experience more autonomy and opportunities of participation in complex tasks. The preliminary research supports that resident's work engagement is related to their autonomy and competence $(61,62)$.

To our knowledge, no other studies have shed light on the mechanisms developed by surgical residents to control the work environment in terms of engagement and persistence. The present study adds new insights from a positive stance and a qualitative perspective in that residents who are more proactive, able to build and maintain trust with their supervisors, or who see errors and frustrations as learning opportunities are more likely to stay in the program because they will experience greater work engagement. These findings open the door for new explanations of persistence or, on the other hand, attrition. Finally, considering that the JD-R model falls short of explanatory mechanisms to explain work engagement $(42,43)$, we added first-hand information about these relationships from the surgical context. The study also entails limitations. We explored residents' perspectives of themselves and their supervisors but not those of supervisors. Similarly, our results are based on self-perceptions only because we did not observe residents' behaviours at the workplace. Finally, we did not explore the influence of organizational and 
institutional issues on resident's job-crafting and work engagement. For instance, the level of specialized care, the type and amount of pressure for quality standards and the culture and values at the organizational level might influence residents' job-crafting.

The study offers implications for practice. Our insights offer tools for residents and supervisors to actively intervene in the process of residents' persistence in training. This study highlights the mechanisms that residents recognize to control the environment and succeed in training. This information can contribute to residents' self-assessments and reflection on their proactivity and performance. In practice, job-crafting is more than an individual phenomenon (63), thus modelling job crafting behaviours in the residents can influence the job-crafting of other residents and indirectly the work-engagement at the collective level. This form of dissemination of job-crafting behaviours can transform positively the work-environment for training. Similarly, our observations reveal different dimensions of the residents' development and support to rethink coaching and mentoring strategies by faculty at the clinical workplace. In particular, our findings recognized the role of supervisors on the resident's ability to gain control at the workplace (resources and demands) to achieve ownership and reach the intention to invest time and effort in their job. These findings have implications to support entrustment decisions at the workplace.

From the limitations, the present study also offers opportunities for further research and interventions to improve the surgical work-environment for training. We call for studies focused on the perceptions of supervisors related with their ability to strengthen resident's job-crafting and work engagement (e.g., through empowerment, transformational and servant styles of leadership) and those aimed to observe residents' job-crafting at the workplace (e.g., ethnographic studies). Similarly, job-crafting interventions can be developed and implemented to diminish burnout and increase work engagement $(64,65)$. Particularly, job-crafting interventions aimed to increase the resources at work (e.g., autonomy, supervision, feedback) has proved to be more effective than those to diminish demands or react to the stressors at the workplace (e.g., active coping) (64). Further research is needed on the effectiveness of these interventions in surgical training. Supervisors also deserve attention. For instance, interventions focused on developing the leadership abilities of supervisors (65) as well as on improving their clinical role to provide effective resources at the workplace (e.g., social support, feedback performance) (66) is an area of interest with regards to residents' work engagement.

In conclusion, our study provides new insights into the mechanisms that surgical residents use to effectively control the work environment for training, in line with the concept of job-crafting, to maintain their engagement and persist in training. It also focuses on the resources provided by supervisors and how residents take advantage of them. Finally, this study offers a new perspective from a positive stance to understand residents' attrition and persistence and to conduct future interventions focused on work engagement. 


\section{References}

I. Rovai AP. In search of higher persistence rates in distance education online programs. Internet High Educ [Internet]. 2003 Jan [cited 2018 May 28];6(I):I-16. Available from: http://linkinghub.elsevier. com/retrieve/pii/S1096751602001586

2. Park CL, Boman J, Care WD, Edwards M, Perry B. Persistence and Attrition: What is Being Measured? J Coll Student Retent Res Theory Pract [Internet]. 2008 Aug 12 [cited 2018 May 28];10(2):223-33. Available from: http://journals.sagepub.com/doi/I0.2190/CS.10.2.g

3. Khoushhal Z, Hussain MA, Greco E, Mamdani M, Verma S, Rotstein O, et al. Prevalence and causes of attrition among surgical residents a systematic review and meta-analysis. In: JAMA Surgery [Internet]. 2017 [cited 2018 May 25]. p. 265-72. Available from: http://archsurg.jamanetwork.com/ article.aspx?doi=10.1001/jamasurg.2016.4086

4. Hoyler M, Finlayson SRG, McClain CD, Meara JG, Hagander L. Shortage of doctors, shortage of data: A review of the global surgery, obstetrics, and anesthesia workforce literature [Internet]. Vol. 38, World Journal of Surgery. 2014 [cited 2018 May 25]. p. 269-80. Available from: http://link. springer.com/10.1007/s00268-013-2324-y

5. Moris D, Karachaliou G-S, Pawlik TM, Nwomeh B. Attrition in general surgery residency: can global and rural surgery shift the paradigm? J Surg Res [Internet]. 2018 Apr [cited 2018 May 28];224:166-8. Available from: http://www.ncbi.nlm.nih.gov/pubmed/29506835

6. Bongiovanni T, Yeo H, Sosa JA, Yoo PS, Long T, Rosenthal M, et al. Attrition from surgical residency training: Perspectives from those who left. Am J Surg [Internet]. 2015 Oct [cited 2018 May 25];2I0(4):648-54. Available from: http://linkinghub.elsevier.com/retrieve/pii/S000296I015003657

7. Wasserman MA. A strategy to reduce general surgery resident attrition a resident's perspective [Internet]. Vol. I5I, JAMA Surgery. 2016 [cited 2018 May 25]. p. 215-6. Available from: http:// archsurg.jamanetwork.com/article.aspx?doi=10.1001/jamasurg.2015.4607

8. Sullivan MC, Yeo H, Roman SA, Ciarleglio MM, Cong X, Bell RH, et al. Surgical residency and attrition: Defining the individual and programmatic factors predictive of trainee losses. J Am Coll Surg [Internet]. 2013 Mar [cited 2018 May 25];216(3):46I-7I. Available from: http://linkinghub. elsevier.com/retrieve/pii/SI0727515I2013403

9. Yeo HL, Abelson JS, Symer MM, Mao J, Michelassi F, Bell R, et al. Association of Time to Attrition in Surgical Residency With Individual Resident and Programmatic Factors. JAMA Surg [Internet]. 2018 Feb 2 I [cited 2018 May 25]; Available from: http://archsurg.jamanetwork.com/article. aspx?doi=10.100I/jamasurg.2017.6202

10. Shaw C, Sarosi GA. Reducing Surgical Resident Attrition. JAMA Surg [Internet]. 2018 Apr 18 [cited 2018 May 25]; Available from: http://archsurg.jamanetwork.com/article.aspx?doi=10.100I/ jamasurg.2018.0619

II. Gifford E, Galante J, Kaji AH, Nguyen V, Nelson MT, Sidwell RA, et al. Factors associated with general surgery residents' desire to leave residency programs: A multi-institutional study. JAMA Surg [Internet]. 2014 Sep I [cited 2018 May 25];149(9):948-53. Available from: http://archsurg. jamanetwork.com/article.aspx?doi=10.1001/jamasurg.2014.935

12. Yeo H, Bucholz E, Ann Sosa J, Curry L, Lewis FR, Jones AT, et al. A national study of attrition in general surgery training: Which residents leave and where do they go? Ann Surg [Internet]. 2010 Sep [cited 2018 May 25];252(3):529-34. Available from: https://insights.ovid.com/crossref ?an $=00153307-201001280-00014$

13. Shweikeh F, Schwed AC, Hsu CH, Nfonsam VN. Status of Resident Attrition From Surgical Residency in the Past, Present, and Future Outlook. J Surg Educ [Internet]. 2018 Mar [cited 2018 May 25];75(2):254-62. Available from: http://linkinghub.elsevier.com/retrieve/pii/SI93I7204I7300983 
14. Rangel EL, Smink DS, Castillo-Angeles M, Kwakye G, Changala M, Haider AH, et al. Pregnancy and Motherhood During Surgical Training. JAMA Surg [Internet]. 20I8 Mar 21 [cited 2018 May 25]; Available from: http://archsurg.jamanetwork.com/article.aspx?doi=10.1001/jamasurg.2018.0153

15. Freischlag JA, Silva MM. Preventing general surgery residency attrition - It is all about the mentoring [Internet]. Vol. I52, JAMA Surgery. 2017 [cited 2018 May 25]. p. 272-3. Available from: http:// archsurg.jamanetwork.com/article.aspx?doi=10.100I/jamasurg.2016.4096

16. Yaghoubian A, Galante J, Kaji A, Reeves M, Melcher M, Salim A, et al. General surgery resident remediation and attrition: A multi-institutional study. Arch Surg [Internet]. 2012 Sep I [cited 2018 May 25];147(9):829-33. Available from: http://archsurg.jamanetwork.com/article.aspx?doi=10.100I/ archsurg.2012.1676

17. Schwed AC, Lee SL, Salcedo ES, Reeves ME, Inaba K, Sidwell RA, et al. Association of general surgery resident remediation and program director attitudes with resident attrition. JAMA Surg [Internet]. 2017 Dec I [cited 20I8 May 25];152(I2):II34-40. Available from: http://archsurg. jamanetwork.com/article.aspx?doi=10.100I/jamasurg.2017.2656

18. Yeo HL, Abelson JS, Mao J, Lewis F, Michelassi F, Bell R, et al. Who Makes It to the End?: A Novel Predictive Model for Identifying Surgical Residents at Risk for Attrition. Ann Surg [Internet]. 2017 Sep [cited 2018 May 25];266(3):499-507. Available from: http://insights.ovid.com/crossref ?an $=00000658-201709000-00013$

19. Carter J V., Polk HC, Galbraith NJ, McMasters KM, Cheadle WG, Poole M, et al. Women in surgery: A longer term follow-up. American Journal of Surgery [Internet]. 2017 Jun [cited 2018 May 25]; Available from: http://linkinghub.elsevier.com/retrieve/pii/S0002961017307II0

20. Brown EG, Galante JM, Keller BA, Braxton J, Farmer DL. Pregnancy-Related Attrition in General Surgery. JAMA Surg [Internet]. 20I4 Sep I [cited 20I8 May 28];149(9):893. Available from: http:// www.ncbi.nlm.nih.gov/pubmed/2502950I

21. Salles A, Lin D, Liebert C, Esquivel M, Lau JN, Greco RS, et al. Grit as a predictor of risk of attrition in surgical residency. Am J Surg [Internet]. 2017 Feb [cited 2018 May 25];213(2):288-91. Available from: http://linkinghub.elsevier.com/retrieve/pii/S0002961016309278

22. Symer MM, Abelson JS, Yeo HL, Sosa JA, Rosenthal MZ. The Surgical Personality: Does Surgery Resident Motivation Predict Attrition? J Am Coll Surg [Internet]. 2018 May [cited 2018 May 25];226(5):777-83. Available from: http://linkinghub.elsevier.com/retrieve/pii/SI07275I5I830I6I3

23. Quillin RC, Pritts TA, Hanseman DJ, Edwards MJ, Davis BR. How Residents Learn Predicts Success in Surgical Residency. J Surg Educ [Internet]. 2013 Nov [cited 2018 May 25];70(6):725-30. Available from: http://linkinghub.elsevier.com/retrieve/pii/SI9317204I3002365

24. Abelson JS, Sosa JA, Symer MM, Mao J, Michelassi F, Bell R, et al. Association of Expectations of Training With Attrition in General Surgery Residents. JAMA Surg [Internet]. 2018 Apr 18 [cited 2018 May 25];10065:I-6. Available from: http://archsurg.jamanetwork.com/article. aspx?doi=10.1001/jamasurg.2018.0611

25. Kelz RR, Mullen JL, Kaiser LR, Pray LA, Shea GP, Drebin JA, et al. Prevention of surgical resident attrition by a novel selection strategy. Ann Surg [Internet]. 2010 Sep [cited 2018 May 25];252(3):5374I. Available from: https://insights.ovid.com/crossref?an=00153307-201001280-00015

26. Gardner AK, Grantcharov T, Dunkin BJ. The Science of Selection: Using Best Practices From Industry to Improve Success in Surgery Training. J Surg Educ [Internet]. 2018 Mar [cited 2018 May 25];75(2):278-85. Available from: http://linkinghub.elsevier.com/retrieve/pii/SI93I720417303525

27. Hughes BD, Perone JA, Cummins CB, Sommerhalder C, Tyler DS, Bowen-Jallow KA, et al. Personality testing may identify applicants who will become successful in general surgery residency. J Surg Res [Internet]. 2019 Jan I [cited 2018 Sep 19];233:240-8. Available from: https://linkinghub. elsevier.com/retrieve/pii/S0022480418305675 
28. Stephenson-Famy A, Houmard BS, Oberoi S, Manyak A, Chiang S, Kim S. Use of the Interview in Resident Candidate Selection: A Review of the Literature. J Grad Med Educ [Internet]. 2015 Dec [cited 2018 May 25];7(4):539-48. Available from: http://www.jgme.org/doi/l0.4300/JGME-D-I4-00236.I

29. Dominguez LC, Stassen L, de GraveW, Sanabria A,Alfonso E, Dolmans D.Taking control: Is job crafting related to the intention to leave surgical training? Koniaris LG, editor. PLoS One [Internet]. 20I8 Jun I [cited 20 I8 Jun 2];|3(6):e0 I97276.Available from:http://www.ncbi.nlm.nih.gov/pubmed/29856750

30. Salles A, Lin DT, Liebert CA, Esquivel M, Mueller C. Belonging, Well-being, and Attrition in General Surgery. J Am Coll Surg [Internet]. 2016 Oct I [cited 20I8 May 25];223(4):e40-I. Available from: http://linkinghub.elsevier.com/retrieve/pii/SI072751516308493

3I. Bell RM, Fann SA, Morrison JE, Lisk JR. Determining personal talents and behavioral styles of applicants to surgical training: A new look at an old problem, Part II. J Surg Educ [Internet]. 2012 Nov [cited 2018 May 25];69(I):23-9. Available from: http://linkinghub.elsevier.com/retrieve/pii/SI93I7204II00I67X

32. Yoo PS, Tackett JJ, Maxfield MW, Fisher R, Huot SJ, Longo WE. Personal and Professional WellBeing of Surgical Residents in New England. J Am Coll Surg [Internet]. 2017 Jun [cited 2018 May 25];224(6):I0I5-9. Available from: http://linkinghub.elsevier.com/retrieve/pii/SI07275I5I6317288

33. Lee N, Appelbaum N, Amendola M, Dodson K, Kaplan B. Improving resident well-being and clinical learning environment through academic initiatives. J Surg Res [Internet]. 2017 Jul I [cited 2018 Sep 19];2I5:6-II. Available from: http://www.ncbi.nlm.nih.gov/pubmed/28688662

34. Adams S, Ginther DN, Neuls E, Hayes P. Attitudes and factors contributing to attrition in Canadian surgical specialty residency programs. Can J Surg [Internet]. 2017 Aug I [cited 2018 May 25];60(4):247-52. Available from: http://canjsurg.ca/vol60-issue4/60-4-247/

35. Ginther DN, Dattani S, Miller S, Hayes P. Thoughts of Quitting General Surgery Residency: Factors in Canada. J Surg Educ [Internet]. 2016 May [cited 2018 May 25];73(3):513-7. Available from: http:// linkinghub.elsevier.com/retrieve/pii/SI93I7204I5002895

36. Elmore LC, Jeffe DB, Jin L, Awad MM, Turnbull IR. National Survey of Burnout among US General Surgery Residents. In: Journal of the American College of Surgeons [Internet]. 2016 [cited 2018 May 25]. p. 440-5I. Available from: http://linkinghub.elsevier.com/retrieve/pii/SI07275I5I630I855

37. Teman NR, Gauger PG, Mullan PB, Tarpley JL, Minter RM. Entrustment of general surgery residents in the operating room: Factors contributing to provision of resident autonomy. J Am Coll Surg [Internet]. 2014 Oct [cited 2018 May 25];219(4):778-87. Available from: http://linkinghub.elsevier. com/retrieve/pii/SI07275I5I4004426

38. Forel D, Vandepeer M, Duncan J, Tivey DR, Tobin SA. Leaving surgical training: Some of the reasons are in surgery. ANZ Journal of Surgery [Internet]. 20I8 May [cited 2018 May 25];402-7. Available from: http://doi.wiley.com/10.1III/ans.14393

39. Wild JRL, Ferguson HJM, McDermott FD, Hornby ST, Gokani VJ. Undermining and bullying in surgical training: A review and recommendations by the Association of Surgeons in Training. International Journal of Surgery [Internet]. 2015 Nov [cited 2018 May 25];23:S5-9. Available from: http://linkinghub.elsevier.com/retrieve/pii/SI743919II50I2042

40. Ling M, Young CJ, Shepherd HL, Mak C, Saw RPM. Workplace Bullying in Surgery. World J Surg [Internet]. 2016 Nov 13 [cited 2018 May 25];40(II):2560-6. Available from: http://link.springer. com/l0.1007/s00268-016-3642-7

4I. Bakker AB, Demerouti E, Sanz-Vergel Al. Burnout and Work Engagement: The JD-R Approach. Annu Rev Organ Psychol Organ Behav [Internet]. 2014 [cited 2018 May 25];I(I):389-4II. Available from: https://www.isonderhouden.nl/doc/pdf/arnoldbakker/articles/articles_arnold_bakker_348.pdf

42. Wang H, Demerouti E, Bakker AB. A review of job crafting research: The role of leader behaviors in cultivating successful job crafters. In: Sharon K. Parker UKB, editor. Proactivity at Work: Making Things Happen in Organizations. Ist editio. New York: Routledge.; 2016. p. 77-I04. 
43. Bakker AB, Demerouti E. Job demands-resources theory: Taking stock and looking forward. J Occup Health Psychol [Internet]. 2017 [cited 2018 May 26];22(3):273-85. Available from: https:// www.isonderhouden.nl/doc/pdf/arnoldbakker/articles/articles_arnold_bakker_444.pdf

44. Hennink MM, Hutter I, Bailey A. Qualitative research methods. SAGE; 201 I. 304 p.

45. Watling CJ, Lingard L. Grounded theory in medical education research: AMEE Guide No. 70. Med Teach [Internet]. 2012 Oct 22 [cited 20I8 Dec I8];34(I0):850-6I. Available from: http://www.ncbi. nlm.nih.gov/pubmed/22913519

46. Ramani S, Könings KD, Mann K, van der Vleuten CPM. A Guide to Reflexivity for Qualitative Researchers in Education. Acad Med [Internet]. 2018 Aug [cited 2018 Dec II];93(8):1257. Available from: http://www.ncbi.nlm.nih.gov/pubmed/29697429

47. Tracy SJ. Qualitative quality: Eight a"big-tent" criteria for excellent qualitative research. Qual Inq. 2010;16(10):837-51.

48. Creswell JW. Qualitative Inquiry \& Research Design: Choosing among five approaches. Vol. II, Australasian Emergency Nursing Journal. 2007. 100 p.

49. Santos HPO, Black AM, Sandelowski M. Timing of Translation in Cross-Language Qualitative Research. Qual Health Res [Internet]. 2014 Sep 4;25(I):I34-44. Available from: https://doi. org/I0.II77//0497323/4549603

50. van Nes F, Abma T, Jonsson H, Deeg $D$. Language differences in qualitative research: is meaning lost in translation? Eur J Ageing [Internet]. 2010 Dec [cited 2018 Dec 13];7(4):313-6. Available from: http://www.ncbi.nlm.nih.gov/pubmed/21212820

5I. Hauer KE, ten Cate O, Boscardin C, Irby DM, lobst W, O'Sullivan PS. Understanding trust as an essential element of trainee supervision and learning in the workplace [Internet]. Vol. 19, Advances in Health Sciences Education. 2014 [cited 2018 May 26]. p. 435-56. Available from: http://link. springer.com/10.1007/s10459-013-9474-4

52. Cate O Ten, Chen HC, Hoff RG, Peters H, Bok H, Van Der Schaaf M. Curriculum development for the workplace using Entrustable Professional Activities (EPAs): AMEE Guide No. 99. Med Teach [Internet]. 2015 Nov 2 [cited 2018 May 26];37(II):983-1002. Available from: http://www.tandfonline. $\mathrm{com} / \mathrm{doi} / \mathrm{full} / \mathrm{I0.3109/0142159X.2015.1060308}$

53. Cate O Ten, Hart D, Ankel F, Busari J, Englander R, Glasgow N, et al. Entrustment Decision Making in Clinical Training. Acad Med [Internet]. 2016 Feb [cited 2018 May 26];91(2):I9I-8. Available from: http://www.ncbi.nlm.nih.gov/pubmed/26630606

54. Crommelinck M, Anseel F. Understanding and encouraging feedback-seeking behaviour: A literature review [Internet]. Vol. 47, Medical Education. 2013 [cited 2018 May 26]. p. 232-4I. Available from: http://doi.wiley.com/I0.1III/medu.12075

55. Sandhu G, Magas CP, Robinson AB, Scally CP, Minter RM. Progressive Entrustment to Achieve Resident Autonomy in the Operating Room: A National Qualitative Study With General Surgery Faculty and Residents. Ann Surg [Internet]. 2017 Jun [cited 2018 Jun 19];265(6):II34-40. Available from: http://insights.ovid.com/crossref?an=00000658-201706000-00017

56. Duijn CCMA, Welink LS, Bok HGJ, Ten Cate OTJ. When to trust our learners? Clinical teachers' perceptions of decision variables in the entrustment process. Perspect Med Educ [Internet]. 2018 Jun 30 [cited 2018 Jun 19];7(3):192-9. Available from: http://link.springer.com/I0.1007/s40037-018-0430-0

57. Sheu L, Kogan JR, Hauer KE. How Supervisor Experience Influences Trust, Supervision, and Trainee Learning. Acad Med [Internet]. 2017 Sep [cited 2018 Jul 10];92(9):1320-7. Available from: http:// www.ncbi.nlm.nih.gov/pubmed/28079727

58. Cook DA, Artino AR. Motivation to learn: an overview of contemporary theories. Med Educ [Internet]. 2016 Oct [cited 2018 May 26];50(10):997-1014. Available from: http://www.ncbi.nlm.nih. gov/pubmed/276287/8 
59. Berg JM, Dutton JE, Wrzesniewski A. Job crafting and meaningful work. In: Dik BJ, Byrne ZS, Steger MF, editors. Purpose and meaning in the workplace [Internet]. I edition. USA: American Psychological Association; 2013 [cited 2018 May 26]. p. 8I-104. Available from: http://www.apa.org/ pubs/books/4318117.aspx?tab=2

60. Rosso BD, Dekas KH, Wrzesniewski A. On the meaning of work: $A$ theoretical integration and review. Res Organ Behav [Internet]. 2010 Jan I [cited 2018 May 26];30(C):91-127. Available from: https://www.sciencedirect.com/science/article/pii/S0191308510000067

61. Scheepers RA. Physicians' professional performance: an occupational health psychology perspective. Perspect Med Educ [Internet]. 2017 Dec 24 [cited 2018 May 26];6(6):425-8. Available from: http://link.springer.com/10.1007/s40037-017-0382-9

62. Scheepers RA, Arah OA, Heineman MJ, Lombarts KMJMH. In the eyes of residents good supervisors need to be more than engaged physicians: The relevance of teacher work engagement in residency training. Adv Heal Sci Educ [Internet]. 2014 May I5 [cited 2018 May 26];20(2):44I-55. Available from: http://link.springer.com/10.1007/s10459-014-9538-0

63. B. Bakker A, Rodriguez-Muñoz A, Sanz Vergel A. Modelling job crafting behaviours: Implications for work engagement. Human Relations. 2015.

64. Demerouti E. Strategies used by individuals to prevent burnout. Eur J Clin Invest [Internet]. 2015 Oct [cited 2018 Jun 19];45(10):I106-12. Available from: http://www.ncbi.nlm.nih.gov/ pubmed/26153110

65. Bakker A. Strategic and proactive approaches to work engagement. Vol. 46, Organizational Dynamics. 2017.

66. van den Berg JW, Mastenbroek NJJM, Scheepers RA, Jaarsma ADC. Work engagement in health professions education. Med Teach [Internet]. 2017 Nov 2 [cited 20I8 Jul 4];39(II):III0-8. Available from: http://www.ncbi.nlm.nih.gov/pubmed/28830279 


\section{Appendix A. Interview guide}

\section{REFLECTION DURING THE INTERVIEW PROCESS}

The main questions are embedded in the STARR model for interviewing (Situation, Task, Activity, Result, Reflection). STARR is a funnelling technique to achieve more concrete and specific experiences of participants. In each question, the interviewer should explore the five aspects of STARR to stimulate reflection in the interviewee.

Breaking the ice question: "Would you describe the supervision structure of your residency program?"

\section{Main Questions}

I. Tell me about one situation/example of your supervisors stimulating and strengthening you in your ability to control your work (to be trained successfully/optimally). How did it influence you?

2. Tell me about one situation/example in which your supervisors missed the opportunity to stimulate and strengthen you in your ability to control your work (to be trained successfully/ optimally). How did it influence you?

3. Tell me about one situation/example that you initiated as a resident to control your own work (to be trained successfully/optimally).

- Do you believe that situation/example influenced the attempts of your supervisors to stimulate and strengthen you? How did it influence your supervisors?

4. Tell me about one situation/example in which you felt you did not take the lead to control your own work (to be trained successfully/optimally). How did it affect you?

- Do you believe that that situation/example influenced the attempts of your supervisors to stimulate and strengthen you? How did it affect your supervisors?

5. Do you believe that the described situations/examples of your supervisors to stimulate and strengthen you in your ability to control your work (to be trained successfully/optimally) enhanced or hindered your dedication, enjoyment and passion for your job as a resident? How did these situations affect you?

6. In relation to the previous question (6), do these situations/examples enhance or hinder your intent to persist and complete surgical training? Why? 
CHAPTER 4

\section{Transformational leadership encourages residents' job crafting in surgical training: A mixed-methods study of residents' perceptions.}




\begin{abstract}
Background: Supervisors' leadership style can enhance resident performance, especially in terms of their ability to deal with the demands in the workplace and to take advantage of the available resources. Dealing with job demands and resources is known as job crafting, which has implications for the persistence of residents in training. The link between supervisors' leadership style and residents' job crafting, however, is not well understood.
\end{abstract}

Methods: This mixed-methods study sought to explore the relationships between a transformational (team-oriented), transactional (task-oriented), and laissez-faire (passive) supervisory style and residents' job crafting and to explain these relationships. Residents filled out the Multifactor Leadership Questionnaire to rate their supervisors' leadership style and the Dutch job-crafting scale to assess their own job crafting. We tested the relationships using linear mixed effects regression analysis. To explain the ensuing results, we subsequently conducted a thematic analysis of semi-structured interviews with residents.

Results: One hundred and sixteen residents from 7 surgical programs participated. A transformational leadership style had a positive effect on residents' job crafting $(b=0.19 ; 95 \% \mathrm{Cl} 0.08$ $0.32 ; p=0.009$ ), whereas the transactional and laissez-faire styles did not. This could be explained by the fact that residents felt their transformational supervisors had a positive influence on the atmosphere for training and on the job resources available to them, and considered them positive role models for how to handle the demands of the environment.

Conclusion: In residents' view, a transformational style is positively related to the ability to craft their jobs and therefore has implications for their persistence in training. Future research should explore supervisors' perspective on this relation and the effectiveness of leadership training for supervisors with a focus on resident outcomes, such as job crafting and persistence in training. 


\section{Background}

The problem of residents dropping out of surgical training has received increasing attention because of its negative effects on the individual and on health systems. Residents' poor well-being in the workplace remains the main reason for the high dropout rate (I-4). Not only supervisors and program coordinators, but also residents are responsible for improving resident well-being: Supervisors play an important role in offering residents support to optimize their learning in the workplace. Residents, in their turn, must undertake action to optimize and gain control of the workplace for training $(5,6)$. Such actions are in keeping with the concept of job crafting $(7)$. Successful job crafting may help explain why more than $80 \%$ of residents complete surgical training in different countries $(4,6,8,9)$.

Originating from the field of proactivity at work, job crafting explains how individuals are able to transform their job actively, instead of simply reacting passively to the working conditions to which they are exposed (I0). According to job demands-resources (JD-R) theory, job crafting is exercised when a worker increases two groups of job resources: structural resources (those that foster autonomy) and social resources (those that improve relatedness, e.g., peer collaboration). Workers also craft their jobs by diminishing hindering job demands (e.g., conflicts) and by increasing challenging demands (those that stimulate personal growth and achievement, e.g., problem solving skills) (II). When workers craft their jobs, they can become more engaged, which is a positive well-being state as opposed to burnout. Work engagement, ultimately, is related to increased job crafting (I2).

A preliminary study found that when residents' work engagement was high, their job crafting was negatively correlated with their intention to leave surgical training (5). A subsequent study offered insight into how residents craft their jobs to persist in training. They do so through the following six mechanisms: I) building trust with supervisors, 2) being proactive in the workplace to gain responsibility, 3) seeking help from peers to deal with the demands of training, 4) seeing errors and frustrations as learning opportunities, 5) finding a suitable work-life balance, and 6) searching for challenging surgical tasks (13). In the said study, residents acknowledged that supervisors' leadership played an important role in the six mechanisms. Nonetheless, how supervisors' leadership drives residents' job crafting still represents a knowledge gap. There is a need for studies that explore how leaders can influence job crafting in different work contexts $(14,15)$. Such studies might help us better understand what actions leaders (i.e., supervisors) could take to support residents in the workplace.

Leaders make use of different styles to lead and motivate people. In the literature we find three leadership styles that prevail in organizations (14). The first is a transformational leadership style (TLS), which is team-oriented and aimed to raise awareness about collective interests in others (e.g., vision of the organization, high standards) (14). Those who have a TLS elicit awareness and 
knowledge of their own job in others and serve as role models (14-16); they are committed to the organizational culture and justice at work, diminish bullying and burnout, and foster work engagement (14, I5, I7-20). Conversely, a transactional leadership style (TrLS) is task-oriented and aims to fulfill objectives, ensure standards and monitor outcomes (14). Those who have a TrLS offer rewards or punishments to others according to their performance during tasks. They are likely to discourage and decrease empowerment, job satisfaction, and work engagement (2I-24). Finally, a laissez-faire leadership style (LfLS) is passive and aims to meet the expectations of the organization. Those who have a LfLS are rarely present and they diminish job satisfaction, productivity, and job effectiveness $(14,25)$.

In this study, we hypothesized that a TLS in supervisors would be positively associated with residents' job crafting in surgical training. We also hypothesized that a TrLS and an LfLS would be negatively associated with residents' job crafting, due to the aforementioned characteristics. The study addressed the following research question: To what extent are supervisors' leadership styles associated with residents' job crafting in surgical training and why, from residents' perspective?

\section{Methods}

We employed a sequential, explanatory mixed-methods research design (26). More specifically, we first measured supervisors' leadership style and residents' job crafting using questionnaires. Then, we conducted interviews with residents to gain a deeper understanding of why these styles were perceived to affect their proactive behaviors. Such a research approach responds to the need to integrate multiple sources of data that together, by drawing on the strengths of quantitative and qualitative methods, can help explain the complex relationship between leadership and job crafting (27-29). The Commission for Medical Education of the Universidad de la Sabana granted ethical approval.

\section{QUANTITATIVE PHASE}

\section{Setting and participants}

This study was conducted in Colombia where residents hold full-time positions in healthcare institutions during four years of surgical training. Annual tuition for training in private programs is close to 12,000 USD, which includes 66 hours of duty per week. Three out of 20 residencies in surgery are accredited as high-quality programs in accordance with national standards; two more are in the process of attaining that accreditation. Considering the number of affiliated institutions, each program hosts more than 30 surgical supervisors. Residents' burnout rate is $33 \%$ and almost II.9\% of residents have serious intentions to leave training (5). 
We invited all the residents of seven surgical programs (a total of 136 residents) to participate voluntarily in the quantitative phase between October and December, 2018. We chose the five programs that were either accredited or in the process of obtaining high-quality accreditation. We included two others that had the longest standing tradition in the country. We emphasized confidentiality and anonymity of data.

\section{Measures}

Supervisors' leadership styles (independent variables)

The variables we measured were three: TLS, TrLS and LfLS. We obtained permission to administer the Multifactor Leadership Questionnaire (MLQ-5X) to residents to evaluate these styles in their supervisors (I5). We asked residents to rate their supervisors in general, hence not their individual supervisors, direct supervisor, or the program director. We chose this approach because, first, residents interacted with multiple supervisors on a daily basis; second, the high number of supervisors per program limited the feasibility of each resident rating them all; and finally, program directors were not fully involved in clinical supervision. Residents were instructed to rate 'the standard surgeon who supervises residents (in the workplace) in the program that you are enrolled in...' on a 5 -point scale ( $\mathrm{I}=$ not at all; $5=$ frequently, if not always). This instruction followed the principle of standard reference by which decision-makers - residents in this case - assign intermediate values to their expectations, ranging from best to worst (30).

\section{Residents' job crafting (dependent variables)}

We measured five variables that corresponded to each job-crafting domain: (I) increasing structural resources; (2) increasing social resources; (3) decreasing hindering demands; (4) increasing challenging demands; and (5) global job crafting. Residents rated their job crafting on the published version of the Dutch job-crafting scale (DJCS) on a 5-point scale (I=never; $5=$ very often). Each of the four subscales had a Cronbach's $\alpha$ of $>0.70$ (7).

\section{Statistical analysis}

We first calculated the descriptive statistics for all variables. For each program, we clustered the individual answers on the MLQ-5X and DJCS to represent the overall scores for each leadership style and job crafting. In these analyses, we calculated means, standard deviations (SD), and $95 \%$ confidence intervals $(\mathrm{Cl})$ for the independent and dependent variables per program. We conducted one-way univariate analyses of variance (ANOVAs) to identify 
significant differences in scores between programs. We adjusted p-values of ANOVAs (Bonferroni correction) considering the number of tests. We computed Cronbach's $\alpha$ for questionnaires.

We used R (R Core Team, 2019) and Ime4 (3I) to perform a linear mixed effects analysis of the relationship between job crafting and leadership styles. As fixed effects, we entered the leadership styles into the model (without interaction term). As a random effect, we had intercepts for the program. We therefore applied the following mixed-effect model to the data in which JC represented global job crafting (or each one of the four job-crafting variables):

$$
\mathrm{JC} \sim \mathrm{TLS}+\mathrm{TrLS}+\mathrm{LfLS}+(\text { I|program })
$$

Visual inspection of residual plots did not reveal any serious deviations from homoscedasticity or normality. P-values were obtained by likelihood ratio tests of the full model with the effect in question against the model without the effect. For each fixed effect we reported the b estimate, the $95 \% \mathrm{Cl}$, and the chi-square $(\mathrm{df}=\mathrm{I}) \mathrm{P}$-value (significance level of $<0.05)$. In general, b estimates around $0.10,0.25$, and 0.40 can be interpreted as small, medium, and large effects (32). For the random effect we reported the variance, standard deviation (SD), the $95 \% \mathrm{Cl}$, and a simulationbased $\mathrm{p}$-value (significance level of $<0.05$ ). We also calculated the interclass correlation for the random effect $(I C C=$ variance $($ program $) /($ variance $($ program $)+$ variance $($ residuals $)))$. Finally, we assessed the model's goodness of fit with the R2m (marginal R-squared) and the R2c (conditional R-squared) indices (33).

\section{QUALITATIVE PHASE}

The qualitative phase took place between January and April, 2019. First, we developed an interview guide to explore the quantitative results (Appendix I). Then, LCD and AS recruited 20 residents using stratified sampling based on demographics (e.g., program and year of training). All interviews were conducted by phone. All participants gave verbal informed consent to be involved in the interviews after we had explained the mechanisms to ensure anonymity, confidentiality, and management of information. LCD conducted the individual, in-depth interviews in Spanish, using a non-technical language to guide the participants in each leadership style and formulate key questions. Upon completion, all interviews were immediately audiotaped and transcribed verbatim. Then, LCD and AS performed a thematic analysis of all transcriptions. With this method, we sought to identify themes within our dataset (34) and reach thematic saturation, that is, the stage in which no new categories appeared, previous data did not require any more modifications, and no additional data were needed (35). After 10 interviews, LCD and AS had identified the main themes, but felt more information was needed to explain some aspects of these themes in depth. We therefore conducted 14 interviews in total, after which LCD and 
AS felt thematic sufficiency was reached. All authors subsequently discussed these themes iteratively to reach consensus.

In this analysis, we acknowledged, through reflexivity, that we as researchers add meaning to the findings. The researchers have different backgrounds, experiences, and perspectives on leadership and residency training, which may have influenced data collection and analysis. LCD, AS, and LS are surgeons, supervisors, and directors of surgical programs. DD and WdG have extensive experience as educational researchers in workplace-based learning in residency training. Ultimately, our interpretation of the findings was influenced by the concepts of JD-R theory (II). Our different perspectives combined with the said theoretical concepts may benefit the strength of the study and the transferability of its findings. Finally, in all stages of the qualitative phase, we followed recommendations for the translation of information, in our case from Spanish into English language (36).

\section{Results}

\section{QUANTITATIVE RESULTS}

We included 116 residents from seven programs ( $92.6 \%$ response rate). Table I presents the characteristics of the participants. The mean scores of the MLQ-5X were: TLS $=3.39 \pm 0.72$; $\operatorname{TrLS}=2.93 \pm 0.46$; and $\mathrm{LfLS}=2.07 \pm 0.75$ ( $\mathrm{I}-5$ range). The mean scores of the DJCS were: global job crafting $=3.50 \pm 0.4 \mathrm{I}$; job crafting to increase I) structural resources $=4.35 \pm 0.52$; 2 ) social resources $=3.75 \pm 0.66$; and 3 ) challenging demands $=3.50 \pm 0.6 \mathrm{I}$ ( $\mathrm{I}-5$ range); and job crafting to diminish hindering demands $=2.59 \pm 0.73$. Table 2 shows the results of the ANOVAs for the main variables between programs. After Bonferroni correction $(p<0.006)$, we identified significant differences in the scores for global job crafting to increase social resources and to increase challenging demands. Similarly, we identified significant differences in the scores for a TLS and a TrLS. The Cronbach's $\alpha$ of the MLQ-5X was 0.94 . Cronbach's alphas for the subscales of the DJCS ranged from 0.63 to 0.78 .

Table 3 presents the linear mixed effects analysis of the relationship between supervisors' leadership styles and global job crafting. A TLS had a positive effect on global job crafting $(b=0.19$; $95 \% \mathrm{Cl}$ 0.08-0.32; $=0.009)$. In general, the difference between programs regarding the effect of leadership style on job crafting was relatively small (ICC ranged between 0.002 and 0.16 ). We found no significant relationships between a TrLS and LfLS and global job crafting.

Table 4 shows the linear mixed effects analysis of the relationship between the leadership styles and each job-crafting domain. In general, a TLS was positively related to all job-crafting domains. In 
three domains (increasing structural and social resources and diminishing hindering demands), the effect was significant $(p<0.05)$. We found no significant effect between a TrLS and any job-crafting domain. An LfLS had only a significant effect on job crafting to decrease hindering demands $(p=0.000 I)$.

The marginal $\mathrm{R} 2 \mathrm{~m}$ was relatively low in all models, suggesting that factors other than supervisors' leadership styles may have influenced residents' job crafting. The conditional R2c was larger in all models, indicating that the effect of the program, albeit small, was important (Tables 3 and 4).

\section{QUALITATIVE RESULTS: EXPLORING THE ASSOCIATIONS BETWEEN SUPERVISORS' LEADERSHIP STYLE AND RESIDENTS' JOB CRAFTING}

Six participants were female (42.8\%). The distribution of participants by year of training was as follows: Year I $(n=4)$, year $2(n=3)$, year $3(n=3)$, and year $4(n=4)$. Three predominant themes emerged from the interviews. Table 5 gives an overview of representative quotations.

Theme I: Supervisors' leadership style influences the atmosphere for training in positive or negative ways

Residents mentioned that supervisors who had a TLS could promote a positive atmosphere for training and showed high standards of patient care. The personal strengths they attributed to such supervisors were altruism, integrity, resilience, and trustworthiness. Residents valued this atmosphere because it made them feel free to discuss their fears and expectations of training, strengthening both their performance (e.g., decision-making and problem-solving skills) and readiness for practice. In residents' view, these supervisors stimulated them to stay in the program and pursue their training.

Conversely, residents characterized supervisors who had a TrLS as people who actively searched for errors, and were punitive and authoritative, which did not encourage them to take the lead in their own training on the job. In most cases, these supervisors created a hostile atmosphere for training where residents experienced fear and mistreatment, leading to defensive behaviors to hide errors and avoid punishment, and to more intentions to leave training.

Finally, residents mentioned that supervisors who had an LfLS showed a lack of commitment to patient care and residents' education and were perceived to help create a negative atmosphere in the workplace. Moreover, they contributed to more demands for the resident (i.e., more workload), resulting in unsafe care for patients. At the same time, however, the rare presence of these supervisors in the workplace encouraged residents to take more care of patients and to deal with workload and pressure. 
Theme 2: Supervisors' leadership style influences the availability of job resources

Residents mentioned that supervisors who had a TLS offered the resident more job resources and challenges in the workplace (e.g., in the form of support, teaching, and feedback). Supervisors who had a TrLS and LfLS, by contrast, provided fewer of these resources and challenges, while creating more hindering demands (e.g., workload and pressure). For instance, supervisors who had a TrLS gave poor feedback and instruction and frequently punished residents by limiting opportunities to participate in surgical care and to take on new challenges (such as the opportunity to operate complex patients). In residents' views, these negative aspects of training led to psychological distress, a lack of autonomy, and more intentions to leave training.

Theme 3: Supervisors' leadership style serves as role model for how to handle the demands in the workplace

According to residents, supervisors with a TLS were positive role models. More specifically, these supervisors were capable of handling the work environment and finding solutions to difficult situations effectively, for instance when surgical complications or conflicts arose at work. Supervisors with a TrLS or an LfLS, on the other hand, were perceived as negative role models, because they created more demands for the resident (in the form of conflicts, ambiguity), while wielding ineffective strategies to solve difficult situations.

\section{Discussion}

The results from our survey demonstrated that supervisors' leadership styles and residents' job crafting differed significantly across the programs under scrutiny. Globally, however, we found the transformational leadership style to have a significant effect on residents' job crafting in both fixed and random effect analyses (with the interaction of programs). Residents valued supervisors with such a style for their positive influence on the training atmosphere and on the availability of job resources, and because they served as positive role models. Conversely, neither the transactional nor the laissez-faire style was found to have a significant effect on residents' job crafting. During the interviews, however, residents argued that these supervisors had a negative influence on the training atmosphere, the availability of job resources, and on role modeling.

We must view these results in relation to the existing research. Our findings echo those of previous research pointing to the positive influence of supervisors with a TLS on the atmosphere in the workplace $(20,37,38)$. In our study, a safe atmosphere - understood as a non-punitive and open environment for training - helped create favorable conditions for residents (e.g., trust in the supervisor, less power distance and less fear to discuss expectations), inducing them to search for more opportunities to participate in decision-making, to solve complex problems, and to 
cope with adversity. In other words, a positive atmosphere is one of the centerpieces of residents' job crafting. Our results, moreover, suggest that such a positive atmosphere may depend on supervisors' ability to create a deep connection with residents, which supervisors with a TLS do. These findings tie in nicely with previous studies on the importance of supervisors' behaviors to a positive learning climate and residents' well-being (39-4I).

To our knowledge, this study is the first to explore the impact of a TLS in surgical education, as most studies have hitherto focused on its effects on clinical outcomes (patient safety and team performance) $(42,43)$. Moreover, our study emphasizes the importance of a TLS to a crucial aspect of residents' education, that is, residents' job crafting, considering the complexity of the surgical work environment for training. Our results also suggest that supervisors must not only offer residents structural resources (e.g., autonomy and responsibility), social resources (e.g., feedback and coaching), and more challenging demands (e.g., participation in complex cases), they must also encourage them to seek these, so that residents can craft their jobs efficiently and improve their performance. These results are in keeping with studies into the effect of a TLS on empowerment and autonomy in healthcare contexts $(22,44)$. We found that supervisors who embrace a TLS can help residents to gain control at work, by demonstrating effective ways to handle hindering demands and stressors (e.g., conflicts, frustrations of training). Few studies have considered judging surgeons who serve as role models by abilities other than their "surgical skills" and "mastery of technique." The ability to deal with conflicting demands and to cope with adversity are examples of what residents expect to learn from their supervisors beyond the traditional dexterity competences (45-47). Our findings indicate that supervisors should be aware of their modeling function with respect to these non-technical competences.

Our qualitative findings, on the other hand, suggested that supervisors with a TrLS have a negative influence on the atmosphere for training. Fear and power distance were important factors that explained such a hostile atmosphere. These factors, in turn, serve to illustrate how the supervisors who embrace this leadership style are disconnected from residents in the workplace: Ultimately, these supervisors negatively affect the availability of job resources and increase hindering demands (i.e., workload). Other studies have reported similar findings with respect to an authoritative leadership style in the supervisors $(20,24,37,38,48)$. Nonetheless, contrary to what we expected, we identified a positive association between an LfLS and residents' job crafting to diminish hindering demands. Hypothetically, this could be explained by the fact that residents were forced to take control of patient care and deal with clinical workload in face of poor supervision from the surgeons in charge. These observations deserve further investigation.

We acknowledge that the study has both strengths and limitations. A strength is that it adds information to the available evidence (conducted in non-healthcare settings from non-educational perspectives) supporting the positive relationship between transformational leadership and job crafting $(28,49,50)$. Moreover, adding a qualitative stage provided more depth and was useful 
since few studies have focused on the qualitative dimensions of a TLS $(23,5 \mathrm{I})$. A first limitation is that the data we collected only represented residents' perspective and, consequently, the study lacks a supervisor perspective. Secondly, we did not study the role of moderators in the relationship between supervisors' leadership and job crafting. Possible moderators are the organizational culture at the level of departments and institutions, as well as residents' attributes (e.g., self-efficacy and grit).

This study has implications for practice and research. It is essential that supervisors become transformational leaders, as it will help residents to become skilled job crafters. As suggested by our results, a TLS in the surgical context typifies supervisors who reveal well-developed personal strengths (e.g., integrity and trustworthiness) and commitment to high standards of patient care. They contribute to a positive atmosphere for training in which they offer residents support aimed to strengthen their performance, motivation, and readiness for practice. Finally, they serve as role models for residents, by demonstrating effective behaviors for handling the demands of the work environment. We believe that organizations committed to strengthening a healthy workforce should implement formal training not only in this type of leadership for supervisors, but also in bottom-up strategies for residents to teach them how to optimize job demands and resources (e.g., job-crafting training as part of residency training) $(12,20)$. Moreover, investing in transformational leadership development for supervisors could help strengthen residents' job fit in surgical training and reduce burnout and dropout, as has been identified in other work contexts $(38,52)$. Considering the limitations, we call for studies into the organizational influences (e.g., culture and power) on the relationship between supervisors' leadership and residents' job crafting. Moreover, supervisors' perspectives on this topic deserve investigation. Similarly, we invite future studies to explore the effect of transformational leadership training and development for supervisors on residents' job crafting.

\section{Conclusion}

In conclusion, a TLS of supervisors in surgery is related to the extent to which residents are able to optimize the job demands and resources for training in order to gain control of the work environment. This relationship is rooted in the positive influence of that leadership style on the environment for training, on role modeling, and on resources for the resident. 
Table I. Descriptive characteristics of programs and participants

I. Information on participants

Number of participants (global)

116

Age (mean, standard deviation, range)

Age: $28.59 \pm 2.48(22-36)$

Male (number and percentage)

$69(59.48 \%)$

Age (mean, standard deviation, range)

Female (number and percentage)

Age: $28.8 \mathrm{I} \pm 2.77(22-36)$

47 (40.52\%)

Age (mean, standard deviation, range)

Age: $28.27 \pm 2(24-34)$

Number and percentage of residents per year of training

Year I

$34(29.31 \%)$

Year 2

$24(20.69 \%)$

Year 3

$32(27.59 \%)$

Year 4

$26(22.41 \%)$

\section{Information on programs}

Number of programs

Average number of residents per training program evaluating

their supervisors' leadership styles (range)

$16.6(10-21)$ 


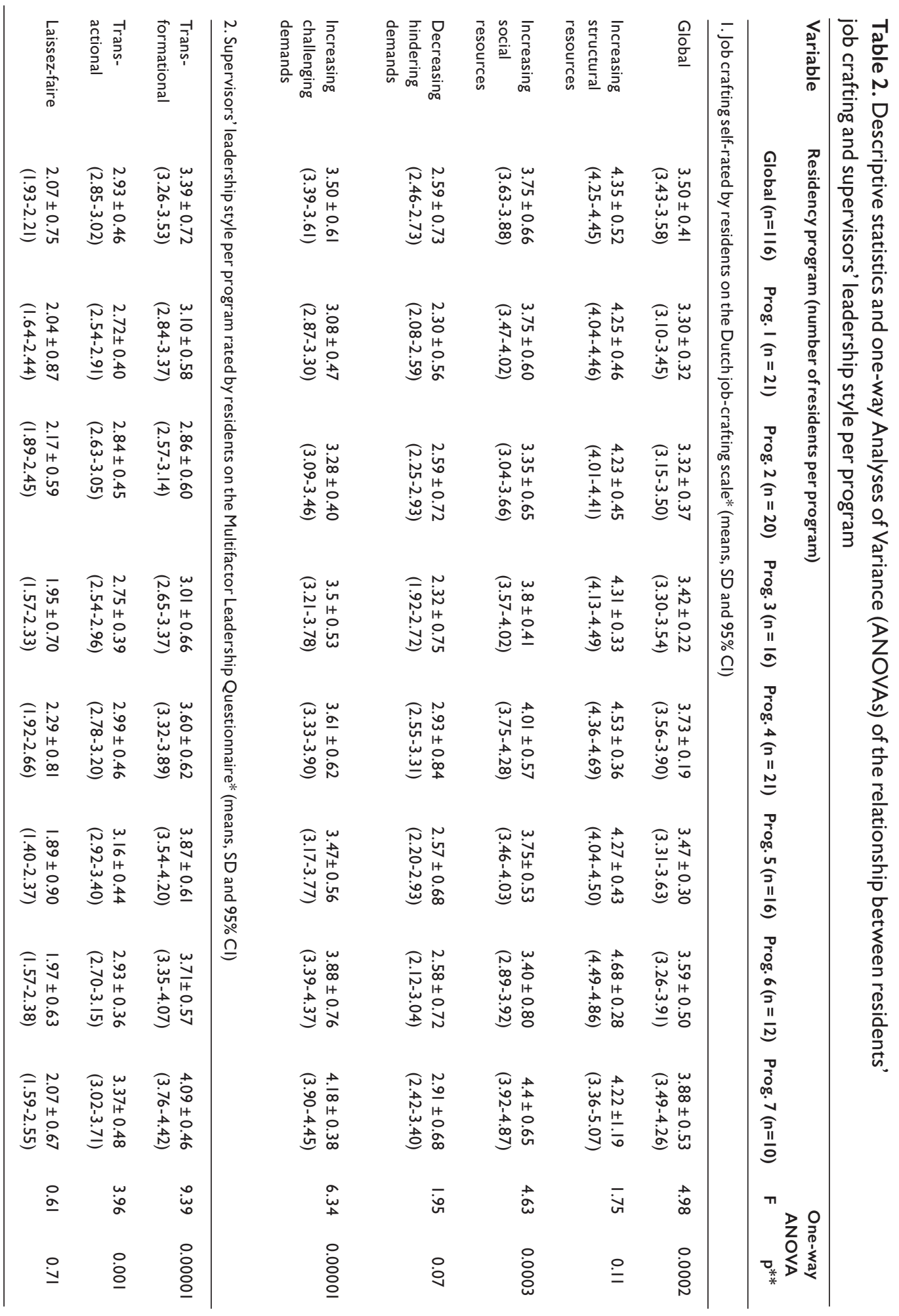




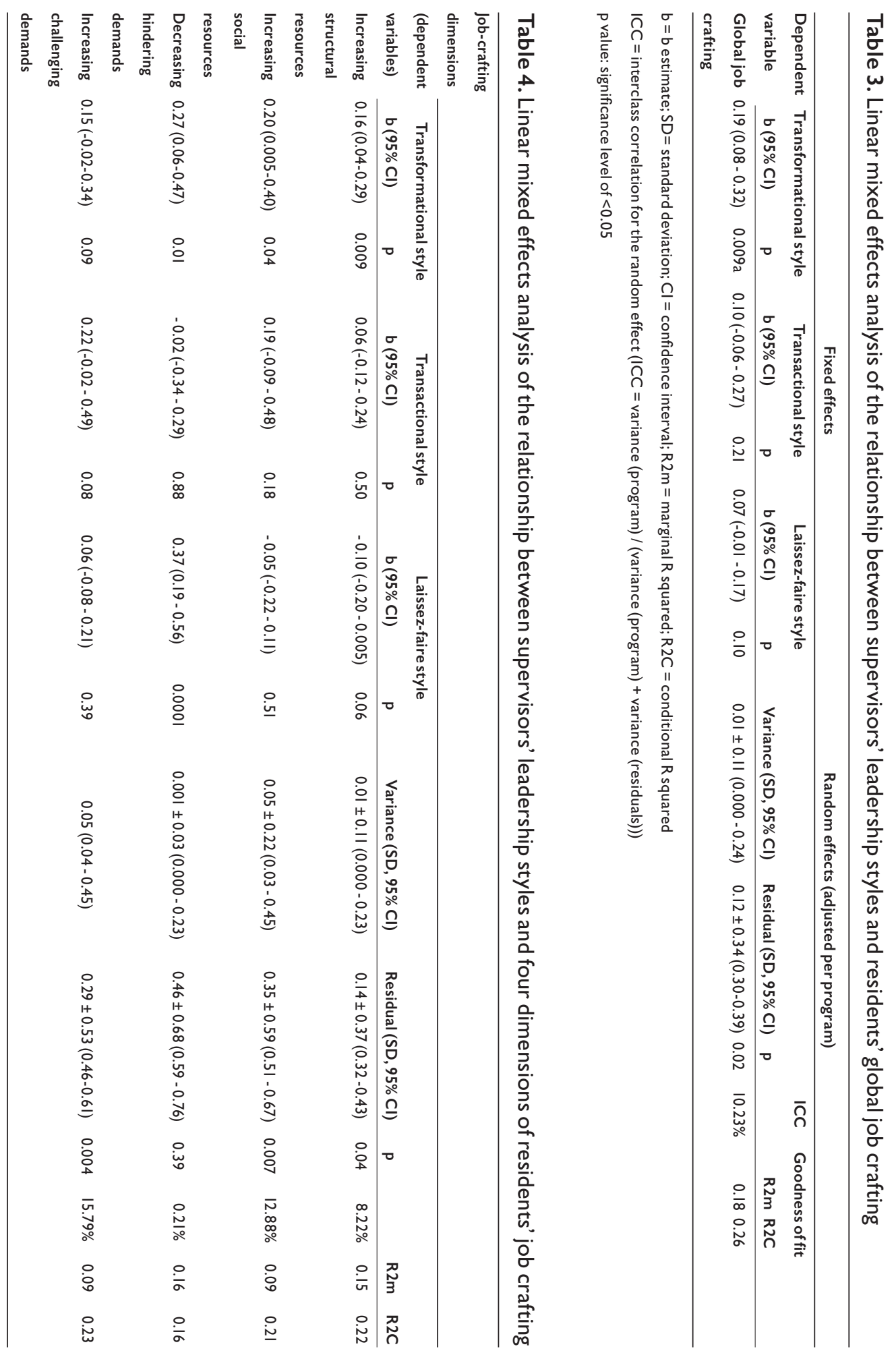




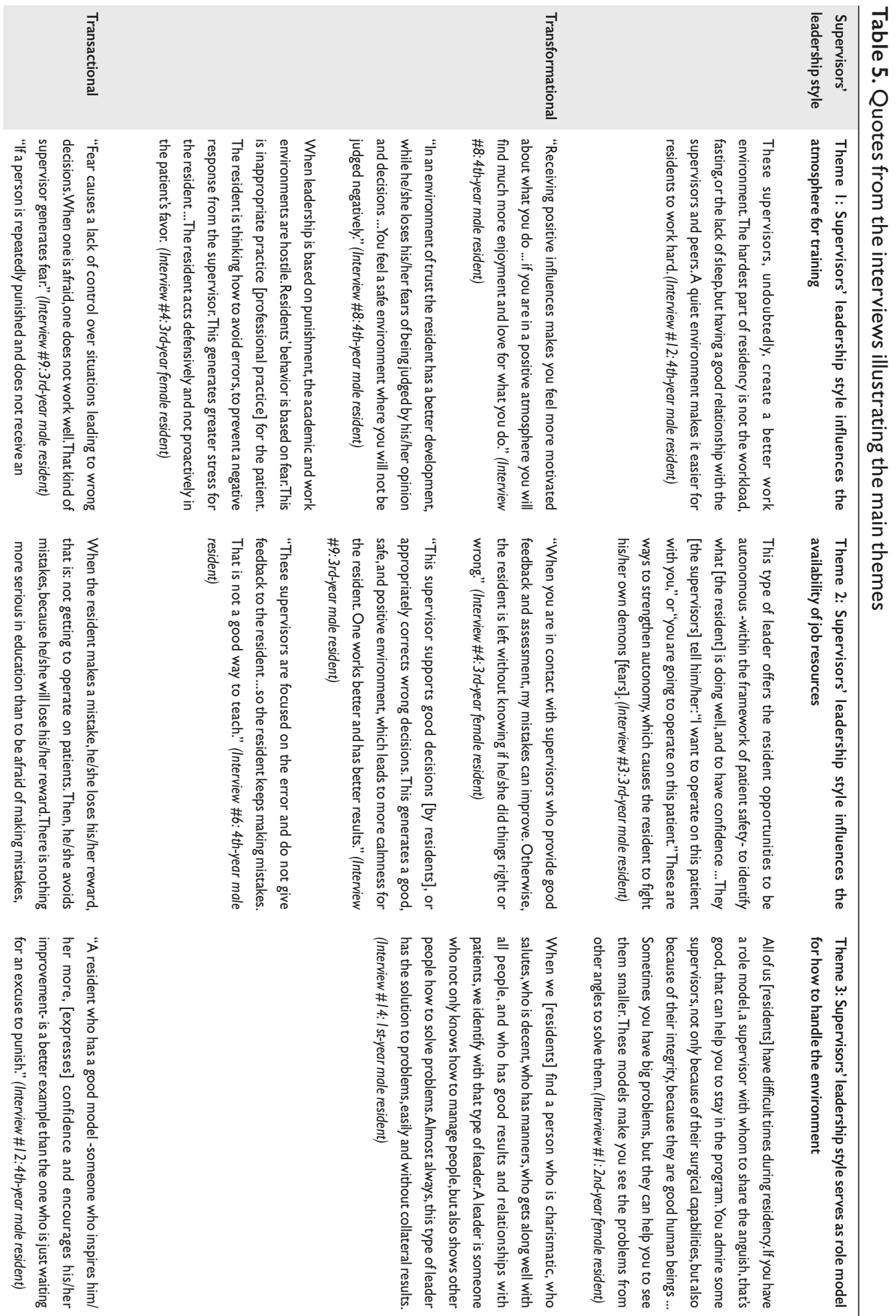




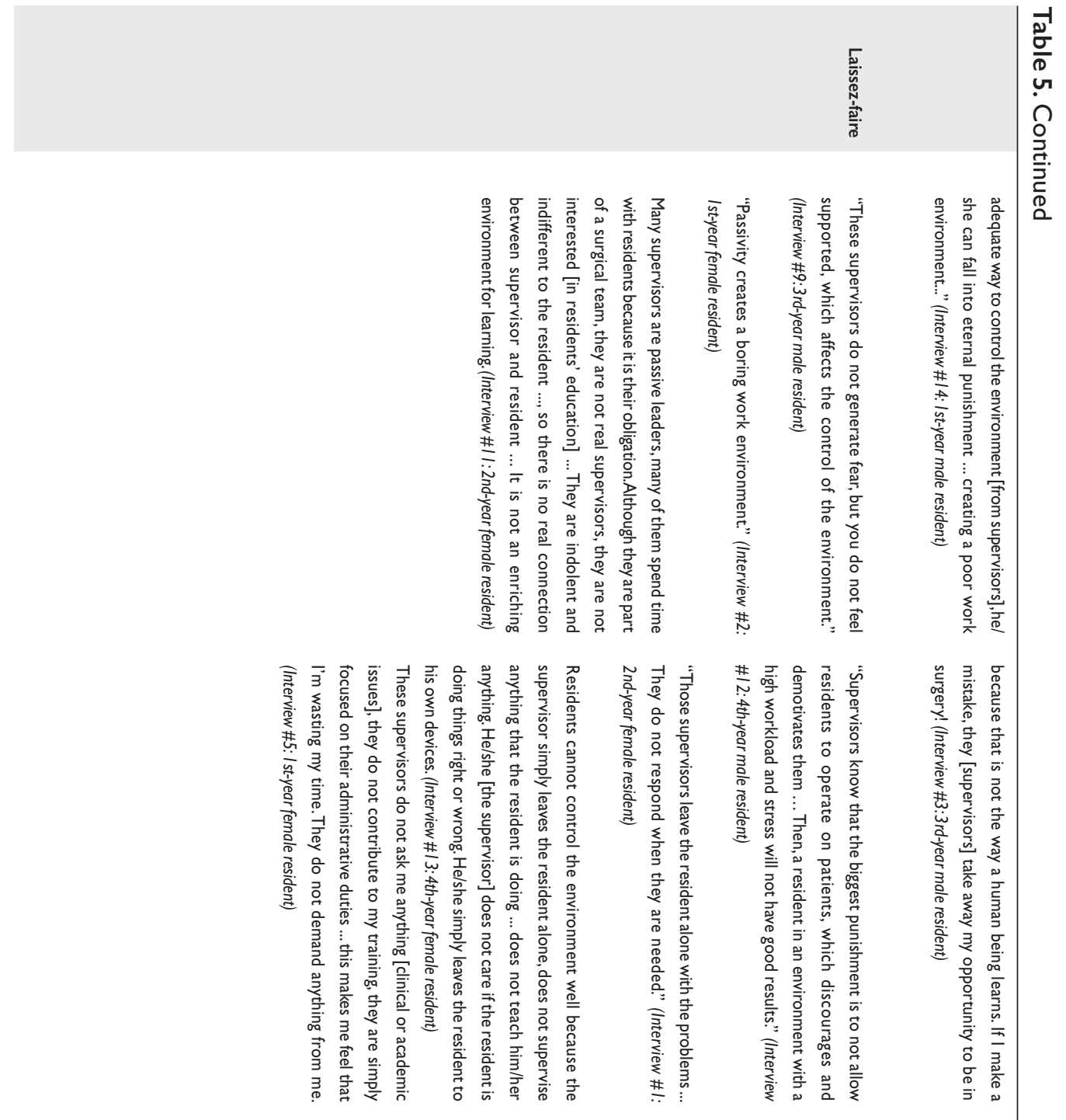

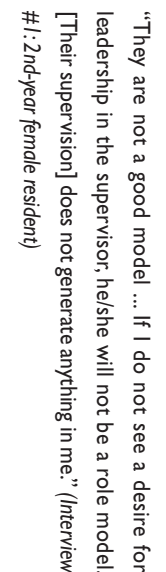

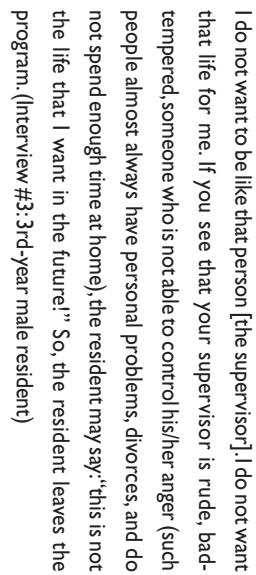

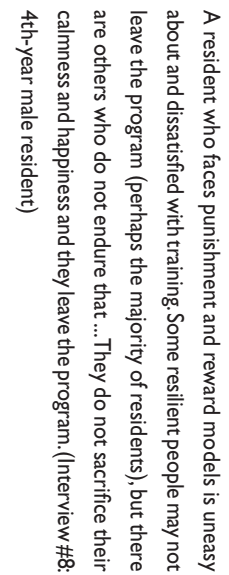

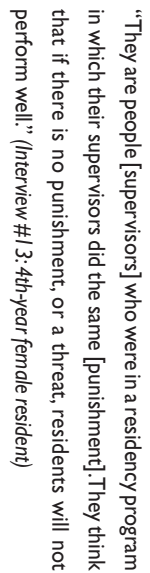




\section{Appendix I. Interview guide for residents}

We surveyed surgical residents from seven programs in Colombia to assess the relationship between supervisors' leadership style and the ability of residents to control, optimize, and effectively manage their work environment for training. A first finding suggested that an inspirational and stimulating leadership style considerate of residents' needs was positively associated with residents' ability to control, optimize, and effectively manage their work environment.

I. Why do you think that this specific type of leadership style by supervisors positively influences residents' abilities to control their own work environment? Please give examples.

In the same survey we identified a second finding: A leadership style by supervisors oriented to exchanging rewards and punishments with the resident, based on the fulfillment of obligations, objectives, outcomes, and standards at work, was not related to residents' ability to control, optimize and effectively manage their work environment for training.

2. Why do you think that this leadership style is not related to residents' ability to control their own work environment? Please give examples.

Then, we identified that a passive leadership style by supervisors (those who are rarely present and fail to meet residents' expectations and needs) was generally not related to residents' ability to control their work environment. These leadership behaviors, however, did seem to specifically influence in a positive fashion residents' ability to diminish obstacles and hindrances in the workplace.

3. Why do you think that this type of leadership style is generally not related to residents' ability to control their own work environment? Please give examples.

4. Why do you think that this type of leadership style is particularly related to residents' ability to diminish obstacles and hindrances at work? Please give examples.

Finally, do you think these supervisory leadership styles we have discussed influence residents' decision to persist or leave the program? Why? 


\section{References}

I. Sullivan MC, Yeo H, Roman SA, Ciarleglio MM, Cong X, Bell RH, et al. Surgical residency and attrition: Defining the individual and programmatic factors predictive of trainee losses. J Am Coll Surg [Internet]. 2013 Mar [cited 2018 May 25];2I6(3):46I-7I. Available from: http://linkinghub. elsevier.com/retrieve/pii/SI072751512013403

2. Bongiovanni T, Yeo H, Sosa JA, Yoo PS, Long T, Rosenthal M, et al. Attrition from surgical residency training: Perspectives from those who left. Am J Surg [Internet]. 2015 Oct [cited 2018 May 25];2I0(4):648-54. Available from: http://linkinghub.elsevier.com/retrieve/pii/S0002961015003657

3. Adams S, Ginther DN, Neuls E, Hayes P. Attitudes and factors contributing to attrition in Canadian surgical specialty residency programs. Can J Surg [Internet]. 2017 Aug I [cited 2018 May 25];60(4):247-52. Available from: http://canjsurg.ca/vol60-issue4/60-4-247/

4. Khoushhal Z, Hussain MA, Greco E, Mamdani M, Verma S, Rotstein O, et al. Prevalence and causes of attrition among surgical residents a systematic review and meta-analysis. In: JAMA Surgery [Internet]. 2017 [cited 2018 May 25]. p. 265-72. Available from: http://archsurg.jamanetwork.com/ article.aspx?doi=10.1001/jamasurg.2016.4086

5. Dominguez LC, Stassen L, de Grave W, Sanabria A, Alfonso E, Dolmans D. Taking control: Is job crafting related to the intention to leave surgical training? Koniaris LG, editor. PLoS One [Internet]. 2018 Jun I [cited 2018 Jun 2];13(6):e0197276. Available from: http://www.ncbi.nIm.nih.gov/ pubmed $/ 29856750$

6. Forel D, Vandepeer M, Duncan J, Tivey DR, Tobin SA. Leaving surgical training: some of the reasons are in surgery. ANZ J Surg [Internet]. 2018 May I [cited 2020 Mar 21];88(5):402-7. Available from: http://www.ncbi.nlm.nih.gov/pubmed/294II485

7. Bakker AB, Ficapal-Cusí P, Torrent-Sellens J, Boada-Grau J, Hontangas-Beltrán P. The Spanish version of the Job Crafting Scale. Psicothema [Internet]. 2018 Feb [cited 20I8 Sep 6];30(I):136-42. Available from: http://www.ncbi.nlm.nih.gov/pubmed/29363483

8. Halim UA, Riding DM. Systematic review of the prevalence, impact and mitigating strategies for bullying, undermining behaviour and harassment in the surgical workplace. Br J Surg [Internet]. 2018 Oct I [cited 2020 Mar 2I];105(II):I390-7. Available from: http://doi.wiley.com/I0.1002/bjs.10926

9. Bustraan J, Dijkhuizen K, Velthuis S, Van Der Post R, Driessen E, Van Lith JMM, et al. Why do trainees leave hospital-based specialty training? A nationwide survey study investigating factors involved in attrition and subsequent career choices in the Netherlands. Vol. 9, BMJ Open. BMJ Publishing Group; 2019.

10. Demerouti E, Peeters MCW, van den Heuvel M. Job Crafting Interventions: Do They Work and Why? In: Positive Psychological Intervention Design and Protocols for Multi-Cultural Contexts. Springer International Publishing; 2019. p. 103-25.

II. Bakker AB, Demerouti E, Sanz-Vergel Al. Burnout and Work Engagement: The JD-R Approach. Annu Rev Organ Psychol Organ Behav [Internet]. 2014 [cited 2018 May 25];I(I):389-4II. Available from: https://www.isonderhouden.nl/doc/pdf/arnoldbakker/articles/articles_arnold_bakker_348.pdf

12. Bakker AB. Strategic and proactive approaches to work engagement. Vol. 46, Organizational Dynamics. 2017.

13. Dominguez LC, Dolmans D, de Grave W, Sanabria A, Stassen LP. Job Crafting to Persist in Surgical Training: A Qualitative Study From the Resident's Perspective. J Surg Res [Internet]. 2019 Jul 4 [cited 2019 Mar 29];239:180-90. Available from: http://www.ncbi.nlm.nih.gov/pubmed/30844632

14. Avolio BJ. Full Range Leadership Development. Second Edi. United States of America: SAGE Publications; 2013. 280 p. 
15. Antonakis J, Avolio BJ, Sivasubramaniam N. Context and leadership: an examination of the ninefactor full-range leadership theory using the Multifactor Leadership Questionnaire. Leadersh $\mathrm{Q}$ [Internet]. 2003 Jun I [cited $2018 \mathrm{Dec} 2$ I];14(3):26I-95. Available from: https://www.sciencedirect. com/science/article/pii/S1048984303000304

16. Lievens I, Vlerick P. Transformational leadership and safety performance among nurses: the mediating role of knowledge-related job characteristics. J Adv Nurs [Internet]. 2014 Mar [cited 2019 Apr 3];70(3):65I-6I. Available from: http://www.ncbi.nlm.nih.gov/pubmed/2398I245

17. Gillet N, Fouquereau E, Bonnaud-Antignac A, Mokounkolo R, Colombat P. The mediating role of organizational justice in the relationship between transformational leadership and nurses' quality of work life: A cross-sectional questionnaire survey. Int ] Nurs Stud [Internet]. 2013 Oct [cited 2019 Apr 3];50(10):1359-67. Available from: http://www.ncbi.nlm.nih.gov/pubmed/23298792

18. Mills CB, Keller M, Chilcutt A, Nelson MD. No Laughing Matter: Workplace Bullying, Humor Orientation, and Leadership Styles. Workplace Health Saf [Internet]. 2019 Apr 21 [cited 2019 Apr 3];67(4):I59-67. Available from: http://www.ncbi.nlm.nih.gov/pubmed/30574845

19. Arnold KA. Transformational leadership and employee psychological well-being: A review and directions for future research. J Occup Health Psychol [Internet]. 2017 Jul [cited 2019 Apr 3];22(3):38I-93. Available from: http://doi.apa.org/getdoi.cfm?doi=10.1037/ocp0000062

20. Mazzetti G, Vignoli M, Petruzziello G, Palareti L. The Hardier You Are, the Healthier You Become. May Hardiness and Engagement Explain the Relationship Between Leadership and Employees' Health? Front Psychol [Internet]. 2019 Jan 14 [cited 2019 Apr 3];9. Available from: https://www. frontiersin.org/article/l0.3389/fpsyg.2018.02784/full

21. Tsuno K, Norito K. Multifactor leadership styles and new exposure to workplace bullying: a sixmonth prospective study. Ind Health [Internet]. 2015 [cited 2019 Apr 3];53(2):139-5I. Available from: http://www.ncbi.nlm.nih.gov/pubmed/25382384

22. Khan BP, Quinn Griffin MT, Fitzpatrick JJ. Staff Nurses' Perceptions of Their Nurse Managers' Transformational Leadership Behaviors and Their Own Structural Empowerment. JONA J Nurs Adm [Internet]. 2018 Dec [cited 2019 Apr 3];48(I2):609-I4. Available from: http://www.ncbi.nlm. nih.gov/pubmed/30407928

23. Morsiani G, Bagnasco A, Sasso L. How staff nurses perceive the impact of nurse managers' leadership style in terms of job satisfaction: a mixed method study. J Nurs Manag [Internet]. 2017 Mar [cited 2019 Apr 3];25(2):I19-28. Available from: http://www.ncbi.nlm.nih.gov/ pubmed/2791756I

24. Manning J. The Influence of Nurse Manager Leadership Style on Staff Nurse Work Engagement. JONA J Nurs Adm [Internet]. 2016 Sep [cited 2019 Apr 3];46(9):438-43. Available from: http:// www.ncbi.nlm.nih.gov/pubmed/27496584

25. Skogstad A, Einarsen S, Torsheim T, Aasland MS, Hetland $H$. The destructiveness of laissez-faire leadership behavior. J Occup Health Psychol [Internet]. 2007 Jan [cited 2019 May 8];12(I):80-92. Available from: http://doi.apa.org/getdoi.cfm?doi=10.1037/1076-8998.12.1.80

26. Creswell JW, Guetterman TC. Mixed Methods Design. In: Educational research : planning, conducting, and evaluating quantitative and qualitative research. 6th editon. Creswell JW, Guetterman TC, editors. UK: Pearson; 2019.655 p.

27. Stentz JE, Plano Clark VL, Matkin GS. Applying mixed methods to leadership research: A review of current practices. Leadersh Q [Internet]. 2012;23(6):II73-83. Available from: http://dx.doi. org/10.1016/j.leaqua.2012.10.001

28. Wang H, Demerouti E, Bakker AB. A review of job crafting research: The role of leader behaviors in cultivating successful job crafters. In: Sharon K. Parker UKB, editor. Proactivity at Work: Making Things Happen in Organizations. Ist editio. New York: Routledge.; 2016. p. 77-104. 
29. Thun S, Bakker AB. Empowering leadership and job crafting: The role of employee optimism. Stress Heal [Internet]. 2018 Jun 8 [cited 2018 Sep 22]; Available from: http://www.ncbi.nlm.nih.gov/ pubmed/29882309

30. Sox HC, Higgins MC, Owens DK. Expected Value Decision Making. In: Medical Decision Making. John Wiley \& Sons, Ltd; 2013. p. 143-69.

3I. Bates D, Mächler M, Bolker B, Walker S. Fitting Linear Mixed-Effects Models using Ime4. J Stat Softw [Internet]. 2015 Jun 23 [cited 2019 Dec 18];67(I):I-47. Available from: http://arxiv.org/abs/1406.5823

32. Lipsey M, Wilson D. Practical meta-analysis (Applied Social Research Methods). Thousand Oaks, CA: SAGE Publications; 2000. 258 p.

33. Nakagawa $S$, Johnson PCD, Schielzeth $H$. The coefficient of determination $R 2$ and intra-class correlation coefficient from generalized linear mixed-effects models revisited and expanded.J R Soc Interface. 2017 Sep I;14(I34).

34. Nowell L, Norris J, E White D, Moules N. Thematic Analysis: Striving to Meet the Trustworthiness Criteria. Vol. 16, International Journal of Qualitative. 2017.

35. Varpio L, Ajjawi R, Monrouxe L V, O’Brien BC, Rees CE. Shedding the cobra effect: problematising thematic emergence, triangulation, saturation and member checking. Med Educ [Internet]. 2017 Jan [cited 2019 Jul 16];5I(I):40-50. Available from: http://doi.wiley.com/I0.1III/medu.13124

36. van Nes $F, A b m a ~ T$, Jonsson $H$, Deeg $D$. Language differences in qualitative research: is meaning lost in translation? Eur J Ageing [Internet]. 2010 Dec [cited 2018 Dec 13];7(4):313-6. Available from: http://www.ncbi.nlm.nih.gov/pubmed/21212820

37. Arnold KA, Connelly CE, Walsh MM, Martin Ginis KA. Leadership styles, emotion regulation, and burnout. J Occup Health Psychol [Internet]. 2015 Oct [cited 2019 Apr 3];20(4):48I-90. Available from: http://www.ncbi.nlm.nih.gov/pubmed/25844908

38. Hildenbrand K, Sacramento CA, Binnewies C. Transformational leadership and burnout: The role of thriving and followers' openness to experience. J Occup Health Psychol [Internet]. 2018 Jan [cited 2019 Apr 3];23(I):3I-43. Available from: http://doi.apa.org/getdoi.cfm?doi=10.1037/ocp000005I

39. Appelbaum NP, Lee N, Amendola M, Dodson K, Kaplan B. Surgical Resident Burnout and Job Satisfaction: The Role of Workplace Climate and Perceived Support. J Surg Res [Internet]. 2019 Feb [cited 2019 Jun 28];234:20-5. Available from: https://linkinghub.elsevier.com/retrieve/pii/ S002248041830605X

40. Lases L, Arah OA, Busch ORC, Heineman MJ, Lombarts KMJMH. Learning climate positively influences residents' work-related well-being. Adv Heal Sci Educ [Internet]. 2019 May 5 [cited 2019 Jul 17];24(2):3I7-30. Available from: http://www.ncbi.nlm.nih.gov/pubmed/30519786

41. Lee N, Appelbaum N, Amendola M, Dodson K, Kaplan B. Improving resident well-being and clinical learning environment through academic initiatives. J Surg Res [Internet]. 2017 Jul I [cited $2018 \mathrm{Sep}$ 19];2I5:6-II. Available from: http://www.ncbi.nlm.nih.gov/pubmed/28688662

42. Hu YY, Parker SH, Lipsitz SR, Arriaga AF, Peyre SE, Corso KA, et al. Surgeons' Leadership Styles and Team Behavior in the Operating Room. J Am Coll Surg [Internet]. 2016 Jan [cited $2018 \mathrm{Dec}$ 22];222(I):4I-5I. Available from: http://www.ncbi.nlm.nih.gov/pubmed/2648I409

43. Horwitz IB, Horwitz SK, Daram P, Brandt ML, Brunicardi FC, Awad SS. Transformational, transactional, and passive-avoidant leadership characteristics of a surgical resident cohort: analysis using the multifactor leadership questionnaire and implications for improving surgical education curriculums. J Surg Res [Internet]. 2008 Jul [cited 2018 Sep 22];I48(I):49-59. Available from: http:// linkinghub.elsevier.com/retrieve/pii/S002248040800I9II

44. Choi SL, Goh CF, Adam MBH, Tan OK. Transformational leadership, empowerment, and job satisfaction: the mediating role of employee empowerment. Hum Resour Health [Internet]. 2016 Dec I [cited 2019 Apr 3];I4(I):73. Available from: http://www.ncbi.nlm.nih.gov/pubmed/27903294 
45. Stegeman JH, Schoten EJ, Terpstra OT. Knowing and acting in the clinical workplace: trainees' perspectives on modelling and feedback. Adv Health Sci Educ Theory Pract [Internet]. 2013 Oct 16 [cited 2019 Jul 17];/8(4):597-6I5. Available from: http://link.springer.com/I0.1007/ s10459-012-9398-4

46. Cope A, Bezemer J, Mavroveli S, Kneebone R. What Attitudes and Values Are Incorporated Into Self as Part of Professional Identity Construction When Becoming a Surgeon? Acad Med [Internet]. 2017 Apr [cited 2019 Jul 18];92(4):544-9. Available from: http://insights.ovid.com/crossref ?an=0000I888-201704000-00047

47. Nisar PJ, Scott HJ. Key attributes of a modern surgical trainer: Perspectives from consultants and trainees in the United Kingdom. J Surg Educ. 20II May I;68(3):202-8.

48. Kissane-Lee NA, Yule S, Pozner CN, Smink DS. Attending Surgeons' Leadership Style in the Operating Room: Comparing Junior Residents' Experiences and Preferences. J Surg Educ. 2016 Jan I;73(I):40-4.

49. Thun S, Bakker AB. Empowering leadership and job crafting: The role of employee optimism. Stress Heal [Internet]. 2018 Oct [cited 2019 Apr 3];34(4):573-8I. Available from: http://www.ncbi.nlm.nih. gov/pubmed/29882309

50. Wang H, Demerouti E, Le Blanc P. Transformational leadership, adaptability, and job crafting: The moderating role of organizational identification. J Vocat Behav [Internet]. 2017 Jun I [cited 2018 Oct 3];100:185-95. Available from: https://www.sciencedirect.com/science/article/pii/ S000I879|I730027I

5I. Elshout R, Scherp E, van der Feltz-Cornelis CM. Understanding the link between leadership style, employee satisfaction, and absenteeism: a mixed methods design study in a mental health care institution. Neuropsychiatr Dis Treat [Internet]. 2013 Jun [cited 2019 Apr 4];9:823-37. Available from: http://www.dovepress.com/ understanding-the-link-between-leadership-style-employee-satisfaction--peer-reviewed-articleNDT

52. Green AE, Miller EA, Aarons GA. Transformational Leadership Moderates the Relationship Between Emotional Exhaustion and Turnover Intention Among Community Mental Health Providers. Community Ment Health J [Internet]. 2013 Aug 4 [cited 2019 Apr 3];49(4):373-9. Available from: http://www.ncbi.nlm.nih.gov/pubmed/22052429 

CHAPTER 5

\section{How surgical leaders transform their residents to craft their jobs: surgeons' perspective}

Dominguez LC, Dolmans D, Restrepo J, de Grave W, Sanabria A, Stassen L. 


\begin{abstract}
Background: Surgeons should transform their residents to take the lead in their jobs and optimize their working conditions, so-called job crafting. We investigated the actions undertaken by surgeons with a transformational leadership style to encourage residents' job crafting, about which there is at present a paucity of information.
\end{abstract}

Methods: We performed a constructivist, grounded theory study. In-depth interviews were held with a purposive sample of surgeons who were perceived as transformational leaders by their residents. During data analysis (open, axial, and selective coding), we compared inductive codes with deductive codes drawn from the job demands-resources and transformational leadership theories to reach a consensus on the interpretation of data and identification of the main themes.

Results: Sixteen surgeons participated. Surgeons undertook 5 actions that enhanced job crafting in residents. They: I) modeled positive behaviors of a good surgeon; 2) used a stepwise individual approach toward autonomy; 3) connected with the resident as a person; 4) supported residents in handling complications and errors; and 5) they coached the resident to deal with competing interests. These actions had 4 consequences for residents. They led to: I) more responsibilities in patient care; 2 ) more constructive relationships in the workplace; 3) less pressure from workload and surgical care duties; and 4) less personal difficulties and errors in patient care.

Conclusions: The actions undertaken by surgeons with a transformational leadership style have a positive association with the residents' ability to craft their jobs. This knowledge has implications for surgeons' leadership development with a view to workplace education. 


\section{Introduction}

Surgical residents learn by working in a complex clinical environment. Unfortunately, increasing demands and a lack of resources for workplace-based training have caused rates of burnout among surgical residents to inflate to $58.39 \%$ globally (I). By demands, we refer to aspects that cost energy, such as facing obstacles and challenges at work $(2,3)$, including workload, pressure, and bullying (4-7). Resources, by contrast, refer to aspects that help to decrease such demands and achieve goals at work (2,3). Decreased feedback and mentoring, and inappropriate resident autonomy are some examples of poor resources in surgical training (4-7). Ultimately, this paucity may result in low performance, depression, or burnout, in turn driving attrition from training programs and suboptimal surgical care (8-II).

Within the complexity of training, surgeons should, through their leadership, help their residents to strengthen their ability to craft their jobs. Job crafting is about the individual ability to optimize the demands and resources in the workplace (3). By doing so, rather than being passive experiencers of the working conditions in which they are immersed, residents can become proactive in shaping their work. Such successful job crafting may eventually promote residents' work engagement - the opposite of burnout (I2) - and their persistence in surgical training $(\mathrm{II}, 13)$.

Leadership can be defined as a dynamic process of mutual influences, change, and constant interactions between individuals in a social environment (14). In the past decade, a transformational leadership style of surgeons has received increasing attention (15-17). Transformational leaders are team-oriented and display behaviors that can be categorized into: i) idealized influence (which they wield, e.g., by means of role modeling); ii) individual consideration (they attend to the needs of others); iii) intellectual stimulation (they foster creativity, innovation, and new ways of thinking in others); and iv) inspirational motivation (they articulate inspiring visions of the future) $(18,19)$.

Job crafting, on the other hand, takes center stage in the job demands-resources (JD-R) theory, a framework for understanding wellbeing (i.e., work engagement) and performance at work (3). Within the JD-R theory, job crafting aims to increase: i) structural resources (those related to autonomy); ii) social resources (those associated with relatedness, such as support from peers); and iii) challenging demands (those that promote personal growth and development) at work. At the same time, job crafting aims to diminish hindering demands (those that inhibit the achievement of goals, such as conflicts at work) (2).

According to the transformational leadership and JD-R theories, leaders should stimulate their followers to craft their jobs $(12,20)$. However, empirical evidence for this approach is lacking. Further research is therefore needed to understand how surgeons transform their residents to take the lead in crafting their job. Such research can help identify specific areas of 
surgeons' leadership that require further development to meet the challenges of workplace education. In a more theoretical vein, such research might also offer more insight into how such transformation occurs (20). With these aims in mind, we formulated the following research questions (RQs):

RQI: What actions do surgeons with a transformational leadership style undertake to strengthen their residents' job crafting in training, from surgeons' perspective?

RQ2: What consequences do these actions have for the resident, from surgeons' perspective?

\section{Methods}

\section{RESEARCH DESIGN}

We conducted a constructivist, grounded theory (CGT) study, which acknowledges the interpretive nature of knowledge generation, as well as the subjectivity of participants and researchers $(21,22)$. Considering its methodological foundations and exploratory approach, a CGT study fitted well with our RQs, as it offered an appropriate framework from which to explore the social processes involved in the topic under scrutiny. The study was approved in its ethical aspects by the Institutional Review Board of the School of Medicine, Universidad de la Sabana, Colombia (\#41519).

In light of the aforesaid, we note that we, as researchers, were actively involved in developing the theory. In other words, we acknowledge that we are not passive observers of the research field. Our backgrounds, experiences, and conception of the main topic have influenced our interpretations and added meaning to the findings of this study and therefore required reflexivity. LCD, AS, and LS are active surgeons, clinical supervisors, and directors of surgical programs in Colombia and the Netherlands, respectively. JR is a neurologist and director of a masters' program in Health Professions Education in Colombia. Consequently, all of them have an understanding and impression of what constitutes leadership in the workplace and residency training. Finally, DD and WdG are educational scientists and researchers with extensive experience in the field of workplace-based learning in postgraduate medical education.

\section{SETTING}

The study was conducted in Colombia, where surgical training is university-based and lasts four years. There are 20 active programs, spanning 400 residency positions per year. Residents do not receive a salary and, as such, they do not enjoy an official employee status in the health institutions 
in which they serve. Nevertheless, they do have legal responsibilities in patient care and daily clinical duties. In almost $60 \%$ of the programs, residents must pay an annual tuition fee of approximately 12,000 USD. The burnout rate in surgical residents is $33.1 \%$ (II).

\section{PARTICIPANTS}

We used a purposive sampling approach, as is common in CGT $(21,22)$, to recruit 16 surgeons who were clear exponents of a transformational leadership style. In a previous study, we had requested residents from seven surgical programs to rate the leadership style of the surgeons in charge of their clinical supervision, using the Multifactor Leadership Questionnaire (23). By aggregating their evaluations, we obtained a composite score for each of the three leadership styles present in each program: transformational, transactional, and laissez-faire leadership. Based on this information, we were able to determine in which programs a transformational leadership style prevailed, which was the case when the following two criteria were met: I) the program was given a score of $>3.5$ for a transformational leadership style (range I-5) and; 2 ) the score for a transformational leadership style was higher than the scores for the other (transactional and laissez-faire) styles. Four programs fulfilled these criteria. However, we expected that not all surgeons of these programs would necessarily be exponents of such a transformational leadership style. LCD and AS therefore enlisted the help of the directors and chief residents of each program to recruit surgeons who were obvious exponents of this style, after having explained to them the main characteristics that go with it. A total of 16 surgeons were identified and invited to participate in individual, in-depth interviews.

\section{DATA COLLECTION}

From September to December, 2019, LCD and JR conducted the interviews in Spanish language (face to face or via telephone) based on a preliminary interview guide (Appendix $A$ ). The interview guide was devised from the job-crafting concepts in the JD-R theory (i.e., to increase structural resources and to diminish hindering demands) $(2,3)$. The purpose and scope of the study were explained to the participants as well as the mechanisms to ensure anonymity, confidentiality, and the further management of information. Prior to participation, all surgeons gave their written or verbal consent. Each interview was audiotaped, transcribed verbatim, and pseudonymized immediately upon completion. In successive meetings, LCD and JR discussed the general impressions they had formed during data collection. 


\section{DATA ANALYSIS}

Data analysis was highly dynamic, as inductive and deductive coding overlapped recurrently throughout the whole process. First, LCD, JR, and AS independently read the verbatim transcripts. In an iterative process, they consequently identified general ideas that guided further data collection in subsequent interviews. These ideas were grouped into small units of analysis, which, in turn, were grouped into related categories, and categories into general themes.

As inductive coding progressed, LCD, AS, and JR reflected on the role of several sensitizing concepts (i.e., aspects that we a priori expected to identify in the analysis based on the transformational leadership and JD-R theories) $(3,24)$. We derived several codes from these theories, such as those relating to job-crafting behaviors (e.g., to increase structural resources) and to a transformational leadership style (e.g., intellectual stimulation). This combination of inductive and deductive coding ultimately helped us to understand participants' perspective on a more theoretical level and to construct our final themes. The resulting themes were discussed with all authors (DD, LPS, WdG) until we reached consensus.

In all stages of analysis (open coding, axial coding, and selective coding), constant comparison of inductive and deductive codes enabled us to develop a theory with interpretive meaning and not just a description of themes. Furthermore, iteration during data analysis and constant comparison allowed us to arrive at theoretical sampling and saturation of information (the stage in which no new data emerge) $(21,22)$. Finally, we validated our findings by comparing these with the existing literature. In all stages of the qualitative phase, we followed standard recommendations for the translation of information, in our case from Spanish into English language $(25,26)$. Similarly, we adopted a framework of consolidated criteria to report our qualitative results (27).

\section{Results}

All 16 surgeons agreed to participate. Characteristics of the study population are presented in Table I. From the analysis, we were able to construct five themes that corresponded to surgeons' actions mentioned in RQI, and four themes representing the consequences of these actions for residents, addressing RQ2. Figure I gives an overview of the main findings. 
Table I. Characteristics of the study population

\begin{tabular}{lc}
\hline Characteristics & Study sample \\
\hline Surgeons, $n$ & 16 \\
Male surgeons, $\mathrm{n}(\%)$ & $14(87.5 \%)$ \\
Female surgeons, $\mathrm{n}(\%)$ & $2(12.5 \%)$ \\
Age of participants (mean, SD, range) & $47.18 ; 7.95 ; 32-65$ \\
Years of surgeons' experience as supervisors (mean, SD, range) & $12.56 ; 7.40 ; \mathrm{I}-30$ \\
Interviews conducted in person, $\mathrm{n}(\%)$ & $12(75 \%)$ \\
Interviews conducted via telephone, $\mathrm{n}(\%)$ & $4(25 \%)$ \\
Duration of interviews, mean (range) & $51.48 \mathrm{~min}(38-65)$ \\
Number of training programs, $\mathrm{n}$ & 4 \\
Number of surgeons per program, $\mathrm{n}(\%)$ & \\
Program I & $5(31.25 \%)$ \\
Program 2 & $5(31.25 \%)$ \\
Program 3 & $4(25 \%)$ \\
Program 4 & $2(12.5 \%)$ \\
\hline
\end{tabular}

n: number; SD: standard deviation

Figure I. Conceptual model of the actions undertaken by supervisors who are exponents of a transformational leadership style and of the consequences for the surgical resident.

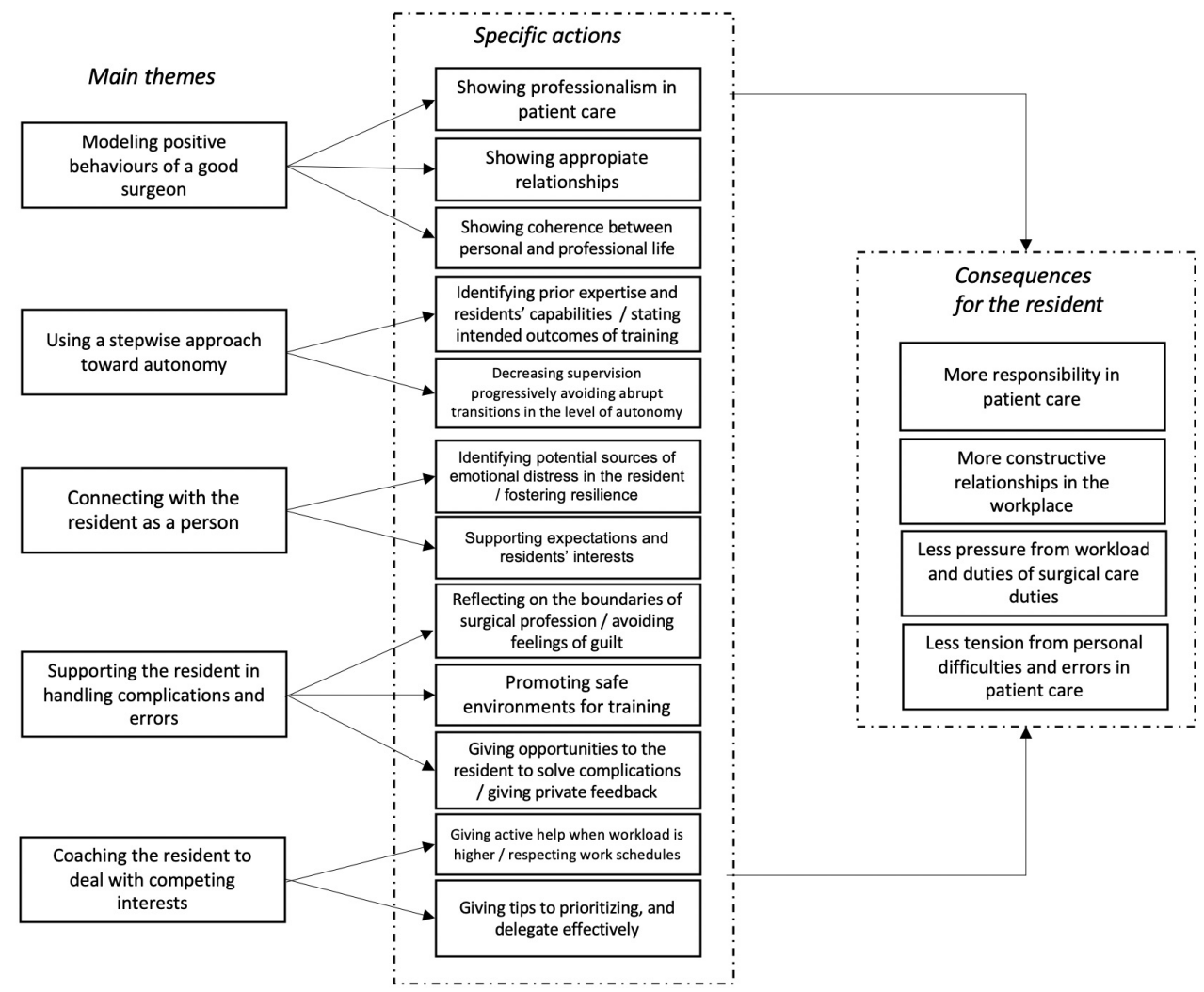


What actions do surgeons with a transformational leadership style undertake to strengthen residents' job crafting?

\section{THEME I. MODELING POSITIVE BEHAVIORS OF A GOOD SURGEON}

Surgeons appreciated the importance of demonstrating correct professional behaviors that residents could identify and emulate. Such role modeling went beyond the manual dexterity to execute surgical operations, as one surgeon mentioned:

An average surgeon is someone who just operates ... An academic surgeon is a leader who sets an example ... making people believe and follow and improve ... If you do not surprise the resident with your positive role model and leadership, they will not have good clinical or academic results ... This is what sets him/her apart from the one who just operates, from the regular surgeon. (Surgeon\#I0)

Surgeons had a clear vision of what they expected of residents during patient care, of their relationships with other surgeons and team members, and of the balance between personal and professional life. The following quotes clearly illustrate this:

I comply with my surgical duties. I know everything about my patient and the result of his/her diagnostic tests. I know their surgical pathology very well ... I am punctual in my duties ... I want that he/she [the resident] sees that I am active with my patient ... They have to realize what I am doing for the patient. So, I stimulate them to care about the patient. (Surgeon\#5)

I put great emphasis on good interpersonal relationships ... on treating others well .... I cannot demand that residents behave well when I behave badly. It is important that they understand that most things can be achieved through good relationships. (Surgeon\#6)

I try to share my experiences with literature, arts, music, and cinema. I want them to realize how these experiences are related to surgery. It also seems very important to me to tell them about my life, my experiences of when I was a resident, when I was a rural surgeon, or when I was at war .... Life goes by too quickly to be only in a hospital or an operating room. (Surgeon\# I6)

Interestingly, they had long-term views of surgical education in which tomorrow's supervisors were today's residents:

The surgeon was an alpha male ... a pernicious leader, bully, abuser, and a person who did not dialog .... But, that's how surgeons used to be. Nowadays, leadership has changed a lot. It is about getting something done with the team [the patient, a project, a research study] .... This requires good examples .... In the future, I hope that the supervisors of the new generations will have $a$ 
different vision of what education really is .... Dinosaurs are going to become extinct at some point. (Surgeon\#7)

\section{THEME 2. USING A STEPWISE INDIVIDUAL APPROACH TOWARD AUTONOMY}

For surgeons, residents' involvement in surgical care required a gradual transformation of their autonomy in the operating room and other clinical settings. However, surgeons emphasized that the speed and scope of such transformation should be based on individual plans of training fitted to the resident's personal needs, his/her prior expertise, and level of intended outcomes of training. As a surgeon commented:

First, you must know the experience of the resident ... then, we should explain to him/her what the job is, what the specific objectives of the current rotation are, as well as the way in which we work .... Thus, a model of specific supervision is built for each resident. (Surgeon\# I6)

Such an approach to autonomy aimed to improve residents' performance, while avoiding abrupt changes in responsibilities during training. The following quote explains this approach in more detail:

I use a sequence of steps .... First, the resident enters surgery and I explain to him/her the steps of the operative procedure.Then, he/she enters several times as an assistant ....After a certain number of procedures, I evaluate whether he/she has the competency to start performing parts of the procedure. So, I allow him/her to carry out some specific steps .... Later, when he/she is more autonomous, I allow him/her to carry out the entire procedure and I just help .... Finally, there is a moment in which I do not participate, physically, in the procedure. The resident completes the procedure alone, but I am available to assist him/her. (Surgeon\#7)

\section{THEME 3. CONNECTING WITH THE RESIDENT AS A PERSON}

The surgeons in our study did not perceive residents as just workers, but as individuals with a personal and family life. They were looking for cues that allowed them to strengthen their interpersonal relationships with residents and identify interests and expectations that could foster their personal development. As one surgeon mentioned:

I believe that it is very important to know the resident as a person. It is important for teaching ... I believe in education from the person. As a surgeon and supervisor, that demands more of me.That goes beyond training him/her to make surgical stitches. (Surgeon\#I). 
The next quote clearly expresses this focus on identifying residents' interests and expectations:

There are "carnivorous" and "herbivorous" surgeons .... I think we need surgeons in many positions. Not everyone is going to be a head transplant surgeon ["carnivore"]. We need surgeons in the emergency room, in the intensive care unit, others should lead nutritional support teams, and [yet] others should be epidemiologists or MBAs ["herbivores"] .... We must help the resident to identify their strengths ... one size does not fit all .... It is important that those who are "herbivorous" meet the minimum skills and requirements to be certified as surgeons. But we have to support their initiatives ... those things that are really fascinating for them. (Surgeon\#3)

In this connection, it was also important to identify potential sources of emotional distress in the resident, to be able to advise about personal difficulties, and to promote resiliency in training. This, however, required authenticity and openness. Consider the next two quotes:

"It is important to know the residents in order to detect their emotional, psychological, or depression problems, and help them .... Surgeons should be sensitized to these human needs residents have." (Surgeon\# 15)

Resilience is very important for the resident. Not "resistant" resilience but "reflective" resilience. Through reflective resilience a person can understand their frustrations and difficulties, reflect on them and take actions ... daily conversations with residents about this are very important. (Surgeon\#I).

\section{THEME 4. SUPPORTING THE RESIDENT IN HANDLING COMPLICATIONS AND ERRORS}

According to surgeons, residents frequently blamed themselves for making errors and causing complications. Their support helped residents to cope with such adverse situations and to understand the risks of surgery and the boundaries of the surgical profession, as the following quotes make clear:

We have always been trained with high self-criticism and self-blame. Many errors, however, are not our fault, but they are very frustrating .... For example, when a resident "fails" to save the life of a traumatized patient, he/she feels guilt and seeks explanations in medical errors or in controversial decisions. (Surgeon\#9).

"I want residents to understand that not everything we do is successful and that sometimes the results are not as expected .... I try to instill tolerance for failure in them by accepting their errors." (Surgeon\#6) 
Moreover, surgeons acknowledged that good support required them to give private feedback, preventing the resident from being humiliated in public when complications arose, especially in surgical meetings. They acknowledged that constructive environments that allowed for open discussion contributed positively to residents' learning from complications. As one surgeon explained:

One should definitely exalt the good things publicly and correct privately .... One should not take the resident to the morbidity and mortality meeting to crucify him/her .... When one punishes him/her publicly, the resident will depart from his/her learning curve. If he/she is underperforming, their performance will become worse. If they avoid complex cases, then he/she will avoid more cases to prevent punishment. They will look for excuses .... (Surgeon\# I0)

Ultimately, surgeons recognized that a surgical educator should offer residents the opportunity to handle complications. Rather than blaming and abandoning the resident when complications arose, they involved the resident in solving complications during the whole continuum of patient care:

First of all, I am in charge of the patient. So, residents' complications are my complications .... If I allowed the resident to participate in the surgical treatment of the patient and something went wrong, it is not just their fault ... he/she is in a learning process. This is why I accept the complications, but I ask [the resident]: "what did we do, what should we have done, and what should we do [now]?”. (Surgeon\#6)

When a patient develops a complication, it is painful .... I help and I accompany the resident to solve complications .... Such situations are frustrating ... I am especially very focused on that they don't become operating technicians who abandon the patient, but who establish a deep relationship with the patient, until he/she gets better ....All of this requires emotional support for the resident. (Surgeon\#4).

\section{THEME 5. COACHING THE RESIDENT TO DEAL WITH COMPETING INTERESTS}

Participants were aware that residents were exposed to a heavy workload, long work shifts, and administrative pressure. Yet, they still appreciated the rationale behind this amount of administrative load in contemporary surgical care and the importance of making residents aware of this. As one surgeon phrased it:

There is a persistent criticism that the system is wrong... many forms should be filled [out]. People [surgeons and residents] always have complaints, but for the proper functioning of the institution there must be economic profit. The provision of health service is not an act of charity 
.... Residents must be aware of these aspects ....Anything that is requested [for example, devices, sutures] can be used with the correct indication and relevance. This involves administrative work that must be done so that the institution does not lose money ....You must be an ally of your institution. The institution and the third payer are not your enemies ... this is as important as operating well [surgical procedures]. (Surgeon\#3)

However, these challenges also called for specific actions on their part. More specifically, to relieve pressure, surgeons made sure not to transfer all workload to residents, to assist them when their load was too high, and to respect their work schedules. In the words of two surgeons:

I help them with the workload [clinical and administrative] ... working with four hands is more efficient .... I also do it because it is my responsibility. I am the surgeon in charge; residents are in training. When they are working, they are helping me to relieve my workload .... I should be grateful to them. (Surgeon\#8)

Historically, surgical residency has requested people to serve full-time.You could not have free time because schedules did not exist.You knew [your schedule] when you arrived, but not when you left the hospital. Nowadays, schedules and work regulations must be met .... (Surgeon\# I 4)

In addition to this, surgeons provided the resident with tips on how to handle the workload. These tips focused on the identification of care priorities (e.g., in the case of patients with lifethreatening conditions) and on the delegation of tasks (based on the task itself, clinical status of patients, and the expertise of other team members), as the following quotes illustrate:

Residents must identify what is most important to do and organize their work .... I insist that they prioritize tasks. For example, we always start the surgical round by visiting critical patients, we define the most important tasks for those patients and the order in which we will carry them out. (Surgeon\#/2)

It is vital that residents learn to delegate to others [e.g., junior residents, interns, students] to reduce the number of activities that overload and blur what needs to be done.This implies learning to work as a team. Overloading is one of residents' problems because they want to do everything by themselves. (Surgeon\# I0). 
What consequences do surgeons believe their actions will have for residents?

\section{RESIDENTS TAKE ON MORE RESPONSIBILITIES IN PATIENT CARE}

Surgeons perceived that their modeling behaviors (Theme I) encouraged residents to assume more responsibilities in patient care based on sound judgment and integrity. For instance, they observed that residents more readily assumed the role of surgeon in training, taking surgical decisions with more confidence and prudence:

"I see that my responsibility to care for the patient impacts residents ... encourages them to do things well [for example, making good decisions], ethically, and motivates them to study.”(Surgeon\#2).

"They [residents] come to appreciate the importance of what they are doing [when they see professionalism in patient care in the supervisor] ... they assume the role of a surgeon in training with responsibility.” (Surgeon\#9)

Similarly, surgeons believed that an individual approach toward autonomy (Theme 2) promoted the competence and responsibility in residents to independently bring surgical operations to a successful completion. As this surgeon commented:

"I believe that [one of the] consequences is generating skills in the resident to operate [on] a patient, independently, in the future. They gain self-confidence”. (Surgeon\#7)

Finally, surgeons noted that their support to residents in dealing with errors (Theme 4) promoted courage and initiative in the resident to overcome complications satisfactorily, to stay compassionate, and to take on responsibilities in subsequent cases. The following quote illustrates such consequences during morbidity and mortality rounds:

When the resident feels, in a surgical meeting, that the complication is not his/her own, but that there is a shared responsibility with other team members, ... his/her critical and analytical ability is strengthened ... [and] future complications [for other patients] are prevented. (Surgeon\# I2).

With respect to compassion, a surgeon commented:

I notice that residents take more care of the patient [when they are supported by the supervisor, as specified under Theme 4]. They are committed and interested .... It makes residents value their patient, and the patient is not just another number. (Surgeon\#4)

Finally, the next quote illustrates how surgeons' support could prevent residents from avoiding new responsibilities: 
The one who takes risks has a greater chance of failure ... but if I fail and am punished for that, then I will not take more risks.... When that vicious circle, based on fear and punishment, is broken ... the person can assume new challenges ... Residents are not going to evade their responsibilities. (Surgeon\#7)

\section{RESIDENTS DEVELOP MORE CONSTRUCTIVE RELATIONSHIPS IN THE WORKPLACE}

Many surgeons noted that modeling (Theme I) was important for residents to strengthen their interpersonal relationships with peers, supervisors, and nurses, and to befriend others. Supervisors observed more collaboration between residents and better communication, as well as more abilities to solve work conflicts satisfactorily with emotional intelligence and kindness. This clearly shines through in the following quotes:

"Residents realize that when they mistreat people they do not do well; they are blocked, and people do not help them. The group does not work this way". (Surgeon\#8)

I feel that the residents improve their communication and they are kind to each other [when they identify positive behaviors in their supervisors and try to emulate these].Their interactions improve ... the consequences are evident. In general, one sees that the resident who was uncompromising and had interpersonal problems changes positively. (Surgeon\# I6)

Similarly, they noted that residents were more inclined to lead and teach others (such as junior residents or medical students):

"One realizes that they [residents] have more 'voice of command,' more leadership [when they identify positive behaviors in their supervisors and try to emulate these].They begin to teach other residents." (Surgeon\#/3).

\section{RESIDENTS EXPERIENCE LESS PRESSURE FROM WORKLOAD AND SURGICAL CARE DUTIES}

Surgeons noted that coaching residents to prioritize and delegate (Theme 5) helped them to better plan their tasks, improve their decision-making capacity, and seek opportunities at work (for instance, to perform surgical operations of interest to them). Consider the next quotes:

"When residents use these strategies [i.e., prioritization, delegation], I observe that they are calmer, they look less distressed.The environment has improved because of reduced pressure."(Surgeon\#7) 
"It [prioritization and delegation] allows the resident to take the time for making better decisions ... not acting in a hurry, but thinking." (Surgeon\#2)

The following quotes illustrate how residents were better able to search for opportunities:

They organize and plan their work better [when delegating effectively] .... They save time ... this allows them to look for opportunities. For example, to operate [on] a patient with a critical condition in the midst of a heavy clinical workload. (Surgeon\#I2).

Similarly, surgeons perceived that respecting residents' work schedules (Theme 5) and modeling satisfactory relationships to improve collaboration (Theme I) were important to relieve residents' workload, thereby minimizing exhaustion. As a result, residents had more free time after work to recover from the surgical environment, as one surgeon remarked:

To learn surgery, you need a lot of hours under the lamp, in the OR, and in the hospital. But free time is also important ... time with family and time to rest .... They [residents] value free time [when supervisors respect their work schedules].They are grateful because it allows them to recharge their batteries. That motivates them. (Surgeon\#9).

\section{RESIDENTS EXPERIENCE LESS TENSION FROM PERSONAL DIFFICULTIES AND ERRORS IN PATIENT CARE}

By connecting with residents (Theme 3), surgeons believed they helped them to find effective ways to solve their personal problems and to advance in their interests (for instance, by improving aspects of their professional development). Likewise, surgeons' support (as mentioned under Theme 4) caused residents to be less afraid of being punished when complications arose, while cultivating their resilience and freeing learning opportunities. In the words of one surgeon (\#I):

Residents become very calm ... they create bonds [when they discuss their personal problems with the supervisor]. The resident, in turn, feels less pressured, less observed, less watched. Feeling closely observed is negative for the resident .... Bonds make them open up their own lives ... it is a valve of emotional relief for residents. So, we can help them.

Also consider this quote, in which a surgeon alludes to residents' gratitude when supervisors truly listen to them and to the positive impact such relationships have on their work:

When residents are treated humanely, one sees that they do their work with more commitment and dedication. There is gratitude in them .... I have seen very positive things in them compared to other residents who came from groups where they were not treated humanely. (Surgeon\#4). 
Finally, supervisors believed that residents really appreciated their encouragement to reflect on the limits of the surgical profession so as to overcome adverse events during training. They perceived less anxiety in residents, as this surgeon remarked:

"They recover quickly [from complications], when reflecting on these aspects, when analyzing the case taking into account the context and the available evidence." (Surgeon\#9)

\section{Discussion}

Our qualitative survey has provided empirical evidence of how surgeons with a transformational leadership style can foster residents' job crafting. The results suggest that these surgeons influence and motivate their residents by means of role modeling, by individualizing and considering residents' needs, and by stimulating them intellectually to develop new ways of thinking. In surgeons' view, these actions foster residents' ability to take control of their job and increase responsibility and autonomy, strengthen their social relationships, and reduce pressure and tensions in the workplace.

The said actions undertaken by the surgeons in this study, addressing our first research question, tie in nicely with the main characteristics of a leader as described in transformational leadership theory $(20,24)$. For instance, surgeons' efforts to model professionalism and satisfactory relationships with others in the workplace, and their approach to strengthening residents' autonomy (Themes I-2) closely resemble the theory's pillars of "idealized influence" and "inspirational motivation." Similarly, surgeons exhibited "individual consideration" by connecting with and supporting residents (Themes 3-4) as well as "intellectual stimulation" by challenging them to find satisfactory solutions to complications and competing interests (Themes 4-5). These actions reveal that surgeons with a transformational leadership style prioritize having "human relationships" with their residents over the actual "task," an observation that is common in transformational leadership research $(28,29)$.

These findings are also consistent with those of earlier studies. A preliminary mixed-methods study into residents' perspective in surgical training, for instance, revealed that surgeons' transformational leadership style had a positive effect on residents' job crafting (23). More specifically, surgeons who were exponents of that style created a constructive atmosphere for training, provided the resident with more resources (in the form of teaching and feedback), and modeled effective ways to handle the demands in the workplace (23). Similar findings were identified in non-surgical settings (30,31).

To address research question two, surgeons' actions also had consequences for residents, which appeared to be in perfect harmony with the job-crafting concept. Our analysis revealed that 
surgeons encouraged their residents to take the lead and craft their jobs by emphasizing their personal strengths, which they considered "constant near perfect performance[s]" shaped by talent, knowledge, and skills (32). This mechanism deserves more empirical underpinning in transformational leadership theory (20). Our findings moreover indicated that by modeling professionalism in patient care, surgeons also fostered other specific strengths in the resident, such as judgment and integrity. Residents need such strengths to enhance structural resources, such as autonomy and responsibility in the workplace, and take on new challenges (first consequence). Similarly, we found that by modeling satisfactory relationships with others, surgeons stimulated emotional intelligence and kindness in the resident, strengths that are needed to enhance social resources, such as peer collaboration and feedback (second consequence). This finding is consistent with previous studies in surgical training (33-35). Finally, by supporting and connecting with the resident, surgeons promoted courage and resilience, which are important qualities to help reduce hindering demands, such as pressure and tensions in the workplace (third and fourth consequences). This finding resonates with previous studies on the role of resilience in surgical training $(36,37)$.

Our study contributes to the existing literature and theory in different ways. First, compared to previous studies, it goes one step further by exploring how leaders can transform their followers to take the lead in crafting their job. While previous studies took either a transformational leadership theory or job-crafting perspective, we have combined the two. Second, as most research on leadership and job crafting has been conducted in non-educational contexts, our study is among the few to bring workplace education into sharper focus. Moreover, previous research predominantly made use of surveys (30,31,38-42); our qualitative approach, however, allowed for a better understanding of how surgeons can transform residents to shape or craft their own job. In this way, we were able to contribute to the body of leadership and job-crafting research in the context of postgraduate medical education, responding to the need to explain how and why leadership occurs in specific social contexts (14). We concluded that surgical leaders can transform to their residents to craft their job by means of role modeling or by idealizing their influence, attending to their needs, and by stimulating them intellectually to develop new ways of thinking. In doing so, they help residents to shape their job by reducing pressure and tensions in the workplace and by encouraging them to strengthen their social relationships. Our findings help us to delineate the specific attributes of a modern surgical leader described in previous studies, with a focus on education in the workplace (43-45).

Besides strengths this study also has limitations. A first limitation is that our study was conducted in one specific setting, namely Colombia, which might limit the generalizability of our findings. Nevertheless, we do find it plausible that most of the themes and consequences discussed are transferable to other countries, because the surgical training model shares similar features across countries, especially in the West, including a hierarchical structure, competition, and pressure on residents to meet high standards (46-49). A second limitation is that the number of female 
participants was low (12.5\% of the sample). This can be explained, in part, by the fact that the proportion of women among faculty in general is still small, despite the significant increase in female surgeons in Colombia. Yet, we argue that there is no reason to assume that our findings would reveal major differences in terms of the actions of transformational leaders and their respective consequences for residents, had more female surgeons been included. A final limitation is that we did not directly observe surgeons' leadership and residents' job crafting behaviors in their real workplace training environment.

We strongly believe that the key features of surgical leadership identified in this study have implications for practice. More specifically, they can help surgeons to self-reflect on their leadership behaviors and raise awareness of what specific actions they can undertake to guide their residents in optimizing job demands and resources in the workplace. In the complex dynamics of the social training environment, surgical leaders must make sure their educational actions are aimed at raising situational awareness among residents. The results of the present study can serve faculty training purposes with a view to coaching, developing, and guiding residents in the workplace. If training is based on the situated actions identified in this study, its intended outcomes may help reduce the ambiguity of leadership in surgeons' daily educational practice.

As for future research, we invite researchers to explore our findings in other countries to enhance their generalizability. Further studies are important because surgical education is undergoing a rapid transformation from hierarchical training models to competency-based medical education $(46-48,50)$. This development calls for more research into the implications of residents' job crafting for supervisors' entrustment decisions in the workplace. Also, a lack of knowledge about a transformational leadership style in women surgeons offers an opportunity for further exploration with a view to residents' development. Finally, we welcome future research into the interactions between leadership and residents' job crafting in the workplace for training based on direct observations and ethnographic perspectives.

To recap, by focusing on the interactions between surgeons and residents in the workplace-based learning setting, this study has provided evidence for the relevance of transformational leadership in surgical education. Our findings have highlighted the positive association that such leadership of surgeon educators has on residents' job crafting in terms of dealing effectively with job demands and resources during training. These observations have practical implications and they offer a window of opportunity for future research. 


\section{Appendix A. Interview guide}

\section{INTRODUCTORY PHASE}

- Welcome the participants and thank them for attending

- Introduce the broad research terms

- Explain how the information will be used. Clarify that information will not be used for any purpose other than research and that participants will never be identified personally. Outline of confidential data use and storage

- Audio recording: Inform the interviewee of recording and ask for approval

- Disclosure of ethical issues: Consent for participation (signature of informed consent)

- Respond to inquiries

Introductory vignette: During this conversation we would like to hear what you do in this department to stimulate different abilities in the surgical resident to help them effectively manage their work environment for training.

\section{Ice-breaking question}

What do you or does your department do to stimulate the resident to take the lead in his/her development/training in the workplace?

\section{Key questions}

I. What do you do to encourage residents to gain autonomy and responsibility in their daily work?

2. What do you do to encourage residents to establish satisfactory interactions and collaboration with others in the workplace?

3. What do you do to encourage residents to see errors and frustrations in their daily work as learning opportunities?

4. What do you do to encourage residents to find a suitable work-life equilibrium?

5. What do you do to encourage residents to deal with the demands of training in their daily work, such as role conflicts and workload?

6. What do you do to encourage residents to find new challenges in their work?

\section{Wrap-up question}

7. Would you like to add anything to what we have discussed so far? 


\section{References}

I. Low ZX, Yeo KA, Sharma VK, Leung GK, Mclntyre RS, Guerrero A, et al. Prevalence of Burnout in Medical and Surgical Residents: A Meta-Analysis. Int J Environ Res Public Health [Internet]. 2019 Apr 26 [cited 2019 Sep 30];16(9):1479. Available from: http://www.ncbi.nlm.nih.gov/pubmed/31027333

2. Tims M, Bakker A, Derks D. Development and validation of the job crafting scale. J Vocat Behav [Internet]. 2012 Feb I [cited 2018 Sep 6];80(I):173-86. Available from: https://www.sciencedirect. com/science/article/abs/pii/S0001879111000789

3. Bakker AB, Demerouti E. Multiple Levels in Job Demands-Resources Theory: Implications for Employee Well-being and Performance. In: Diener E, Oishi S, Tay L, editors. Handbook of wellbeing. Salt Lake City, UT: DEF Publishers. DOI:nobascholar.com: DEF Publishers. DOI:nobascholar.com; 2018. p. I-I3.

4. Chiapponi C, Meyer CY, Heinemann S, Meyer F, Biberthaler P, Bruns CJ, et al. Stress-Related Job Analysis for Medical Students on Surgical Wards in Germany. J Surg Educ [Internet]. 2017 Jan [cited 2019 Sep 4];74(I):I45-53. Available from: http://www.ncbi.nlm.nih.gov/pubmed/27468974

5. Ebrahimi S, Kargar Z. Occupational stress among medical residents in educational hospitals. Ann Occup Environ Med [Internet]. 2018 Dec 8 [cited 2019 Sep 4];30(I):5I. Available from: http://www. ncbi.nlm.nih.gov/pubmed/30101032

6. Huang Y, Chua TC, Saw RPM, Young CJ. Discrimination, Bullying and Harassment in Surgery: A Systematic Review and Meta-analysis. World J Surg [Internet]. 2018 Dec 3 [cited 2019 Sep 4];42(I2):3867-73. Available from: http://link.springer.com/10.1007/s00268-018-47/6-5

7. Halim UA, Riding DM. Systematic review of the prevalence, impact and mitigating strategies for bullying, undermining behaviour and harassment in the surgical workplace. $\mathrm{Br}$ J Surg [Internet]. 2018 Oct [cited 2019 Sep 4];105(II):I390-7. Available from: http://www.ncbi.nlm.nih.gov/ pubmed/3000700I

8. Dimou FM, Eckelbarger D, Riall TS. Surgeon Burnout: A Systematic Review. J Am Coll Surg [Internet]. 2016 Jun [cited 2019 Sep 4];222(6):1230-9. Available from: http://www.ncbi.nlm.nih.gov/ pubmed/27106639

9. Siegel TR, Nagengast AK. Mitigating Burnout. Surg Clin North Am [Internet]. 2019 Oct [cited 2019 Sep 4];99(5):I029-35. Available from: http://www.ncbi.nlm.nih.gov/pubmed/31446908

10. Smeds MR, Janko MR, Allen S, Amankwah K, Arnell T, Ansari P, et al. Burnout and its relationship with perceived stress, self-efficacy, depression, social support, and programmatic factors in general surgery residents. Am J Surg [Internet]. 2019 Jul 9 [cited 2019 Aug 30]; Available from: http://www. ncbi.nlm.nih.gov/pubmed/31307660

II. Dominguez LC, Stassen L, de Grave W, Sanabria A, Alfonso E, Dolmans D. Taking control: Is job crafting related to the intention to leave surgical training? PLoS One [Internet]. 2019 Jul I [cited 2020 Sep 27];13(6). Available from: https://pubmed.ncbi.nlm.nih.gov/29856750/

12. Bakker AB. Strategic and proactive approaches to work engagement. Vol. 46, Organizational Dynamics. 2017.

13. Dominguez LC, Dolmans D, de Grave W, Sanabria A, Stassen LP. Job Crafting to Persist in Surgical Training: A Qualitative Study From the Resident's Perspective. J Surg Res [Internet]. 2019 Jul 4 [cited 2019 Mar 29];239:180-90. Available from: http://www.ncbi.nlm.nih.gov/pubmed/30844632

14. Winkler I. Characteristics of Contemporary Theoretical Approaches in Leadership Research. In: Contributions to Management Science. Springer; 2009. p. 5-7.

15. Hu YY, Parker SH, Lipsitz SR, Arriaga AF, Peyre SE, Corso KA, et al. Surgeons' Leadership Styles and Team Behavior in the Operating Room. J Am Coll Surg [Internet]. 2016 Jan [cited 2018 Sep 22];222(I):4I-5I. Available from: https://linkinghub.elsevier.com/retrieve/pii/SI07275I5I50I6I9I 
16. Horwitz IB, Horwitz SK, Daram P, Brandt ML, Brunicardi FC, Awad SS. Transformational, transactional, and passive-avoidant leadership characteristics of a surgical resident cohort: analysis using the multifactor leadership questionnaire and implications for improving surgical education curriculums. J Surg Res [Internet]. 2008 Jul [cited 2018 Sep 22];I48(I):49-59. Available from: http:// linkinghub.elsevier.com/retrieve/pii/S002248040800I9II

17. Barling J, Akers A, Beiko D. The impact of positive and negative intraoperative surgeons' leadership behaviors on surgical team performance. Am J Surg [Internet]. 2018 Jan I [cited 2020 Apr 20];2I5(I):I4-8. Available from: http://www.ncbi.nlm.nih.gov/pubmed/28754536

18. Avolio BJ. Full Range Leadership Development. Second Edi. United States of America: SAGE Publications; 2013. 280 p.

19. Lord RG, Day D V., Zaccaro SJ, Avolio BJ, Eagly AH. Leadership in applied psychology: Three waves of theory and research. J Appl Psychol [Internet]. 2017 Mar [cited 20I8 Sep 6];102(3):434-5I. Available from: http://www.ncbi.nlm.nih.gov/pubmed/28125257

20. Siangchokyoo N, Klinger RL, Campion ED. Follower transformation as the linchpin of transformational leadership theory: A systematic review and future research agenda. Leadersh $\mathrm{Q}$. 2020 Feb I;3I(I).

21. Watling CJ, Lingard L. Grounded theory in medical education research: AMEE Guide No. 70. Med Teach. 2012 Oct;34(I0):850-6I.

22. Hennink MM, Hutter I, Bailey A. Qualitative research methods. SAGE; 20II. 304 p.

23. Domínguez LC, Dolmans D, de Grave W, Donkers J, Sanabria A, Stassen L. Transformational leadership encourages residents' job crafting in surgical training: A mixed-methods study of residents' perceptions. Submitted.

24. Avolio B. Full Range Leadership. In: Full Range Leadership Development. SAGE Publications, Inc.; 2014. p. 49-74.

25. van Nes F, Abma T, Jonsson H, Deeg D. Language differences in qualitative research: is meaning lost in translation? Eur J Ageing [Internet]. 2010 Dec [cited 2018 Dec 13];7(4):313-6. Available from: http://www.ncbi.nlm.nih.gov/pubmed/21212820

26. Santos HPO, Black AM, Sandelowski M. Timing of Translation in Cross-Language Qualitative Research. Qual Health Res [Internet]. 2014 Sep 4;25(I):I34-44. Available from: https://doi. org//0.1177/10497323/4549603

27. Tong A, Sainsbury P, Craig J. Consolidated criteria for reporting qualitative research (COREQ): a 32-item checklist for interviews and focus groups. Int J Qual Heal care J Int Soc Qual Heal Care [Internet]. 2007 Dec 16 [cited 2019 Jul 16];19(6):349-57. Available from: https://academic.oup.com/ intqhc/article-lookup/doi/l0.1093/intqhc/mzm042

28. Thomson NB, Rawson J V., Slade CP, Bledsoe M. Transformation and Transformational Leadership: A Review of the Current and Relevant Literature for Academic Radiologists. Vol. 23, Academic Radiology. Elsevier USA; 2016. p. 592-9.

29. Geerts JM, Goodall AH, Agius S. Evidence-based leadership development for physicians: A systematic literature review. Vol. 246, Social Science and Medicine. Elsevier Ltd; 2020. p. II 2709.

30. Wang H-J, Demerouti E, Le Blanc P. Transformational leadership, adaptability, and job crafting: The moderating role of organizational identification. J Vocat Behav [Internet]. 2017 Jun [cited 2019 Aug 28];/00:185-95. Available from: https://linkinghub.elsevier.com/retrieve/pii/S000|879|1730027|

31. Hetland J, Hetland H, Bakker AB, Demerouti E. Daily transformational leadership and employee job crafting: The role of promotion focus. Eur Manag] [Internet]. 2018 Dec [cited 2019 Aug 28];36(6):746-56. Available from: https://linkinghub.elsevier.com/retrieve/pii/S02632373I830002I

32. Miglianico M, Dubreuil P, Miquelon P, Bakker AB, Martin-Krumm C. Strength Use in the Workplace: A Literature Review. Vol. 21, Journal of Happiness Studies. Springer; 2020. p. 737-64. 
33. Sharp G, Bourke L, Rickard MJFX. Review of emotional intelligence in health care: an introduction to emotional intelligence for surgeons [Internet]. ANZ Journal of Surgery. Blackwell Publishing; 2020 [cited 2020 Apr 20]. Available from: http://www.ncbi.nlm.nih.gov/pubmed/31965690

34. Barzallo Salazar MJ, Minkoff H, Bayya J, Gillett B, Onoriode H, Weedon J, et al. Influence of surgeon behavior on trainee willingness to speak up: A randomized controlled trial. In: Journal of the American College of Surgeons [Internet]. Elsevier Inc.; 2014 [cited 2020 Apr 20]. p. 100I-7. Available from: http://www.ncbi.nlm.nih.gov/pubmed/25256368

35. Salles A, Wright RC, Milam L, Panni RZ, Liebert CA, Lau JN, et al. Social Belonging as a Predictor of Surgical Resident Well-being and Attrition. J Surg Educ. 2019 Mar 1;76(2):370-7.

36. Hayek S, Buonpane C, Hummel C, Lane S, Ellison H, Young K, et al. How Applicants to General Surgery Residency Define Resilience. J Surg Educ [Internet]. 2020 [cited 2020 Jun 22];77(4). Available from: https://pubmed.ncbi.nlm.nih.gov/32192887/

37. Cope A, Bezemer J, Mavroveli S, Kneebone R. What Attitudes and Values Are Incorporated into Self as Part of Professional Identity Construction When Becoming a Surgeon? In: Academic Medicine [Internet]. Lippincott Williams and Wilkins; 2017 [cited 2020 Jun 22]. p. 544-9. Available from: https://pubmed.ncbi.nlm.nih.gov/28351068/

38. Solberg E, Wong SI. Crafting one's job to take charge of role overload: When proactivity requires adaptivity across levels. Leadersh Q. 2016 Oct I;27(5):713-25.

39. Luu TT. Linking authentic leadership to salespeople's service performance: The roles of job crafting and human resource flexibility. Ind Mark Manag. 2020 Jan I;84:89-104.

40. Thun S, Bakker AB. Empowering leadership and job crafting: The role of employee optimism. Stress Health [Internet]. 2018 Oct I [cited 2020 Apr 2I];34(4):573-8I. Available from: http://www.ncbi. nlm.nih.gov/pubmed/29882309

4I. Xin X, Cai W, Zhou W, Baroudi S El, Khapova SN. How can job crafting be reproduced? Examining the trickle-down effect of job crafting from leaders to employees. Int J Environ Res Public Health. 2020 Feb I;17(3).

42. Esteves T, Pereira Lopes M. Leading to Crafting: The Relation Between Leadership Perception and Nurses' Job Crafting. West J Nurs Res [Internet]. 2017 Jun I [cited 2020 Apr 2I];39(6):763-83. Available from: http://www.ncbi.nlm.nih.gov/pubmed/27432346

43. Rosengart TK, Mason MC, LeMaire SA, Brandt ML, Coselli JS, Curley SA, et al. The seven attributes of the academic surgeon: Critical aspects of the archetype and contributions to the surgical community. Am J Surg [Internet]. 2017 Aug I [cited 2020 Apr 20];214(2):165-79. Available from: http://www.ncbi.nlm.nih.gov/pubmed/28284432

44. Swendiman RA, Marcaccio CL, Han J, Hoffman DI, Weiner TM, Nance ML, et al. Attitudes and Habits of Highly Humanistic Surgeons: A Single-Institution, Mixed-Methods Study. Acad Med [Internet]. 2019 Jul I [cited 2020 Apr 20];94(7):1027-32. Available from: http://www.ncbi.nlm.nih. gov/pubmed/30844930

45. Dickinson KJ, Bass BL, Pei KY. What embodies an effective surgical educator? A grounded theory analysis of resident opinion. In: Surgery (United States) [Internet]. Mosby Inc.; 2020 [cited 2020 Aug 7]. Available from: http://www.surgjournal.com/article/S003960602030270I/fulltext

46. Mcllhenny C, Kurashima Y, Chan C, Hirano S, Domínguez-Rosado I, Stefanidis D. General surgery education across three continents. Am J Surg [Internet]. 2018 Feb I [cited 2020 Feb 29];215(2):209_ 13. Available from: http://www.ncbi.nlm.nih.gov/pubmed/29246406

47. Wright Jr. JR, Schachar, NS. Necessity is the mother of invention: William Stewart Halsted's addiction and its influence on the development of residency training in North America. Can J Surg [Internet]. 2020 Jan 16 [cited 2020 Feb 29];63(I):EI3-9. Available from: http://www.ncbi.nlm.nih.gov/ pubmed/31944636 
48. Kotsis S V., Chung KC. Application of the "see one, do one, teach one" concept in surgical training. Plast Reconstr Surg [Internet]. 2013 May [cited 2020 Mar 3];13 I(5):I194-20I. Available from: http:// www.ncbi.nlm.nih.gov/pubmed/23629100

49. Norrell K, Marasigan J, Bogener J. New Paradigms in Post-Graduate Surgical Education. Mo Med [Internet]. 2017 [cited 2020 Apr 2I];I 14(4):278-82. Available from: http://www.ncbi.nlm.nih.gov/ pubmed/302286II

50. Ten Cate O, Chen HC, Hoff RG, Peters H, Bok H, Van Der Schaaf M. Curriculum development for the workplace using Entrustable Professional Activities (EPAs): AMEE Guide No. 99. Med Teach. 2015 Nov 2;37(II):983-1002. 

Considering their disappointing rates of attrition, the need to understand residents' persistence in surgical training is clear. However, understanding how persistence occurs based only on static elements, such as individual and programmatic factors (including residents' sex, gender, and/or program characteristics), remains difficult. This asks for dynamic explanations of how residents deal with demanding, rigorous and competitive training in the complexity of modern health care and workplace learning. To diminish attrition, improvements in residents' educational setting are needed, while preserving clinical care and patient safety, although "the world will never be perfect". Work plays a significant role in a resident's life. Ideally, residents should not respond passively to the working conditions in which they are immersed. Residents can proactively change those conditions to make their work meaningful, in keeping with the concept of job crafting (I-3). Moreover, surgeons have a major responsibility in this endeavour: through their leadership they can transform their residents to accomplish those proactive changes in their work. Given this dual approach to enhance residents' persistence, this $\mathrm{PhD}$ dissertation aimed to explore the following research questions:

I. To what extent do surgical residents feel that they possess job-crafting abilities and which job-crafting mechanisms do they use to enhance their work engagement to persist in training? (Studies I and 2)

2. How do supervisors' leadership styles relate to residents' job-crafting abilities from the perspective of both residents and supervisors'? (Studies 3 and 4)

In the present chapter, we first answer the research questions based on empirical evidence included in four original studies. Then, in the second part, we discuss the strengths, limitations, practical implications and directions for future research.

To what extent do surgical residents feel that they possess job-crafting abilities and which job-crafting mechanisms do they use to enhance their work engagement to persist in training?

To address this research question, Chapter 2 sheds light on the job crafting abilities of surgical residents, based on self-reports via the Dutch Job-crafting Scale (3). As hypothesized, job crafting diminished the residents' intention to leave training. This was mediated by their work engagement, characterized by vigour, dedication and absorption, which is a positive well-being state as opposed to burnout (4). The results also revealed that residents with serious intentions to leave training had lower levels of job crafting and work engagement compared to those without such intentions. These findings indicate that job crafting is a useful ability to challenge the complexity of surgical training. By crafting their jobs, residents can proactively optimize the "imperfect working conditions" of training, specifically the excessive demands and poor resources that may lead to burnout. These findings echo those of the few studies that emphasize job-crafting's role in decreasing the intentions to leave a job among employees at non-health care organizations $(5,6)$. Similarly, our results are supported by the theoretical underpinnings of the job demands-resources (JD-R) theory, indicating that job crafting is an important precursor of work engagement and 
performance (2). However, our study adds information to the limited body of evidence on jobcrafting's role in work engagement in the educational context, a specific context in which people learn by working $(7,8)$. Additionally, the theoretical concept of job crafting was not written with the field of medical education in mind and, to date, there is a limited body of empirical studies on jobcrafting in that field. In this venue, the present study offers initial evidence on the role of job crafting in postgraduate training by emphasizing its relevance for persistence in training.

In Chapter 3 we discussed how residents were able to craft their jobs by nurturing satisfactory interactions at the workplace, by looking for opportunities to strengthen their performance and competence, and by developing visions of themselves as "true surgeons" in training. Moreover, residents acknowledged that surgeons in charge of their training must contribute actively to those processes. In Chapter 3, residents identified the most important working conditions they must craft. First, they mentioned autonomy and responsibility in surgical care: these are known as structural job-resources in the JD-R theory. This helps them to develop trust with their supervisors and to negotiate opportunities of participation in complex procedures or, according to the JD-R theory, to increase challenging job demands. Second, they mentioned the need to craft their collaboration and peer support (increase social job resources) to improve their interactions at the workplace and to diminish the amount of workload and pressure. Finally, they mentioned the relevance of crafting their errors in care and surgical complications (decreasing hindering job demands) in order to rebuild trust with supervisors, solve problems and persist in training. These findings are in line with previous research on the role of job crafting to satisfy the basic needs that enhance work engagement: autonomy, relatedness and competence at work $(9,10)$. Similarly, our findings align nicely with previous observations on the importance of job crafting for identity development and to make work meaningful $(\mathrm{I}, 2, \mathrm{II})$. Moreover, drawing on these results, our study adds to previous literature in different ways. First, to our knowledge, no other studies have shed light on the proactive mechanisms developed by surgical residents to enhance their work engagement to persist. Our study contributes to the call to elaborate the concept of job crafting in specific workplace contexts (12-14). Finally, the study emphasizes that persistence in training is more than a "passive acceptation" of the working conditions as previous studies on residents' attrition suggest $(15,16)$ : it is the result of the resident's active approach.

How do supervisors' leadership styles relate to residents' job-crafting abilities from the perspective of both residents and supervisors'?

The results of Chapter 3 drew our attention to one fact: residents mentioned that the surgeons in charge of their training have an important role in strengthening their ability to craft their jobs. More specifically, that role depends on the surgeons' leadership style in the workplace. As hypothesized in Chapter 4, we found that surgeons with a transformational leadership style had a positive effect on residents' job crafting. Residents felt that those surgeons contributed to a supportive training environment in which residents found a non-threatening trusting atmosphere 
to craft their jobs. Furthermore, in residents' views, those surgeons were willing to offer more job resources for the resident, such as support, teaching and feedback. Ultimately, residents perceived that surgeons with a transformational leadership style were committed to modelling effective ways to handle the surgical environment's demands, like finding effective solutions to difficult situations such as surgical complications or conflicts arising at work. Because transformational leadership is change-oriented, our results are in keeping with preliminary evidence indicating that such leaders have a positive effect on their followers' abilities to proactively change their working conditions or, in other words, to craft their jobs $(13,17,18)$. Our findings are also related to previous research on transformational leaders' influence on the positive workplace atmosphere and on the provision of role models and job resources for their followers (13,19-2I). This study adds to the current literature in different directions. First, it contributes to the understanding of the positive effect of surgeons' transformational leadership on residents' education from a job crafting perspective. Previous research focused almost exclusively on its effects on clinical outcomes such as patient safety and team performance $(22,23)$. Ultimately, the JD-R and transformational leadership theories should build in other frameworks for their theoretical maturation and development $(4,24)$. In the present study, the JD-R theory contributed to filling a theoretical gap in transformational leadership theory, the lack of clear understandings of the relationship between leaders' behaviours and followers' responses (24). Simultaneously, the leadership framework contributed to elaborating on an unsettled issues in the JD-R theory: the need for explanatory underlying mechanisms influencing employees' wellbeing (4).

Having identified the effect in Chapter 4, we set out to understand how surgeons transform their residents to craft their jobs. In Chapter 5, therefore, we explored the surgeons' perspectives. We identified surgeons who were perceived by residents as supervisors who encouraged residents to take the lead in crafting their jobs and interviewed them to learn about their transformational actions. Foremost, we noted their deliberate actions to act as a role model for their residents: exhibiting professionalism in patient care, satisfactory interactions, and coherence between personal and professional life. Then, we explored their actions to increase the availability of resources for residents to foster their ability to control the environment. First, surgeons believed that they strengthened residents' autonomy at the workplace through a progressive approach of increasing participation and responsibility. Second, they coached residents to deal with competing training interests (i.e., workload and administrative pressure). Third, these surgeons connected with residents, being open and available to discuss their expectations and interests, as well as to deal with possible sources of emotional distress. Finally, surgeons reported that they support residents in handling complications and errors without abandoning or blaming them. Ultimately, the resources and demands that surgeons believed residents were able to craft from their actions coincide with those mentioned by residents in Chapter 3. However, the results in Chapter 5 emphasize that residents' transformation might occur when leaders prioritize "human relationships" instead of prioritizing the "task" $(25,26)$. Our observations indicate that the surgeons' primary target in transforming their residents to 
craft their jobs might be stimulating their personal strengths. Previous studies conducted from the residents' perspectives fit well with our findings, given that these studies also emphasized the importance of personal strengths in the resident to increase feedback, coaching and collaboration (27-3I). The contributions of this study resemble those of Chapter 3 regarding the role of supervisors with focus on residents' education and not only on clinical outcomes. Moreover, the study offers a different contribution: it responds to the call to elaborate on how leaders transform their followers, principally from the leaders' perspective (24).

\section{Strengths and limitations}

This PhD dissertation has different strengths. First, we combined two theoretical frameworks to assist the exploration of the research questions in the surgical context. Our studies were underpinned by the job demands-resources and transformational leadership theories. Those theoretical lenses allowed us to understand residents' work engagement to persist in surgical training. Second, we applied a variety of methods, such as quantitative cross sectional, constructivist grounded theory (CGT) and sequential explanatory mixed-methods research, to unravel the complexity of job crafting in the clinical training context. Finally, combining the perspectives of residents and surgeons made it possible to explore the roles of both stakeholders in the process of job-crafting and work engagement to persist in training.

Nonetheless, the findings in this PhD dissertation must be interpreted in light of its limitations. First, the studies were conducted in only one training context, at Colombia. Although we included multiple programs, public and private, from different regions and educational traditions in the country, the transferability of findings to other contexts may be limited. Second, the PhD dissertation relies on self-report research methods and lacks a direct observation of residents' job crafting and surgeons' leadership behaviours in practice. Ultimately, this $\mathrm{PhD}$ dissertation lacks explanation of how the residents' transformation occurs to craft their jobs at different stages of the training program.

\section{Suggestions for future research}

The limitations of the present PhD dissertation offer opportunities for the research agenda. A first opportunity is to perform studies in other training contexts to add generalizability to our findings. Despite the fact that the present research context has similarities with respect to other western countries, such as a hierarchical structure, competition and pressure for high standards in the resident (32-35), we believe the Colombian context poses specific challenges for residents. In particular, the training context is university-based, whereas in other countries it is hospitalbased. That difference may account for differences in the availability of educational resources for 
the resident and facilities for training. Related is the fact that residents lack a formal contract with the hospital. This creates additional demands for the resident, considering they have to pay a fee for their training instead of receiving a salary. Some residents even work as general physicians in parallel with their training, which imposes extra workload. A second opportunity for research is to conduct ethnographic observational studies in the surgical field to capture the scope of residents' job crafting. Those studies can explore topics including how residents actually increase their challenges and resources at the workplace while diminishing hindering demands, and how surgeons contribute to those endeavours. Finally, we suggest future studies to explicitly explore how residents' transformation to craft their jobs occurs or develops over time. Longitudinal qualitative studies through periodic in-depth interviews with residents at different times in the training program may give such insights.

\section{Practical implications}

In this research, we have explored the nature of residents' work engagement to persist in surgical training. Our findings revealed that residents' job crafting is crucial for this and that supervising surgeons have an important role in transforming their residents to craft their jobs. These findings offer opportunities to develop interventions to strengthen both residents' job crafting and surgeons' leadership. First, interventions should begin by explaining to residents and surgeons what job crafting is, why it is important, and what can be achieved when jobs are crafted. Then, additional training for residents can focus on how to craft particular structural and social job resources; we identified resources on which such training can be focused, such as enhancing autonomy, participation and peer collaboration. At the same time, resident training should be designed to craft their hindering job demands, such as conflict and workload. Such resident training may contribute to integrating job crafting in the core of competency frameworks in the health professions (36). When focussing on surgeons, our research also has implications for leadership training. This should contain the following aspects: I) modelling for residents how to increase job resources and handle job demands; 2) supporting residents' understanding of their working conditions; 3) coaching residents to develop self-directed behaviours to craft their working conditions according to their needs and preferences; and 4) offering feedback to promote residents' self-reflections on their job crafting behaviours.

\section{Conclusion}

Focused on residents' work engagement to persist in surgical training, the present research sheds a positive light on the negative problem of its counterpart attrition. From that perspective, residents' job crafting emerges as an important precursor of their work engagement. Our results indicate that residents' proactive capacity to optimize and change their working conditions is 
influenced by surgeons' leadership. These findings have important implications for practice. Specifically, more attention should be paid to strengthening residents' job crafting as a vital aspect of their self-regulated learning at the workplace. Additionally, more emphasis should be placed on surgeons' leadership to drive positive changes in those aspects of residents' education. Ultimately, our findings and the implications we have identified offer opportunities for further research.

\section{References}

I. Wrzesniewski A, Dutton JE. Crafting a Job: Revisioning Employees as Active Crafters of Their Work. Acad Manag Rev [Internet]. 200I Apr [cited 2019 Aug 29];26(2):179. Available from: http:// www.jstor.org/stable/259118?origin=crossref

2. Berg JM, Dutton JE, Wrzesniewski A. Job crafting and meaningful work. In: Dik BJ, Byrne ZS, Steger MF, editors. Purpose and meaning in the workplace [Internet]. I edition. USA: American Psychological Association; 2013 [cited 2018 May 26]. p. 8I-104. Available from: http://www.apa.org/ pubs/books/43I8II7.aspx?tab=2

3. Tims M, Bakker A, Derks D. Development and validation of the job crafting scale. J Vocat Behav [Internet]. 2012 Feb I [cited 20I8 Sep 6];80(I):I73-86. Available from: https://www.sciencedirect. $\mathrm{com} /$ science/article/abs/pii/S0001879111000789

4. Bakker AB, Demerouti E. Job demands-resources theory: Taking stock and looking forward. J Occup Health Psychol [Internet]. 2017 [cited 2018 May 26];22(3):273-85. Available from: https:// www.isonderhouden.nl/doc/pdf/arnoldbakker/articles/articles_arnold_bakker_444.pdf

5. Zhang T, Li B. Job crafting and turnover intention: The mediating role of work engagement and job satisfaction. Soc Behav Pers [Internet]. 2020 [cited 2020 Aug 9];48(2):8759. Available from: www. sbp-journal.com

6. Shin Y, Hur WM, Park K, Hwang H. How managers' job crafting reduces turnover intention: The mediating roles of role ambiguity and emotional exhaustion. Int J Environ Res Public Health. 2020 Jun I;I7(II):I-I8.

7. Creed PA, Hood M, Hu S. Job crafting by students who work and study. Int J Educ Vocat Guid [Internet]. 2020 Jul I [cited 2020 Aug 9];20(2):33I-49. Available from: https://doi.org//0.1007/ s10775-019-09406-2

8. Okuda K. Learning through Meaning Making: Applying Job Crafting in Field Learning. J Teach Soc Work [Internet]. 2018 Oct 20 [cited 2020 Aug 9];38(5):470-85. Available from: https://www. tandfonline.com/doi/abs//0.1080/0884I233.2018.1520779

9. Bakker AB, Oerlemans WGM. Daily job crafting and momentary work engagement: A selfdetermination and self-regulation perspective. J Vocat Behav [Internet]. 2019 Jun I [cited 2020 Aug 8];II2:4I7-30. Available from: https://linkinghub.elsevier.com/retrieve/pii/S000I879|I830I57X

10. Bakker AB, van Woerkom M. Flow at Work: a Self-Determination Perspective. Occup Heal Sci. 2017 Dec; I (I-2):47-65.

II. Wrzesniewski A, Lobuglio N, Dutton JE, Berg JM. Job crafting and cultivating positive meaning and identity in work. Adv Posit Organ Psychol [Internet]. 2013 [cited 2020 Aug 8];I:28I-302. Available from: /record/2014-2259I-013

12. Bakker AB, Hakanen JJ, Demerouti E, Xanthopoulou D. Job resources boost work engagement, particularly when job demands are high. J Educ Psychol [Internet]. 2007 May [cited 2020 Jul 22]; 99(2): 274-84. Available from: /record/2007-06672-004?casa_token=06bXf8AqfmUAAAAA:hhzrcVatgWKq 
HHbzplnvRQ0iSqhAAU0KFIOYDX2NBJLAckTzV5exvqzcVy4emx6kESdnYVOEqb_88I5d5tn3nlaW

13. Wang $H$, Demerouti $E$, Bakker $A B$. A review of job crafting research: The role of leader behaviors in cultivating successful job crafters. In: Sharon K. Parker UKB, editor. Proactivity at Work: Making Things Happen in Organizations. Ist editio. New York: Routledge.; 2016. p. 77-104.

14. Lazazzara A, Tims M, de Gennaro D. The process of reinventing a job: A meta-synthesis of qualitative job crafting research. J Vocat Behav [Internet]. 2019 Jan 6 [cited 2019 Aug 13]; Available from: https://www.sciencedirect.com/science/article/pii/S0001879119300016

15. Ellis RJ, Holmstrom AL, Hewitt DB, Engelhardt KE, Yang AD, Merkow RP, et al. A comprehensive national survey on thoughts of leaving residency, alternative career paths, and reasons for staying in general surgery training. Am J Surg. 2020 Feb I;219(2):227-32.

16. Adams S, Ginther DN, Neuls E, Hayes P. Attitudes and factors contributing to attrition in Canadian surgical specialty residency programs. Can J Surg [Internet]. 2017 Aug I [cited 2020 Jul 14];60(4):247-52. Available from: https://pubmed.ncbi.nlm.nih.gov/28562235/

17. Thun S, Bakker AB. Empowering leadership and job crafting: The role of employee optimism. Stress Heal [Internet]. 2018 Oct [cited 2019 Apr 3];34(4):573-8I. Available from: http://www.ncbi.nlm.nih. gov/pubmed/29882309

18. Wang H, Demerouti E, Le Blanc P. Transformational leadership, adaptability, and job crafting: The moderating role of organizational identification. J Vocat Behav [Internet]. 2017 Jun I [cited 2018 Oct 3];100:185-95. Available from: https://www.sciencedirect.com/science/article/pii/ S000187911730027।

19. Mazzetti G, Vignoli M, Petruzziello G, Palareti L. The Hardier You Are, the Healthier You Become. May Hardiness and Engagement Explain the Relationship Between Leadership and Employees' Health? Front Psychol [Internet]. 2019 Jan 14 [cited 2019 Apr 3];9. Available from: https://www. frontiersin.org/article/l0.3389/fpsyg.2018.02784/full

20. Arnold KA, Connelly CE, Walsh MM, Martin Ginis KA. Leadership styles, emotion regulation, and burnout. J Occup Health Psychol [Internet]. 2015 Oct [cited 2019 Apr 3];20(4):48I-90. Available from: http://www.ncbi.nlm.nih.gov/pubmed/25844908

21. Hildenbrand K, Sacramento CA, Binnewies C. Transformational leadership and burnout: The role of thriving and followers' openness to experience. J Occup Health Psychol [Internet]. 2018 Jan [cited 2019 Apr 3];23(I):3I-43. Available from: http://doi.apa.org/getdoi.cfm?doi=10.1037/ocp000005I

22. Hu YY, Parker SH, Lipsitz SR, Arriaga AF, Peyre SE, Corso KA, et al. Surgeons' Leadership Styles and Team Behavior in the Operating Room. J Am Coll Surg [Internet]. 2016 Jan [cited 2018 Dec 22];222(I):4I-5I. Available from: http://www.ncbi.nlm.nih.gov/pubmed/2648I409

23. Horwitz IB, Horwitz SK, Daram P, Brandt ML, Brunicardi FC, Awad SS. Transformational, transactional, and passive-avoidant leadership characteristics of a surgical resident cohort: analysis using the multifactor leadership questionnaire and implications for improving surgical education curriculums. J Surg Res [Internet]. 2008 Jul [cited 2018 Sep 22];148(I):49-59. Available from: http:// linkinghub.elsevier.com/retrieve/pii/S002248040800I9II

24. Siangchokyoo N, Klinger RL, Campion ED. Follower transformation as the linchpin of transformational leadership theory: A systematic review and future research agenda. Leadersh $\mathrm{Q}$. 2020 Feb I;3I(I).

25. Thomson NB, Rawson J V., Slade CP, Bledsoe M. Transformation and Transformational Leadership: A Review of the Current and Relevant Literature for Academic Radiologists. Vol. 23, Academic Radiology. Elsevier USA; 2016. p. 592-9.

26. Geerts JM, Goodall AH, Agius S. Evidence-based leadership development for physicians: A systematic literature review. Vol. 246, Social Science and Medicine. Elsevier Ltd; 2020. p. II 2709.

27. Sharp G, Bourke L, Rickard MJFX. Review of emotional intelligence in health care: an introduction 
to emotional intelligence for surgeons [Internet]. ANZ Journal of Surgery. Blackwell Publishing; 2020 [cited 2020 Apr 20]. Available from: http://www.ncbi.nlm.nih.gov/pubmed/31965690

28. Barzallo Salazar MJ, Minkoff H, Bayya J, Gillett B, Onoriode H, Weedon J, et al. Influence of surgeon behavior on trainee willingness to speak up: A randomized controlled trial. In: Journal of the American College of Surgeons [Internet]. Elsevier Inc.; 2014 [cited 2020 Apr 20]. p. 100I-7. Available from: http://www.ncbi.nlm.nih.gov/pubmed/25256368

29. Salles A, Wright RC, Milam L, Panni RZ, Liebert CA, Lau JN, et al. Social Belonging as a Predictor of Surgical Resident Well-being and Attrition. J Surg Educ. 2019 Mar I;76(2):370-7.

30. Hayek S, Buonpane C, Hummel C, Lane S, Ellison H, Young K, et al. How Applicants to General Surgery Residency Define Resilience. J Surg Educ [Internet]. 2020 [cited 2020 Jun 22];77(4). Available from: https://pubmed.ncbi.nlm.nih.gov/32192887/

31. Cope A, Bezemer J, Mavroveli S, Kneebone R. What Attitudes and Values Are Incorporated into Self as Part of Professional Identity Construction When Becoming a Surgeon? In: Academic Medicine [Internet]. Lippincott Williams and Wilkins; 2017 [cited 2020 Jun 22]. p. 544-9. Available from: https://pubmed.ncbi.nlm.nih.gov/28351068/

32. Mcllhenny C, Kurashima Y, Chan C, Hirano S, Domínguez-Rosado I, Stefanidis D. General surgery education across three continents. Am J Surg [Internet]. 2018 Feb I [cited 2020 Feb 29];215(2):209_ 13. Available from: http://www.ncbi.nlm.nih.gov/pubmed/29246406

33. Wright Jr. JR, Schachar, NS. Necessity is the mother of invention: William Stewart Halsted's addiction and its influence on the development of residency training in North America. Can J Surg [Internet]. 2020 Jan 16 [cited 2020 Feb 29];63(I):El3-9. Available from: http://www.ncbi.nlm.nih.gov/ pubmed/31944636

34. Kotsis S V., Chung KC. Application of the "see one, do one, teach one" concept in surgical training. Plast Reconstr Surg [Internet]. 2013 May [cited 2020 Mar 3]; I3I(5):II94-20I. Available from: http:// www.ncbi.nlm.nih.gov/pubmed/23629100

35. Norrell K, Marasigan J, Bogener J. New Paradigms in Post-Graduate Surgical Education. Mo Med [Internet]. 2017 [cited 2020 Apr 2I];II4(4):278-82. Available from: http://www.ncbi.nlm.nih.gov/ pubmed/302286II

36. Dauphinee WD. Building a core competency assessment program for all stakeholders: the design and building of sailing ships can inform core competency frameworks [Internet]. Vol. 25, Advances in Health Sciences Education. Springer; 2020 [cited 2020 Aug 9]. p. 189-93. Available from: https:// pubmed.ncbi.nlm.nih.gov/32030572/ 



\section{Chapter 1: Introduction}

This $\mathrm{PhD}$ dissertation began with a general examination of residents' attrition, considering its negative impact on the provision of surgical care, training programs, and individuals. In the first part of Chapter I, we described three different perspectives explaining attrition, using mainly quantitative studies that were based on the perceptions of those who tend to leave training. We explained that only a limited number of studies have explored the problem from a positive side and used qualitative approaches to inquiry. Subsequently, in the second part of this chapter we looked at the problem from a positive side, that is, by spotlighting what it is that the vast majority of residents actually do to persist in training. Introducing the dimension of persistence into the study of attrition, we explained the relevance of residents' work engagement - the opposite of attrition -, and how it strongly depends on the actions initiated by residents to craft their working conditions. We argued that job crafting is crucial for residents to avoid being passive experiencers of their working conditions and to become proactive in shaping their work. In this venture, we emphasized that, so far, not many studies have looked at the role surgeons' leadership styles play in transforming their residents to craft their jobs and to enhance their work engagement. We therefore addressed the following two research questions:

I. To what extent do surgical residents feel that they possess job-crafting abilities and which job-crafting mechanisms do they use to enhance their work engagement to persist in training?

2. How do supervisors' leadership styles relate to residents' job-crafting abilities from the perspective of both residents and supervisors'?

At the end of the chapter, we presented the theoretical underpinnings that could help us to answer the main questions. More specifically, we explained the central concepts of the Job demands-resources (JD-R) and transformational leadership theories. Finally, we presented the context of the study.

\section{Chapter 2}

In the study described in Chapter 2, we first investigated: I) the extent to which residents across the years of residency training possess job crafting abilities; 2) the relationship between residents' job crafting abilities and the intention to leave training, including the influence of work engagement; and 3 ) the levels of job crafting and work engagement of residents with and without serious intentions to leave training. Drawing from the Job demands-resources (JD-R) theory, we conducted a quantitative cross-sectional study with a correlational design using self-assessments of 202 general surgery residents from 15 residency programs in the country of Colombia. To rate their job crafting, work engagement, and intention to leave training, residents filled out the Dutch 
Job Crafting Scale (DJCS), Utrecht Work Engagement Scale (UWES- I7), and an adapted version of the Nurse Turnover Intention Scale (NTIS), respectively. Our findings suggest that surgical residents, irrespective of their year of training, have well-developed job crafting abilities. As hypothesized, job crafting had a negative effect on residents' intention to leave training, which, moreover, was mediated by their work engagement. Finally, the results revealed that residents with serious intentions to leave training had lower levels of job crafting skills and work engagement, compared to those without such intentions. Hence, our findings underscored the relevance of residents' job crafting to their work engagement and, ultimately, to their persistence in surgical training.

\section{Chapter 3}

The results of Chapter 2 called our attention to the need to further explain how surgical residents actually craft their working conditions, enhancing their work engagement in the process, to persist in training. In Chapter 3, we therefore took a closer look at the specific mechanisms underlying residents' job crafting. Drawing from principles of the JD-R theory, we conducted a constructivist grounded theory (CGT) study based on semi structured in-depth interviews with 25 surgical residents from five residency programs. We found six mechanisms, specifically: I) building trust with supervisors; 2) being proactive in the workplace to gain responsibility; 3) seeking help from peers to deal with the demands of training; 4) seeing errors and frustrations as learning opportunities; 5) finding a suitable work-life balance; and 6) searching for challenging surgical tasks. In the said study, residents acknowledged that surgeons played an important role in mediating these job crafting mechanisms, thereby enhancing their work engagement and, ultimately, persistence. The results demonstrated that residents' job crafting is crucial to establish satisfactory interactions in the workplace, to look for opportunities to strengthen performance and competence, and to develop visions of themselves as "true surgeons" in training. Hence, the study underscored the fact that persisting in training through work engagement is an active process that depends on residents' ability to take advantage of resources and challenges and to diminish hindering demands in the workplace.

\section{Chapter 4}

The results of Chapter 3 drew our attention to one specific fact: residents mentioned that the surgeons in charge of their training made an important contribution to their job crafting. This contribution could be related to surgeons' specific leadership qualities in the workplace. In Chapter 4, we therefore conducted a sequential mixed study, drawing from the JD-R and transformational leadership theories, to explore the effect of surgeons' leadership styles on residents' job crafting from residents' perspective. First, 116 surgical residents from seven 
programs filled out the Multifactor Leadership Questionnaire and the DJCS to rate their supervisors' leadership style and their own job crafting, respectively. We found that surgeons with a transformational leadership style had a positive effect on residents' job crafting. Subsequent individual in-depth interviews with 14 surgical residents offered further insight into why this was the case. More specifically, residents mentioned that surgeons with a transformational leadership style contributed by creating a supportive climate for training with conditions that were favorable for crafting their jobs. In residents' view, moreover, these surgeons were also willing to offer the resident more job resources (in the form of support and coaching), while modeling effective ways of handling the demands of the surgical environment. These findings highlight surgeons' role in strengthening residents' ability to craft their jobs, which may enhance their work engagement and, ultimately, their persistence in training.

\section{Chapter 5}

Having confirmed the effect hypothesized in Chapter 4, we set out to understand how surgeons might transform their residents to craft their jobs by exploring supervisors' perspective. To this end, in Chapter 5 we conducted a CGT study into surgeons' perspective, drawing from the JD-R and transformational leadership theories. In-depth interviews were held with a purposive sample of 16 surgeons from four residency programs who were perceived as transformational leaders by their residents. We identified five actions that surgeons undertook to enhance job crafting in residents. They: I) modeled positive behaviors of a good surgeon; 2) used a stepwise individual approach toward autonomy; 3) connected with the resident as a person; 4) supported the resident in handling complications and errors; and 5) they coached the resident to deal with competing interests. These actions had four consequences for residents. They led to: I) more responsibilities in patient care; 2 ) more constructive relationships in the workplace; 3) less pressure from workload and surgical care duties and; 4) less tensions from personal difficulties and errors in patient care. By focusing on the interactions between surgeons and residents in the workplace-based learning setting, this study has provided evidence for the relevance of transformational leadership in surgical education. Our findings have highlighted the positive consequences of such leadership in surgeon educators for residents' job crafting in terms of dealing effectively with job demands and resources during training.

\section{Chapter 6: Discussion}

In Chapter 6, we answered the research questions and discussed our findings in relation to the existing literature. Based on the studies included in Chapters 2-3, we provided answers to our first research question: "To what extent do surgical residents feel that they possess job-crafting abilities and which job-crafting mechanisms do they use to enhance their work engagement to 
persist in training?." We can conclude that job-crafting appears to be well developed in residents without serious intentions to leave training. Job crafting skills also have a negative effect on such intentions, which is mediated by their work engagement. In other words, residents persist in training by crafting their jobs, enhancing their work engagement in the process. They do so through several mechanisms aimed to establish satisfactory interactions with surgeons and peers (social resources), to look for opportunities to strengthen their autonomy and competence in decision-making and surgical operations (structural resources and challenging demands), and to diminish the negative impact of frustrations and errors of training (hindering demands). Then, the studies included in Chapters 4-5 provided answers to our second research question: "How do supervisors' leadership styles relate to residents' job-crafting abilities from the perspective of both residents and supervisors?" We can conclude that surgeons with a transformational leadership style have an important role in strengthening residents' job crafting skills. This transformation in residents to face the working conditions in which they are immersed can be attributed to specific actions that surgeons undertake in the workplace, such as modeling, connecting, offering support, and coaching. Finally, at the end of the chapter we discussed the practical implications flowing from these findings, the strengths and limitations of this dissertation, and suggestions for future research. 



\section{Hoofdstuk I: introductie}

Dit proefschrift begon met een algemeen onderzoek naar uitval van aiossen, gezien de negatieve invloed hiervan op de verlening van chirurgische zorg, op de vervolgopleiding en op de betrokken personen. In het eerste deel van Hoofdstuk I beschreven we drie verschillende visies op de oorzaken van deze uitval, aan de hand van hoofdzakelijk kwantitatieve onderzoeken gebaseerd op de percepties van degenen die geneigd zijn met de opleiding te stoppen. We legden uit dat slechts een gering aantal onderzoeken de kwestie van een positieve kant had onderzocht en dat daarbij bovendien kwalitatieve onderzoeksbenaderingen waren gehanteerd. Vervolgens bekeken we de kwestie in het tweede deel van dit hoofdstuk van een positieve kant, namelijk door in te zoemen op de vraag wat het overgrote deel van de aiossen eigenlijk doet om de opleiding toch te vervolgen. Bij het toevoegen van een nieuwe invalshoek, namelijk "het continueren van de opleiding", aan het onderzoek naar uitval, legden we uit hoe belangrijk het is dat aiossen bij hun werk betrokken zijn (het tegenovergestelde van uitval) en hoe dit sterk afhangt van de acties die aiossen zelf in gang zetten om hun arbeidsomstandigheden vorm te geven. We stelden dat deze vormgeving, in het navolgende aangeduid als job crafting, voor aiossen van wezenlijk belang is om te voorkomen dat zij hun werkomstandigheden passief ondergaan en om proactief te worden in het inrichten van hun werk. In dit streven benadrukten we dat er tot nu toe nog niet veel onderzoeken hebben gekeken naar de rol die de leiderschapsstijlen van chirurgen spelen bij het aanzetten van hun aiossen tot job crafting en tot meer betrokkenheid bij hun werk. Daarom stelden we de volgende twee onderzoeksvragen aan de orde:

I. In hoeverre vinden aiossen chirurgie dat zij over job-crafting-vaardigheden beschikken en welke mechanismen voor job crafting wenden zij aan om meer betrokken te raken bij hun werk zodat ze de opleiding continueren?

2. Hoe verhouden de leiderschapsstijlen van supervisoren zich tot de job-crafting-vaardigheden van aiossen, volgens zowel aiossen als supervisoren?

Aan het einde van het hoofdstuk presenteerden we de theoretische onderbouwing die ons zou kunnen helpen om de hoofdvragen te beantwoorden. Meer specifiek legden we de kernbegrippen van de job-demands-resources-theorie (JD-R-theorie) en van de transformationeel-leiderschapstheorie uit. Tot slot presenteerden we de achtergrond van het onderzoek.

\section{Hoofdstuk 2}

In de in Hoofdstuk 2 beschreven studie onderzochten we eerst: I) in hoeverre aiossen uit alle jaren van de vervolgopleiding over job-crafting-vaardigheden beschikten; 2 ) het verband tussen hun jobcrafting-vaardigheden en het voornemen om de opleiding te stoppen, alsmede de invloed van hun 
betrokkenheid bij het werk; en 3) de mate waarin aiossen die wel én niet serieus voornemens waren de opleiding te stoppen gebruik maakten van job crafting en bij hun werk betrokken waren. Gestuurd door de JD-R-theorie verrichtten we een kwantitatief, cross-sectioneel onderzoek met een correlationeel ontwerp, waarbij we gebruik maakten van zelfbeoordelingen van 202 aiossen algemene chirurgie uit 15 vervolgopleidingen in Colombia. Om hun job crafting, hun betrokkenheid bij het werk en hun voornemen om de opleiding te stoppen te beoordelen, vulden aiossen drie vragenlijsten in, respectievelijk de Spaanse vertalingen van de Nederlandse Job Crafting Scale (DJCS), Utrechtse Work Engagement Scale (UWES-17), en een aangepaste versie van de Nurse Turnover Intention Scale (NTIS). Onze bevindingen geven aan dat aiossen chirurgie, ongeacht hun opleidingsjaar, bekwaam zijn in job craften. Zoals verondersteld, had job craften een negatief effect op het voornemen van aiossen om de opleiding te stoppen, welke bovendien beïnvloed werd door hun betrokkenheid bij het werk. Tot slot toonden de resultaten aan dat aiossen die serieus voornemens waren om de opleiding te stoppen, minder bekwaam waren in job craften en minder betrokken waren bij hun werk dan aiossen die dit voornemen níet hadden. Hiermee onderstreepten onze bevindingen het belang van job crafting door aiossen voor hun betrokkenheid bij het werk en uiteindelijk voor het continueren van de opleiding tot chirurg.

\section{Hoofdstuk 3}

Dankzij de resultaten van Hoofdstuk 2 werd onze aandacht gevestigd op de behoefte aan meer inzicht in hoe aiossen chirurgie hun arbeidsomstandigheden eigenlijk vormgeven en zodoende meer betrokken raken bij hun werk, zodat zij de opleiding continueren. In Hoofdstuk 3 gingen we daarom dieper in op de specifieke mechanismen die aan job crafting door aiossen ten grondslag liggen. Geleid door de principes van de JD-R-theorie verrichtten we een constructivistischgefundeerde-theoriestudie (CGT-studie) die gebaseerd was op semigestructureerde diepteinterviews met 25 aiossen chirurgie uit vijf vervolgopleidingen. Daaruit kwamen zes mechanismen naar voren, namelijk: I) een vertrouwensband scheppen met supervisoren; 2 ) zich op de werkplek proactief opstellen om meer verantwoordelijkheden te krijgen; 3) de hulp van collega's inroepen om aan de opleidingseisen te kunnen voldoen; 4) fouten en frustraties zien als leerkansen; 5) een goede balans vinden tussen werk en privé; en 6) op zoek gaan naar uitdagende chirurgische taken. In het onderzoek gaven de aiossen aan dat chirurgen een belangrijke rol speelden bij het stimuleren van deze job-crafting-mechanismen, waardoor ze er tevens voor zorgden dat zij meer betrokken raakten bij hun werk en uiteindelijk de opleiding continueerden. De resultaten toonden aan dat job crafting door aiossen van wezenlijk belang is voor het tot stand brengen van een goede samenwerking op de werkplek, voor het zoeken naar kansen om prestaties en competenties te verbeteren en voor het zichzelf gaan zien als "echte chirurgen" in opleiding. Hiermee benadrukte het onderzoek dat het continueren van de opleiding door betrokken te zijn bij het werk een actief proces is dat afhankelijk is van de mate waarin aiossen in staat zijn om middelen en uitdagingen te benutten en om eisen die een belemmering vormen op de werkplek in te perken. 


\section{Hoofdstuk 4}

De resultaten van Hoofdstuk 3 wezen op een bijzonder feit: aiossen gaven aan dat de chirurgen die hen opleidden een belangrijke bijdrage leverden aan hun job crafting. Deze bijdrage hield mogelijk verband met specifieke leiderschapskwaliteiten van deze chirurgen op de werkplek. In Hoofdstuk 4 verrichtten we daarom aan de hand van de JD-R-theorie en de transformationeel-leiderschapstheorie een sequentieel multimethodisch onderzoek naar wat volgens aiossen het effect is van de leiderschapsstijlen van chirurgen op hun job crafting. Eerst vulden 116 aiossen chirurgie uit zeven vervolgopleidingen 2 vragenlijsten in, namelijk de Multifactor Leadership Questionnaire en de DJCS om respectievelijk de leiderschapsstijl van hun supervisoren en hun eigen job crafting te beoordelen. We constateerden dat chirurgen met een transformationeel-leiderschapsstijl een positief effect hadden op job crafting door aiossen. De individuele diepte-interviews die we vervolgens hielden met 14 aiossen chirurgie boden meer inzicht in de vraag waarom dit het geval was. Meer specifiek gaven aiossen aan dat chirurgen met een transformationeel-leiderschapsstijl hielpen bij job crafting door te zorgen voor een ondersteunend leerklimaat met gunstige omstandigheden voor het vormgeven van hun werk. Volgens de aiossen waren deze chirurgen bovendien ook bereid om hun meer arbeidsmiddelen aan te reiken (in de vorm van ondersteuning en coaching), en fungeerden zij tegelijkertijd als rolmodel door te laten zien hoe effectief om te gaan met de eisen van de chirurgische omgeving. Deze bevindingen benadrukken de rol die chirurgen spelen bij het versterken van de mate waarin hun aiossen in staat zijn om hun werk vorm te geven, wat ervoor kan zorgen dat zij meer betrokken raken bij hun werk en uiteindelijk de opleiding continueren.

\section{Chapter 5}

Nadat we in Hoofdstuk 4 het veronderstelde effect hadden bevestigd, probeerden we inzichtelijk te maken hoe chirurgen hun aiossen mogelijk aanzetten tot job crafting door het perspectief van supervisoren te belichten. Hiertoe verrichtten we in Hoofdstuk 5 een CGT-studie naar het perspectief van chirurgen, waarbij we ons lieten leiden door de JD-R-theorie en de transformationeel-leiderschapstheorie. Er werden diepte-interviews gehouden met een doelgerichte steekproef van 16 chirurgen uit vier vervolgopleidingen die door hun aiossen als transformationele leiders werden gezien. We onderscheidden vijf acties die chirurgen ondernamen om job craften door aiossen te stimuleren. Zij: I) fungeerden als rolmodel door voor te doen hoe een goede chirurg zich gedraagt; 2) maakten gebruik van een stapsgewijze, individuele aanpak richting autonomie; 3) onderhielden persoonlijk contact met de aios; 4) hielpen de aios om te gaan met complicaties en fouten; en 5) coachten de aios in het omgaan met tegenstrijdige belangen. Deze acties hadden vier gevolgen voor aiossen. Zij leidden tot: I) meer verantwoordelijkheden in de patiëntenzorg; 2) meer constructieve relaties op de werkplek; 3) minder druk door werklast en chirurgische zorgtaken; en 4) minder spanningen door persoonlijke problemen en fouten in de patiëntenzorg. Door te zoomen op het contact tussen chirurgen en aiossen in de werkplek- 
leeromgeving, toonde dit onderzoek het belang aan van transformationeel leiderschap in de chirurgie opleiding. Onze bevindingen wezen op de positieve gevolgen van dergelijk leiderschap van opleiders chirurgie voor job crafting door aiossen met betrekking tot het effectief omgaan met arbeidseisen en -middelen tijdens de opleiding.

\section{Hoofdstuk 6: Discussie}

In Hoofdstuk 6 beantwoordden we de onderzoeksvragen en bespraken we onze bevindingen in relatie tot de bestaande literatuur. Op basis van de onderzoeken uit Hoofdstuk 2-3 beantwoordden we onze eerste onderzoeksvraag: "In hoeverre vinden aiossen chirurgie dat zij over job-craftingvaardigheden beschikken en welke mechanismen voor job crafting wenden zij aan om meer betrokken te raken bij hun werk zodat ze de opleiding continueren?" We kunnen concluderen dat aiossen die niet serieus voornemens zijn de opleiding te stoppen, bekwaam blijken te zijn in job craften. Job-crafting-vaardigheden hebben een negatief effect op dit voornemen, dat bovendien wordt beïnvloed door hun betrokkenheid bij het werk. Met andere woorden, aiossen continueren de opleiding door middel van job craften, waardoor ze tegelijkertijd meer betrokken raken bij hun werk. Dit doen ze aan de hand van diverse mechanismen die erop gericht zijn om een goede samenwerking met chirurgen en collega's tot stand te brengen (sociale middelen), te zoeken naar kansen waarmee ze hun autonomie en competenties op het gebied van besluitvorming en chirurgische verrichtingen kunnen vergroten (structurele middelen en uitdagende eisen), en om de negatieve invloed van frustraties en fouten tijdens het leren in te perken (belemmerende eisen). De onderzoeken uit Hoofdstuk 4-5 gaven vervolgens antwoord op onze tweede onderzoeksvraag: "Hoe verhouden de leiderschapsstijlen van supervisoren zich tot de job-crafting-vaardigheden van aiossen volgens zowel aiossen als supervisoren?" We kunnen concluderen dat chirurgen met een transformationeel-leiderschapsstijl een belangrijke rol spelen bij het stimuleren van de job-craftingvaardigheden van aiossen. Deze transformatie in aiossen om de arbeidsomstandigheden waarin zij worden ondergedompeld tegemoet te treden, kunnen worden toegeschreven aan specifieke acties die chirurgen op de werkplek ondernemen, zoals contact maken, fungeren als rolmodel, bieden van ondersteuning en coaching. Tot slot bespraken we aan het einde van het hoofdstuk de gevolgen voor de praktijk die uit deze bevindingen voortvloeien, alsmede de sterke punten en de beperkingen van dit proefschrift en deden we aanbevelingen voor toekomstig onderzoek. 

Impact paragraph

(n)

Impact paragraph

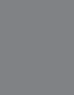

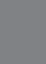

Impact paragraph

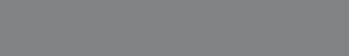
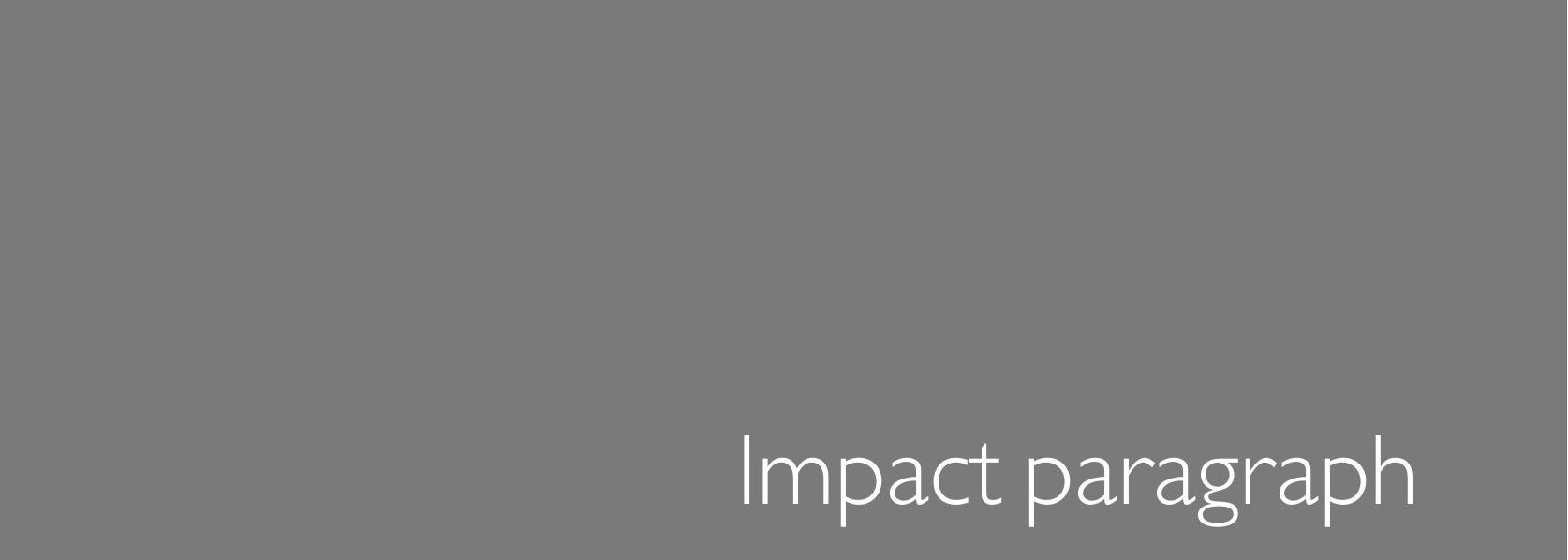


\section{I. (Research) \\ What is the main objective of the research described in the thesis and what are the most important results and conclusions?}

The aim of this dissertation is to contribute to a better understanding of residents' persistence in surgical training. The dissertation is underpinned by the job demands resources (JD-R) and the transformational leadership theories $(I, 2)$. Central in our research is the idea that persistence strongly depends on residents' work engagement, which is a positive wellbeing state at work whose main characteristics are dedication, vigor and absorption (I). We conducted four empirical studies using quantitative, qualitative and mixed methods designs, from the perspective of residents and surgeons. Our results highlight the importance of residents crafting their jobs within the surgical workplace to enhance their work engagement. In this way, they can increase the available resources and challenges in the clinical environment (i.e., autonomy and peer collaboration) and diminish those demands that hinder their performance (i.e., conflict, workpressure). Such capacity is in keeping with the concept of job crafting (3). In this vein, we also highlighted that surgeons in charge of training have a paramount role on that capacity of residents to craft their jobs: they can do so through their leadership. To conclude, the present dissertation indicates that more attention should be paid to strengthening residents' job crafting as a crucial capacity of their self-regulated learning at the workplace. Additionally, the research also emphasises that more attention should be placed on surgeons' leadership to drive positive changes in those aspects of residents' training and development.

\section{2. (Relevance) \\ What is the (potential) contribution of the results from this research to science, and, if applicable, to social sectors and social challenges?}

Surgical training has been founded on rigour, hierarchies, high demands and competitiveness. Such characteristics of the environment, in turn, are precursors of negative consequences for the resident. The increasing rates of burnout and attrition of training programs, and the lack of worklife balance are some examples of such consequences. These consequences, additionally, have a negative impact on the normal operation of hospitals and, ultimately, in the sustainability of the surgical workforce. Thus, is of great importance that surgery, like other large medical specialties, is an indivisible and indispensable part of health care and equity (4).

This dissertation is relevant for the society because we gained a better understanding in how residents craft their jobs in the benefit of their wellbeing and persistence in training, in the benefit of the organization and, therefore, in the benefit of the sustainability of the surgical workforce. We also gained better insight in how surgeons can help residents to do so. Surgeons should offer 
a supportive environment to strengthen the capacity of residents to optimize their jobs to enhance their work-engagement. As members of the training programs, surgeons must be aware of their responsibility to support residents to self-regulate their job at the workplace. These benefits are critical considering the challenges faced by healthcare systems around the world in terms of global surgery, such as the shortage of the surgical workforce, the raising of the global burden of surgical disease and its costs, and the negative consequences of unsafe surgical care (4). Therefore, all efforts aimed to overcome these challenges are of relevance to society.

\section{3. (Target group) \\ To whom are the research results interesting and/or relevant? And why?}

The results are directed, in the first instance, to the surgical residents. This dissertation offers relevant information on how residents might craft different demands and resources at the workplace to improve their wellbeing. First, they can reflect on the importance of this capacity as part of their self-regulation in the workplace. Second, residents can seek for improvements on this capacity within the environment with their supervisors, peers and allied staff. Our results are also directed to surgeons. In the perceptions of residents, surgeons play an important role to strengthen the capacity of residents to control the work environment. Our results can assist surgeons to reflect and translate into practice different aspects of their modelling, connecting, coaching and supporting role for their residents at the workplace. With these implications in mind, our results can also be transferred to residents and supervisors of other surgical specialties, considering the similarities in the dynamics of workplace education. Curriculum designers and program directors also represent a target group of our research. They have a major role in incorporating formal training on the ability of residents to craft their job within the surgical curriculum. It has implications for workplace-based assessments, feedback and remediation, especially among those who have difficulties and struggle to control a complex environment for training. Those who are in charge of wellbeing policies in residency training, as part of the Human Resources Management (HRM), can also benefit of our findings. It is very important that human resources developers take into account the active role of residents and supervisors within these policies. They can do so offering formal training in job crafting and leadership in the clinical environment. Inspired by our results, residents and supervisors might transform the work environment in a positive way, avoiding a passive role as recipients of the organizational policies. Ultimately, our results are relevant for medical educational researchers focused in workplace learning. Our results can stimulate further research on the importance of job crafting, wellbeing and performance in the clinical context for training. 


\section{4. (Activity) \\ In what way can these target groups be involved in and informed about the research results, so that the knowledge gained can be used in the future?}

Two studies from this thesis (Chapters 2 and 3 ) are available as published manuscripts. Chapter 4 and 5 are currently under editorial review. The published manuscripts and those under review were submitted to journals aimed to different target groups (surgeons, medical educators and a general audience). The research has also gained interest at national and international conferences such as the Conference of the Association for Medical Education in Europe (AMEE 2016), the Rogano Conference (2016), the Maastricht University SHE (School of Health Professions Education) Academy $(2016,2017,2018)$, the National Congress of the Colombian Association of Surgery $(2017,2019)$ and the Intermediate congress of the Colombian Association of Surgery (2018), among others. The results have been disseminated through the Division of Education of the Colombian Association of Surgery, academic conversations and local scenarios with strong presence of surgeons and residents. More speaking engagements for presentations are being scheduled in 2021. Links and key findings have also been shared on social media. The thesis will also be printed as a book and will be publicly available in 2021 . In this venue, our presence at national and international conferences and on social media platforms over the next I-2 years should help to expedite the further dissemination of our findings and facilitate interest and uptake of our results.

Finally, our results have implications for the design of specific interventions for residents and surgeons which can be summarized in: (a) how can we prepare residents to craft their jobs and, (b) how can we strengthen surgeons' leadership to assist residents to craft their jobs. In the discussion chapter we offer a description of the central elements of these interventions. The impact of such interventions may take longer (within 5 years) to produce.

\section{References}

I. Bakker AB, Demerouti E. Job demands-resources theory: Taking stock and looking forward.

J Occup Health Psychol [Internet]. 2017 [cited 2018 May 26];22(3):273-85. Available from: https:// www.isonderhouden.nl/doc/pdf/arnoldbakker/articles/articles_arnold_bakker_444.pdf

2. MacGregor Burns J. Transforming Leadership. New Yoork: Grove Press; 1978. 240 p.

3. Tims M, Bakker A, Derks D. Development and validation of the job crafting scale. J Vocat Behav [Internet]. 2012 Feb I [cited 2018 Sep 6];80(I):173-86. Available from: https://www.sciencedirect. com/science/article/abs/pii/S0001879111000789

4. Meara JG, Leather AJM, Hagander L, Alkire BC, Alonso N, Ameh EA, et al. Global Surgery 2030: Evidence and solutions for achieving health, welfare, and economic development. Vol. 386, The Lancet. Lancet Publishing Group; 2015. p. 569-624. 
Acknowledgments

\section{the}

(n) 
Perhaps most readers flip immediately to the acknowledgments section when they pick up a book like this. Hence, if decided to start here, they will find the crew responsible for this journey. I am writing in the first person singular, by using "l" or "my", when, in fact, this book deserves plurality. A caveat, thus, is necessary: many people and institutions deserve heartfelt thanks. I am immensely grateful to wonderful human beings as well as with extraordinary institutions that made this possible. This book is entirely yours. It contributes to bringing my dreams into reality but, even more, to realize the dreams of many. Maybe the list of acknowledgments will be marred by unintentional omissions. I offer my sincere apologies for any inadvertence.

First and foremost, I am plenty of gratitude to God: Thanks for giving me love, faith, and hope. Thanks also to my family. They have long been gracefully tolerant to my concerns during this $\mathrm{PhD}$ trajectory. Diana, thanks for your courage, patience, unconditional love and support, and critical contributions to my work. To my dear children Nacho, Esi, and Fefito, thanks to walk with me on this journey: you are my inner strength and my north. I promise you to reward this time. Mama and Papa, tireless fighters, I owe you a lot. María Teresa, Carolina and Beto, Diana Plazas, José, Leyla, Andrés, and my grandmother (somewhere in heaven), I will always be grateful for being there.

A few years ago, at FAIMER Institute, I was absorbed by different inquiries as a lifelong learner in medical education. Many of my expectations, dreams, and doubts were shared with Janet Grant, to whom I owe much of my love and fascination for medical education. She encouraged me to pursue a MHPE and then a PhD. Unsurprisingly, from our casual conversations, the School of Health professions Education (SHE) at Maastricht University appeared in my way. Thanks, Janet, for your kindly advise. Later, my first contact with SHE was facilitated by Francois Cilliers throughout an AMEE conference in Italy. I must thank Francois for his generosity, guidance, and genuine interest in my initiative.

Shortly after I arrived at Maastricht University, I realized the real magnitude of SHE: I was standing, not only the most impressive program in Health Professions Education worldwide, but one of the strongest, vibrant and dynamic academic communities. I was embraced by the great privilege to belong to SHE, as well as by the enormous responsibility and duties entailed on it. Both, undoubtedly, contributed to strengthening my identity as an educator and surgeon. To improve healthcare, education is called upon to make significant contributions: thanks to SHE to expand knowledge, cooperation, and transference of educational theory into practice. In SHE, I had the fortune to exchange ideas with exceptional scholars, educators, and clinicians. I thank all of them, as well as the PhD candidates who attended each meeting during the SHE academy, journal clubs, SHE presents, PhD courses, Rogano and AMEE conferences, for their interest and contributions to my work. I also was fortunate to learn about their projects, culture, and backgrounds. All my gratitude, respect, and appreciation to Jeroen van Merrienboer and his team: thank you for opening the doors of SHE to my country, to my institution, and me. 
This project became ever more thoroughly a team product since I benefit from the extraordinary supervision of Diana Dolmans, Laurents Stassen, and Willem de Grave. I've never worked with a sharper, more conscientious group of researchers. I am very grateful to have been able to learn from them, not only from their expertise as educators, clinicians, and researchers but also as persons. Thanks for your openness, transparency, and academic rigor. It must be for these reasons that the word "supervisor" still seems strange to me, sometimes sounds distant, and sometimes appear rigid. In Diana, Laurents and Willem I found more than supervisors: they were professors and transformational leaders in the true sense of the word. I look forward to new opportunities to work with you. Alvaro Sanabria was also present during all my PhD trajectory. To him, my deepest thanks, admiration, and respect: he has been my professor, colleague, and friend for a long time. This achievement is also your Alvaro. I Also thank Jannecke Frambach, Jimmy Leppink, and Jeroen Donkers who offered me their ideas and experience with the same generosity at different times. To Angelique van den Heuvel, who has done a huge work with her outstanding edition of this book, I am in everlasting debt. Thanks also to the always generous Lilian Swaen and Nicky Verlenge for their professional and human support. Ultimately, thanks to the members of the assessment committee for their critical review of our work.

A project like this required substantial local support. I am very grateful to Universidad de la Sabana for understanding this project in two large dimensions. The first, as an opportunity within their ambitious vision of education, society, and medicine, claiming to join the institution with the global network of cooperation and enthusiastic exchange of ideas from programs and organizations with high academic standards. Second, to understand this project in the dimension of my needs as a member of a family, as an educator, and active surgeon. This roster a generous group of persons at different levels of the organization to support, organize and facilitate my PhD trajectory. Special thanks to the Commission of Faculty, Sub-commission of Medical Education, Subcommission of Research, Department of Surgery and Department of Medical Education in the Faculty of Medicine; to the Committee of Training and Education of the Clínica Universidad de la Sabana; and the Committee on Aid for Professors' Formation and the Commission of General Affairs of the Superior Council in Universidad de la Sabana. I want to give a special thanks to Camilo Osorio and Rafael Carrillo, without whom this journey would not have started. Thanks also to Adriana Cortes for her kindness and willingness in all administrative aspects regarding my PhD trajectory, and to Laura Gómez and Oscar Carreño, my research assistants, whose work was invaluable.

In writing this book I profited greatly from conversations, insights, and encouragement by a number of my Sabanas' colleagues, but also from other institutions. I am very grateful to Valentín Vega, Eric Espitia, Jorge Restrepo, Diego Sierra, Juan José Pepín, Eduardo Valdivieso, Adriana Serna, and Gabriel Echeverry (wherever you are Viejo Gabriel!), for their exciting and passionate visions of surgical education. Also, for their optimism, joyfulness, and willingness to "mamar gallo" and laugh at the impossible, even in adverse situations. I also would like to thank Arnold Bakker and 
Milou Silkens for sharing their ideas on my $\mathrm{PhD}$ studies. I am also grateful to many colleagues, from most surgical residency programs in Colombia, who generously offered me their support and cooperation. I would like to thank very especially Gustavo Quintero, Felipe Vargas, Felipe González, Maikel Pacheco, German Jiménez, Rodolfo Barrios, Lilian Torregrosa, Rodrigo Castaño, Adonis Ramírez, Diego Márquez, Carlos Zapata, Mauricio Osorio, Luis Gerardo Cadavid, José Carlos Posada, and Carlos Bustillo. I also thank all chiefs of residents of surgical programs who offered their valuable help to coordinate the logistical aspects of each of my studies in their respective institutions. Thanks to Francisco Olmos for his guidance at different stages of my PhD. Thanks to Rafa, Luis Felipe, Carlos, and Jorge, my old friends, who always were present to encourage me optimism, enthusiasm, and confidence.

I warmly thank each Colombian surgeon and resident who participated in this research. I am most indebted to almost four hundred of them, who generously entrusted us with the details of their life during the collection of data. Your voices, openness, and experiences enriched this book. I have omitted, deliberately, the names of participants during interviews, as well as the name of their institutions, following our early obligation to protect their identity. Thanks to my patients, they were always at the core of my reflections. Thanks to all who were interested in my research and took a few minutes of their time to exchange ideas in forums, congresses, symposia, and courses in different settings. I am immensely grateful because those conversations resulted in helpful ideas and productive reflections on my work. Thanks to the editors and reviewers from different surgical and medical education journals who contributed to improve our studies and manuscripts. Ultimately, thanks to Ipskamp for their impeccable work during the edition of this book. At this point, the readers who are starting or finishing this book may realize what King Pele's words mean to me: "no individual can win a game for himself". 
Luis Carlos Domínguez Torres was born in Bogotá (Colombia). He is married with Diana and has three children: Juan Ignacio, Esteban and Federico.

Upon graduation as Medical Doctor at Pontificia Universidad Javeriana (Bogotá, Colombia) in 1998, Luis Carlos obtained a Masters' degree in Health Administration at the Faculty of Economy and Administration Sciences (Pontificia Universidad Javeriana), and a Masters' of Political Science at the Faculty of Social Sciences (Universidad de los Andes, Colombia). From 2002 and 2006 he completed his residency training in General Surgery at Hospital Universitario San Ignacio Pontificia Universidad Javeriana (Bogotá, Colombia).

His involvement in medical education began in 2007 when he engaged as a surgeon, clinical supervisor, and lecturer in the Department of Surgery, Faculty of Medicine, at Pontificia Universidad Javeriana and Universidad de la Sabana (Colombia). He quickly became intrigued and fascinated by medical education. His professional advancement in educational leadership, research, project management, and evaluation in medical education, continued when he was eligible for the International Fellowship in Medical Education (IFME) at the Foundation for Advancement of International Medical Education and Research (FAIMER institute, Philadelphia) in 2012. His early interest in surgical identity, as well as in surgeons' wellbeing and performance outcomes, started during the IFME and when he was appointed as chair of the Department of Surgery and coordinator of surgical residency training in Universidad de la Sabana (2013-2019). Particularly, during his Masters' in Health Professions Education (MHPE), developed jointly with Keele University (UK), FAIMER, and CenMEDIC (the Centre for Medical Education in Context, UK), he explored the role of identity deconstruction in surgeons who left their practice. His masters' dissertation, under the supervision of Professors Janet Grant and Rodney Gale, was successfully defended in 2016. His early findings moved his interest on the role of residents' wellbeing and its relationship with persistence and attrition in surgical residency training. Hence, under the supervision of Professors Diana Dolmans, Laurents Stassen, and Willem de Grave, Luis Carlos conducted a PhD-project at the School of Health Professions Education (SHE) at Maastricht University (the Netherlands), focused on the latter topic. He defended successfully his PhD thesis in 2021.

Currently, Luis Carlos is an associate professor of surgery and medical education at Universidad de la Sabana. He is an active surgeon, researcher, and educator in Colombia. 


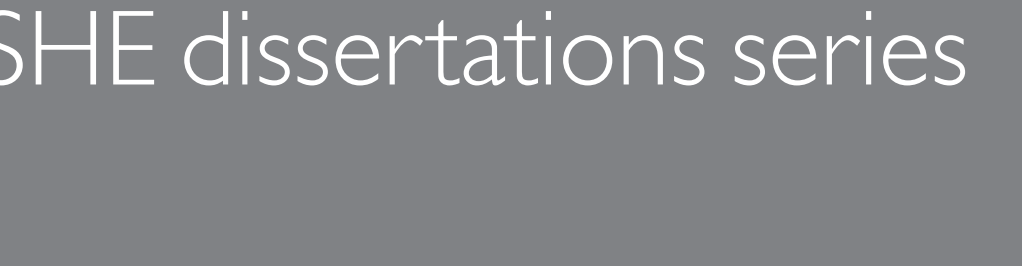

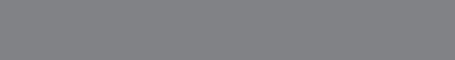

(n)

(n)

(1)

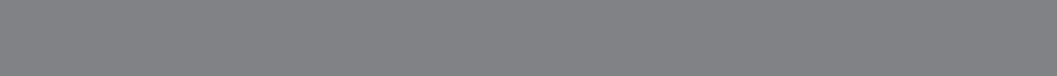

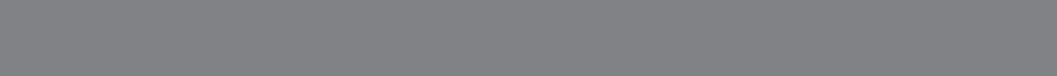

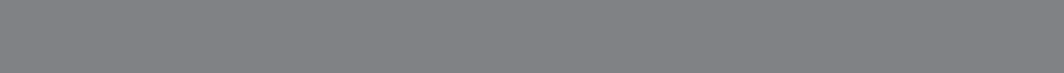
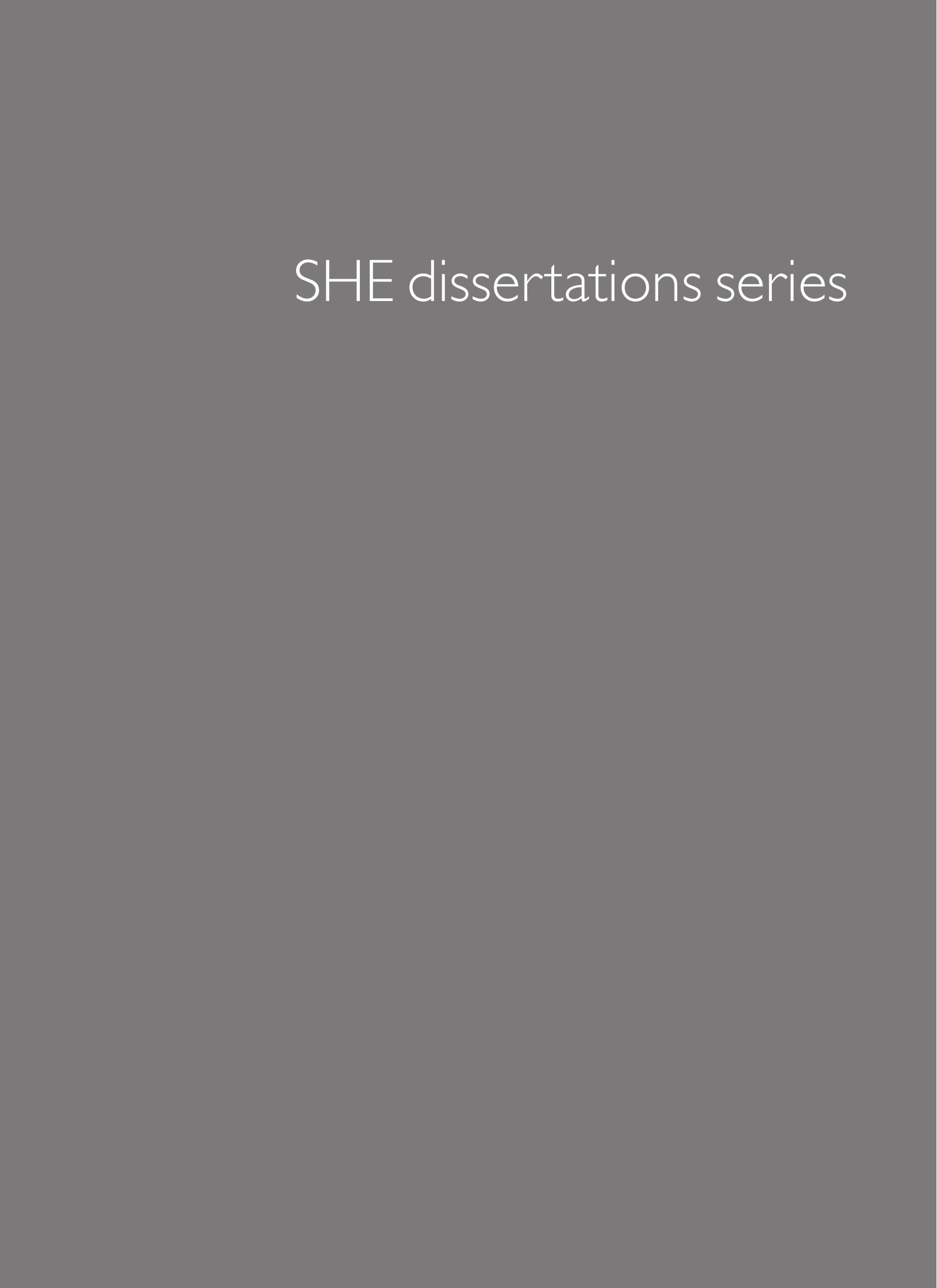
The SHE Dissertation Series publishes dissertations of PhD candidates from the School of Health Professions Education (SHE) who defended their PhD theses at Maastricht University. The most recent ones are listed below.

For more information go to: https://she.mumc.maastrichtuniversity.nl

Iqbal, Z. (I5-12-2020) All stakeholders matter in faculty development: Designing entrustable professional activities for small group facilitation

Tran, QT. (09-12-2020) Nationwide implementation of medical skills training laboratories in a developing country: studies from Vietnam

Pacifico, J. (30-II-2020) Making the Implicit Explicit: Uncovering the Role of the Conceptions of Teaching and Learning and the Perceptions of the Learning Climate in Postgraduate Medical Training.

Nishigori, H. (I7-II-2020) Why do doctors work for patients? Medical professionalism in the era of neoliberalism

Oudkerk Pool, A. (06-II-2020) Competency-based portfolio assessment - Unraveling stakeholder perspectives and assessment practices

Geel van, K. (05-II-2020) Lifelong learning in radiology: all eyes on visual expertise Stammen, L. (16-10-2020) Pursuing - High-Value, Cost-Conscious Care - The Role of Medical Education

Meulen van der, M. (15-10-2020) Assessment of physicians' professional performance using questionnaire-based tools

Matsuyama, Y. (05-10-2020) Contextual attributes fostering self-regulated learning in a teachercentered culture: learner's professional identity formation is a trigger

Rovers, S. (16-09-2020) Growing knowledge, supporting students' self-regulation in problembased learning

Bourgeois-Law, G. (03-09-2020) Conceptualizations of remediation for practicing physicians

Giuliani, M. (19-05-2020) A Critical Review of Global Curriculum Development, Content and Implementation in Oncology 
Schreurs, S. (20-03-2020) Selection for medical school; the quest for validity

Schumacher, D. (19-03-2020) Resident Sensitive Quality Measures: Defining the Future of Patient-Focused Assessment

Sehlbach, C. (2I-02-2020) To be continued.... Supporting physicians' lifelong learning

Kikukawa, M. (17-12-2019) The situated nature of validity: Exploring the cultural dependency of evaluating clinical teachers in Japan

Kelly, M. (10-12-2019) Body of knowledge. An interpretive inquiry into touch in medical education

Klein, D. (06-II-2019) The performance of medical record review as an instrument for measuring and improving patient safety

Bollen, J. (0I-II-2019) Organ donation after euthanasia: medical, legal and ethical considerations

Wagner-Menghin, M. (25-09-2019) Self-regulated learning of history-taking: looking for predictive cues

Wilby, K. (02-07-2019) When numbers become words: Assessors' processing of performance data within OSCEs

Szulewski, A. (20-06-2019) Through the eyes of the physician: Expertise development in resuscitation medicine

McGill, D. (29-05-2019) Supervisor competence as an assessor of medical trainees; Evaluating the validity and quality of supervisor assessments

Van Rossum, T. (28-02-2019) Walking the tightrope of training and clinical service; The implementation of time variable medical training 